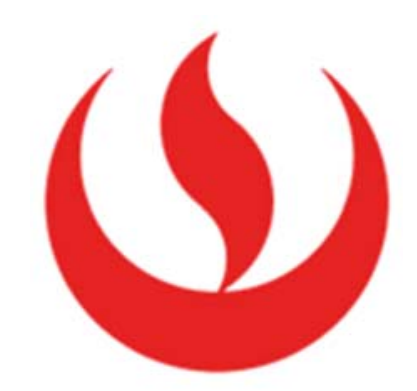

UNIVERSIDAD PERUANA DE CIENCIAS APLICADAS

FACULTAD DE NEGOCIOS

CARRERA DE ADMINISTRACION DE EMPRESAS

\title{
EL ADULTO MAYOR Y SU APORTE ECONÓMICO A LA SOCIEDAD PERUANA
}

TESIS
para obtener el grado de: Licenciado en administración de empresas

AUTOR(ES):

Macedo Salazar de Curay, Sarita Katiuska (0000-0002-8137-1721)

Mata Aquiño, Alan Emmanuel (0000-0003-0638-2487)

ASESOR:

Esther Jacqueline Barrantes Ramírez (0000-0002-8481-7995)

Lima, 17 de julio del 2018 
A Olinda Oliva Arrasco Vda. de Salazar, mi abuela, porque la vida perdure en mi memoria el dulce recuerdo de su sonrisa para siempre.

Sarita Katiuska Macedo Salazar

A mi pequeña Almudena, quien me enseño de forma empírica a valorar cada segundo de vida, haciendo mis días más largos y noches más cortas.

Alan Emmanuel Mata Aquiño 


\section{Resumen}

La presente investigación pretende describir la situación económica de los adultos mayores en la sociedad peruana, teniendo en cuenta que se considera adulto mayor a todas las personas mayores de 60 años. Para conocer la realidad de este grupo etario se recurrió a diversos especialistas en el campo; así mismo, se trabajó con 02 tipos de muestras, siendo una de ellas, los adultos mayores vulnerables, que no aportan económicamente a su familia ni al estado; y la otra muestra, compuesta por adultos mayores que se encuentran activos y aportan a la economía del hogar. En las visitas realizadas a ambos grupos se pudo obtener datos relevantes como núcleo familiar, formación académica, estilos de vida, oficios, profesiones, etc.; evidenciando que los adultos mayores son capaces de seguir aportando económicamente, así como también seguir contribuyendo con experiencias y valores a la sociedad. En el primer capítulo se plantea la problemática de los adultos mayores en el mundo, como un fenómeno demográfico de una población en crecimiento, para luego contextualizarlo en la sociedad peruana.

La investigación realizada es de tipo cualitativa, etnográfica -descriptiva, en la cual se utilizó 02 herramientas (entrevista y observación) y 02 instrumentos (el cuestionario y la bitácora respectivamente).

Finalmente, se presentan las conclusiones y recomendaciones, que dieron como resultado la falta de cultura de un envejecimiento productivo y políticas públicas que ayuden a minorizar los efectos del envejecimiento; así mismo, se plantea llevar este tema a una investigación cuantitativa.

Palabras clave: Adulto mayor, aporte económico, envejecimiento productivo, vejez. 


\begin{abstract}
This research tries to describe the Economic situation of elderly people in Peruvian society, taking into account that all people over 60 years old are considered. To know the reality of this group, several specialists in the area were consulted; Likewise, we worked with 02 types of samples, one of them, the fragil elderly, who does not contribute economically to their family or the state; and the other one, integrated by elderly people who are active and contribute to the household economy.

In the visits made to both groups it was possible to obtain relevant data such as family nucleus, academic formation, lifestyles, trades, professions, etc.; evidencing that older adults are able to continue contributing economically, as well as continue contributing with experiences and values to society. In the first chapter the problem of older adults in the world is raised, as a demographic phenomenon of a growing population, and then contextualized in Peruvian society.
\end{abstract}

The research carried out is qualitative, ethnographic-descriptive, in which 02 tools were used (interview and observation) and 02 instruments (the questionnaire and the logbook respectively).

Finally, conclusions and recommendations are presented, which resulted in the unknowledge found of a productive old age and public policies that help to minimize the effects of aging; likewise, it proposes to take this topic to quantitative research.

Keywords: Older adult, economic contribution, productive aging, old age. 


\section{Tabla de contenidos}

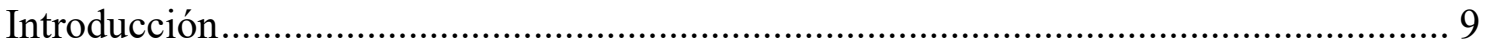

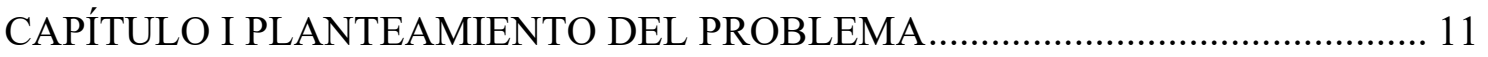

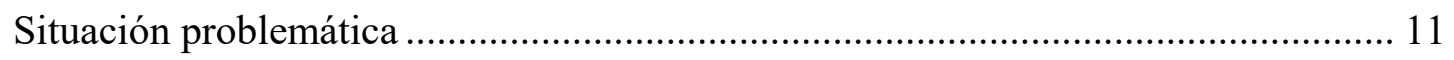

Formulación del Problema .................................................................................. 17

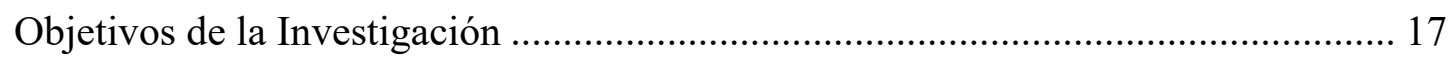

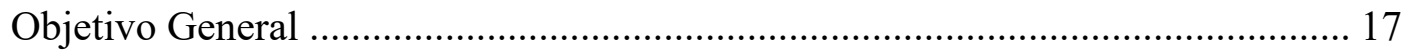

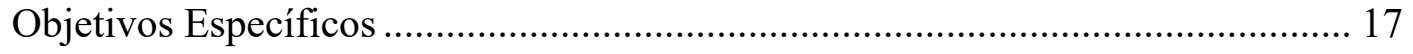

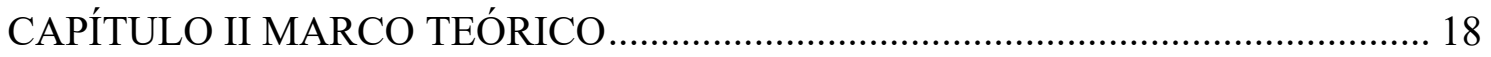

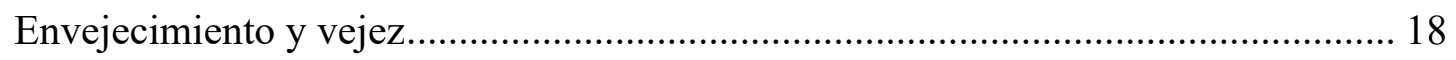

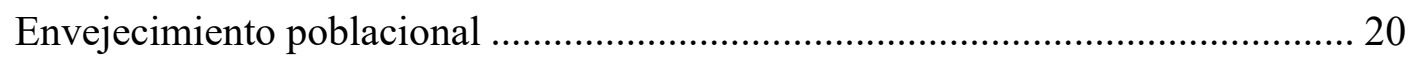

Organismos interesados en velar por el envejecimiento .................................... 21

Organización de las Naciones Unidas (ONU) .................................................... 21

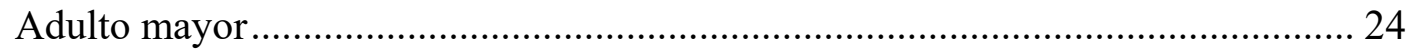

Nivel educativo, empleo y productividad en los adultos mayores …........................ 25

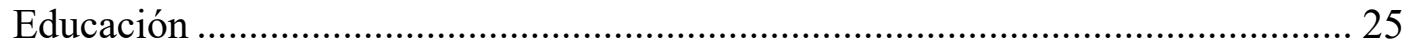

Actividad económica y trabajo en el adulto mayor .............................................. 26

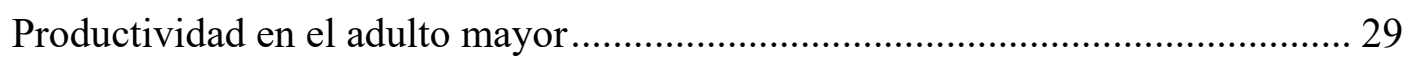

Contribución no remunerada de los adultos mayores......................................... 30

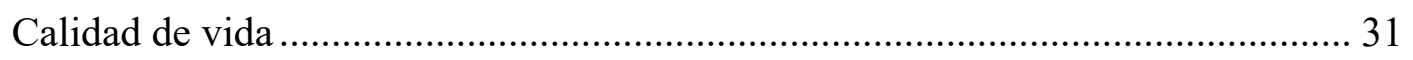

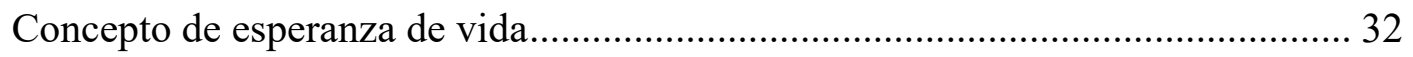

Políticas del Estado Peruano y el adulto mayor .......................................................... 34

La ley de las personas adultas mayores (ley 30490) …......................................... 34

La dirección de las personas adultas mayores- DIPAM ...................................... 35

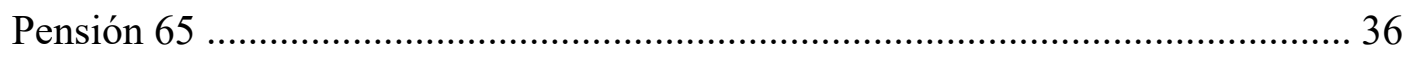

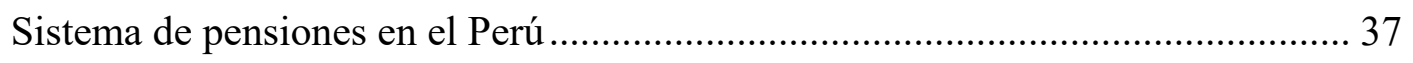

Acceso al sistema de salud para los adultos mayores.......................................... 39

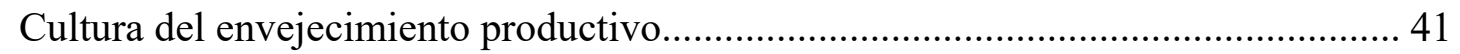

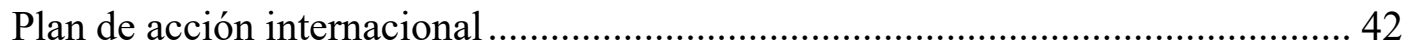

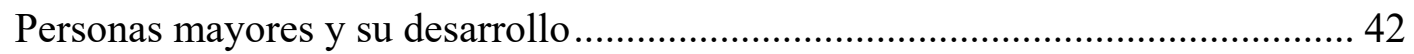

Rol de la familia en el envejecimiento productivo y creación de un entorno propicio 43

CAPÍTULO III METODOLOGÍA DE LA INVESTIGACIÓN ................................... 45

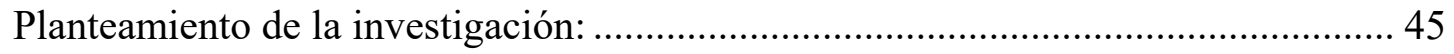




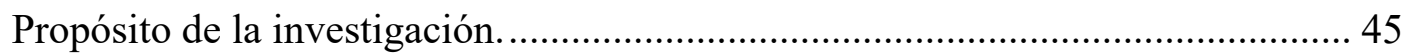

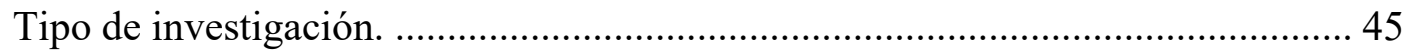

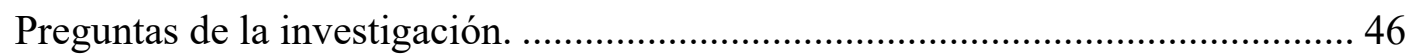

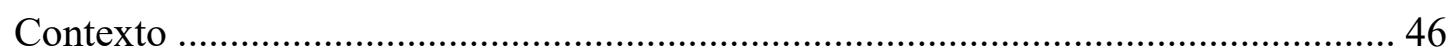

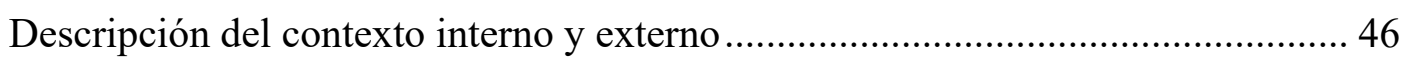

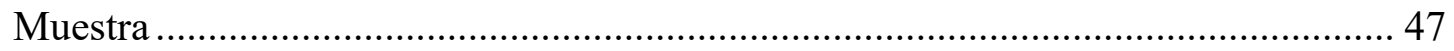

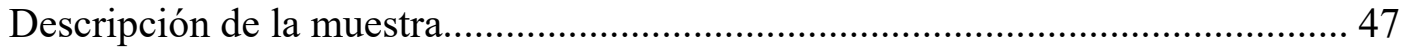

Diseño o abordaje principal (recolección de datos)................................................... 48

Identificación de la estructura de la entrevista .................................................... 48

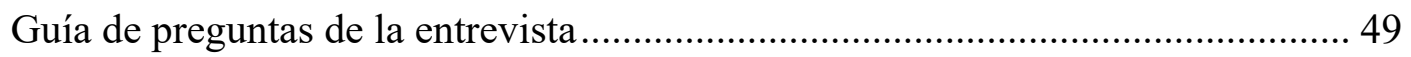

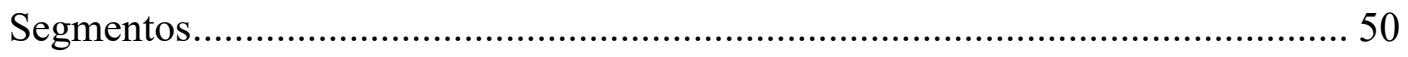

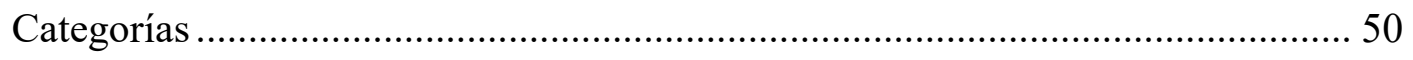

El instrumento de investigación: Diseño y descripción del instrumento (Entrevista)

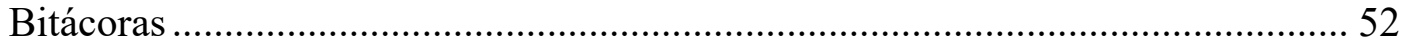

Procedimiento (Procesamiento de la información). .................................................... 54

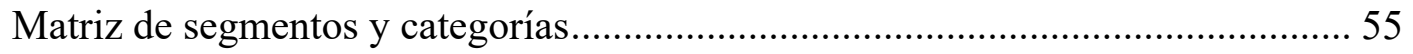

Matriz de descripción de contexto interno y externo de la muestra ........................... 56

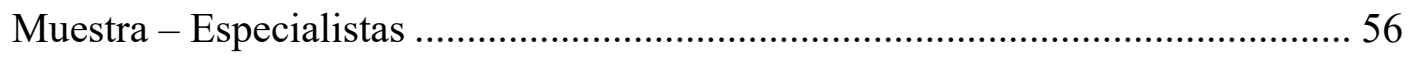

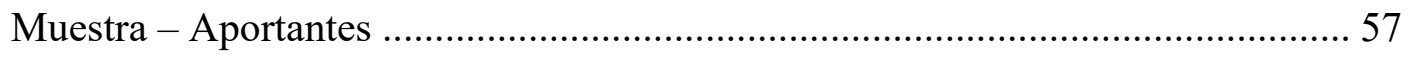

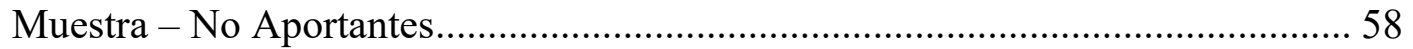

Matriz de Procesamiento de Información................................................................ 58

Análisis de aspectos positivos y negativos para el segmento 1: Especialista......... 58

Análisis de aspectos positivos y negativos para el segmento 2: Aportantes .......... 59

Análisis de aspectos positivos y negativos para el segmento 3: No Aportantes .... 60

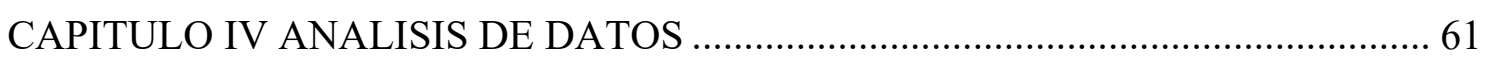

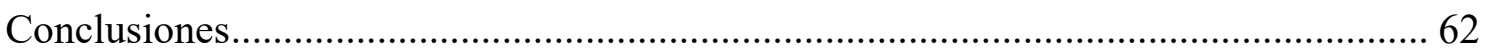

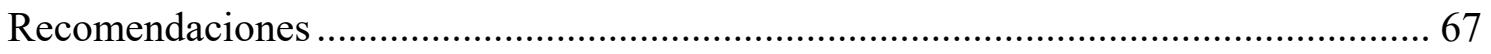

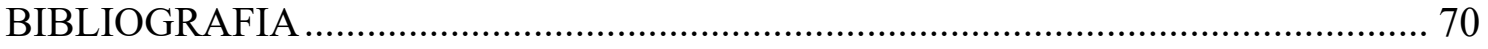

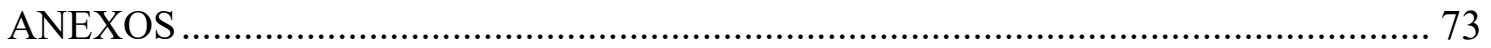




\section{Índice de tablas}

Tabla 1: Organismos de las Naciones Unidas especializados en el adulto mayor ......... 22

Tabla 2: Eventos internacionales sobre el envejecimiento poblacional ...................... 23

Tabla 3: Población adulta mayor por condición de actividad - Perú 2017 ................... 28

Tabla 4: Población adulta mayor económicamente activa ocupada según actividad - Perú 2017

Tabla 5: Evolución de indicadores demográficos, Perú (1950-2100) ............................ 34

Tabla 6: Objetivos Estratégicos del PLANPAM ......................................................... 36

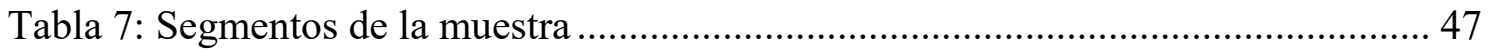

Tabla 8: Principales características de los adultos mayores independientes, aportantes, y de los adultos mayores, como población vulnerable. ........................................... 50

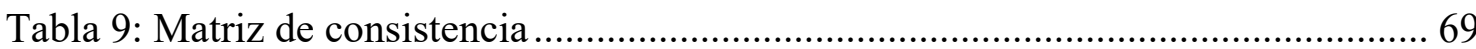




\section{Índice de figuras}

Figura 1: Pirámide de la población en el mundo en 1995 y su proyección a 2025........ 12

Figura 2: Pirámide de la población en el Perú en 1950 y 2017 .................................... 14

Figura 3: Población adulta mayor en el Perú que tiene un sistema de pensiones........... 15

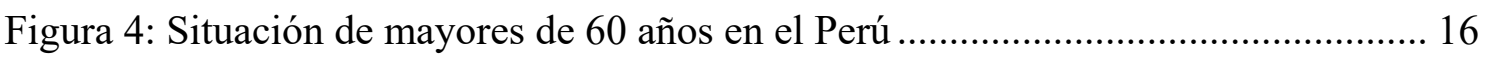

Figura 5: Proporción de la población de 60 años o más en 2015 y 2050 ...................... 21

Figura 6: Contribución económica del adulto mayor al hogar ....................................... 31

Figura 7: Población beneficiaria del programa pensión 65, según área de residencia ... 37

Figura 8: Flujo de fondos del sistema de salud peruano............................................... 40

Figura 9: El adulto mayor y su aporte económico a la sociedad peruana ..................... 44 
Introducción

El adulto mayor y su aporte económico en la sociedad peruana, es un tema relevante en un país como el Perú, en donde ya es evidente un incremento de la población de la tercera edad, como parte de un fenómeno demográfico mundial, debido al aumento de la esperanza de vida al nacer y una serie de factores como la disminución de la tasa de fecundidad y la disminución de la mortalidad, que sumados han hecho que la población adulta mayor en el Perú actualmente y por primera vez en su historia, conformen el $10 \%$ de su población total, esperando que para el 2050 representen a más del $20 \%$ de la misma.

La ley peruana indica, que la edad en que la una persona debe jubilarse es a los 65 años, de esta forma termina su vida laboral y disfruta de una pensión de jubilación, pero sólo en el caso de haber aportado durante su vida laboral activa a un fondo de pensiones público o privado, a través de un trabajo formal; algo que en la sociedad peruana no ha ocurrido en una gran proporción de la población, ni está ocurriendo.

En cifras del INEI, sólo el 37,6\% de la población actual de adultos mayores cuenta con un sistema de pensiones.

Se dice que el adulto mayor se vuelve vulnerable cuando reúne ciertos requisitos como la falta del apoyo familiar, dependencia física para desarrollar sus funciones básicas, problemas de salud, etc.; volviéndose parte de la población que representa una carga económica para la sociedad peruana; quien a su vez no cuenta con las herramientas para cubrir las necesidades básicas de esta población.

En el primer capítulo de esta investigación se describe la situación problemática de la población adulta mayor y se plantea como objetivo general describir la situación real del adulto mayor en el Estado Peruano y si éste se encuentra preparado para soportar el incremento de la esperanza de vida en el Perú.

En el capítulo dos, se abordan los aspectos teóricos que respaldan el tema de investigación como son; el envejecimiento y vejez; el nivel educativo, empleo y productividad en los adultos mayores; las políticas del Estado Peruano y la cultura del envejecimiento productivo. 
En el capítulo tres, se detalla la metodología de investigación utilizada, los datos que se obtuvieron a través de las entrevistas y la observación realizada a tres segmentos:

El primer segmento, lo conformaron los especialistas en temas del adulto mayor como por ejemplo la directora de la Oficina del Adulto Mayor en el Ministerio de la Mujer y Poblaciones Vulnerables, órgano normativo encargado de indicar los grandes lineamientos en una hoja de ruta, dirigiendo las estratégicas de las políticas públicas a nivel nacional.

El segundo segmento estuvo conformado por adultos mayores económicamente independientes, activos laboralmente, que siguen aportando a un sistema de pensiones y cuentan con acceso a un sistema de salud público y/o privado.

El tercer segmento lo conformaron adultos mayores vulnerables, personas que no aportan a un sistema de pensiones, que no lograron jubilarse para recibir una pensión y no laboran debido a que sus condiciones físicas no se lo permiten, considerándose como una carga para el estado y/o la beneficencia, debido a que en la mayoría de los casos no cuentan con un apoyo familiar.

Por último, en el capítulo cuatro se analizan e interpretan los datos del presente proyecto de investigación.

Es importante referir que durante el desarrollo de la presente investigación se resaltó el aporte de las personas mayores, con un claro enfoque en desasociar el concepto de fragilidad y persona adulta mayor; sobre todo considerando a esta población como actores sociales que contribuyen positivamente mediante la experiencia. 


\section{CAPÍTULO I \\ PLANTEAMIENTO DEL PROBLEMA}

\section{Situación problemática}

El envejecimiento poblacional es uno de los temas más preocupantes y trascendentales para el desarrollo de las sociedades a nivel mundial; así mismo, lo es para los organismos o entidades públicas y privadas. Desarrollar las políticas públicas en forma reflexiva al entorno de este fenómeno, se realiza con el fin de proteger la alta vulnerabilidad de los adultos mayores frente a la seguridad social y la viabilidad del sostenimiento de esta población en el futuro. (Prieto, 2015).

Según el informe de Perspectivas de la Población Mundial realizado por la Organización de las Naciones Unidas (ONU) en el 2017, se proyecta que el número de personas adultas mayores se duplique para el 2050 y se triplique para el 2100. Actualmente en el mundo existen 962 millones de personas adultas mayores y se estima de 1.400 millones en 2030 y 2.100 millones en 2050, y podría aumentar a 3.100 millones en 2100 a nivel mundial. (ONU, 2018).

Podemos observar que el fenómeno del envejecimiento como tal puede ser un fenómeno reversible en el tiempo y que dependerá de múltiples factores asociados a variables como fecundidad, natalidad, mortalidad, etc. 
Figura 1: Pirámide de la población en el mundo en 1995 y su proyección a 2025.

Pirámide de la población en 1995 y 2025

\section{Edades}

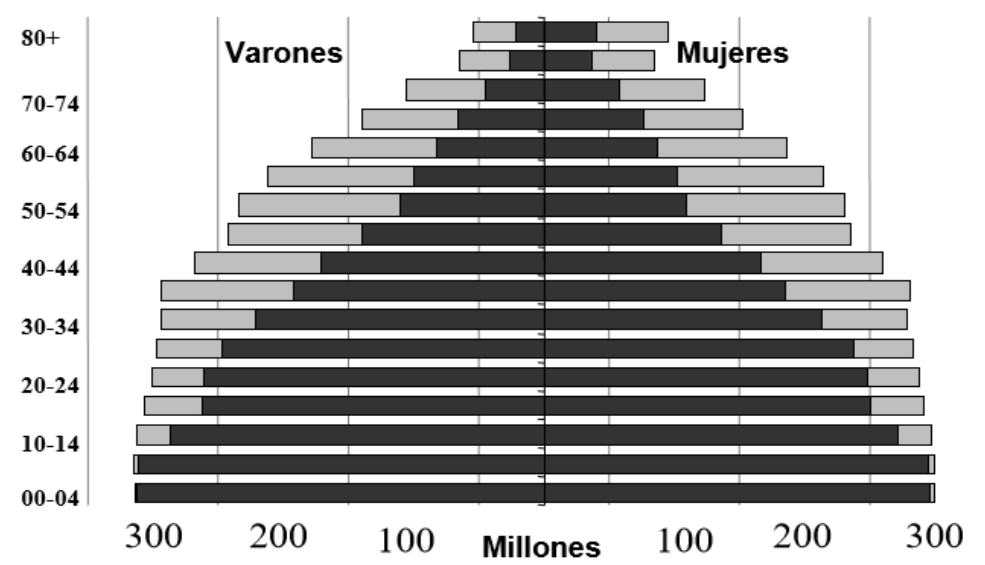

Fuente: Tomado de la ONU 2017

Factores determinantes para el aumento de las personas adultas mayores en el mundo son el aumento de la esperanza de vida y la disminución de la tasa de fecundidad, constituyendo la suma de ambos en un reto para las sociedades del mundo (ONU, 2017).

La tasa de fecundidad y natalidad son consecuencia de diversos cambios en las concepciones y cultura de las sociedades como lo son, el retraso en la edad del matrimonio, el número de hijos, el acceso al trabajo de la mujer y la búsqueda de igualdad de género, la restructuración de valores, etc.; así mismo, la disminución de la mortalidad es un factor que explica el envejecimiento demográfico y representa el éxito de las entidades sanitarias, avances tecnológicos en el área de la salud y la calidad de vida (Agulló, 2001,p.74).

Sin embargo, nos interesa resaltar que la capacidad de respuesta social ayudará a los adultos mayores a que sigan aportando a la sociedad, he ahí la importancia de diseñar proyectos y programas que alienten el envejecimiento activo y que afecten lo menos posible el crecimiento económico, el ahorro, la inversión, los índices de mano de obra, la estructura y funciones de la familia, etc. 
Es importante que al referirnos a la población adulto mayor tengamos en cuenta lo siguiente:

“...un alto porcentaje de ellas se encuentran en situación vulnerable, tanto porque todavía se ven obligadas a trabajar para subsistir como por no tener acceso a los servicios básicos. Estas restricciones las hacen depender de un entorno familiar que tampoco dispone de suficientes recursos para atender todas las necesidades de sus miembros. Por ello, la pobreza encuentra en las edades avanzadas una de sus expresiones más dramáticas" (CELADE, 2000, p.15)

De lo anterior podemos inferir que un adulto mayor en la actualidad, si no se encuentra en las condiciones para seguir trabajando, difícilmente podrá acceder o satisfacer sus necesidades básicas y más aún si no cuentan con el apoyo de su familia, volviéndose más vulnerable, hundiéndose en su pobreza y arrastrando todo lo que implica esto (enfermedades, desnutrición, etc.).

"Los países que han demostrado mejores resultados con políticas de envejecimiento activo, se han quedado por debajo de la demanda de su población adulta mayor, en parte porque el desarrollo económico no contempla las desigualdades de este grupo sino también porque la sociedad en si no responde a estos cambios" (Viveros, 2001, p.31).

Por lo mismo, Carmen Miró señala que el crecimiento de la población adulta mayor traerá problemas de gran magnitud y seriedad para lo cual nuestras sociedades no se encuentran preparadas. (Miró 2003, p.21)

Cuando definimos vulnerabilidad tomaremos el concepto de Katzman, citado por Prieto, donde se indica lo siguiente:

“...la incapacidad de una persona o de un hogar para aprovechar las oportunidades disponibles en distintos ámbitos socioeconómicos, para mejorar su situación de bienestar o impedir su deterioro." (Prieto, 2001, p.6).

La calidad de vida de los adultos mayores podría mejorar si las sociedades y sus políticas de acción son dirigidas hacia una buena distribución de las riquezas para enfrentar los cambios sociales, logrando así disminuir los riesgos y vulnerabilidad de las personas, más aún de los adultos mayores (Viveros, 2001) 
Desde la perspectiva de Ramos (Ramos, 2009), la diversidad de características de los adultos mayores, los aleja de ser un grupo homogéneo puesto que resalta, no es lo mismo ser una persona mayor de 60 años a serlo de 70 o incluso bordear los 80; debido a que estas diferencias son muy resaltantes cuando esta población es pobre, con o sin pensión, con o sin protección social, varones o mujeres, etc. Las anteriores características influyen en caracterizar diferentes términos de bienestar y calidad de vida.

Según nuestro Instituto Nacional de Estadística e Informática (INEI), en el Perú, como resultado de los grandes cambios demográficos experimentados en las últimas décadas, la estructura por edad y sexo de la población está experimentando cambios significativos. En la década de los años cincuenta, la estructura de la población peruana estaba compuesta básicamente por niños (as); así de cada 100 personas, 42 eran menores de 15 años de edad; en el año 2017, de cada 100 personas, 27 son menores de 15 años. En este proceso de envejecimiento de la población peruana, aumenta la proporción de la población adulta mayor de 5,7\% en el año 1950 a 10,1\% en el año 2017” (INEI, 2017).

Figura 2: Pirámide de la población en el Perú en 1950 y 2017
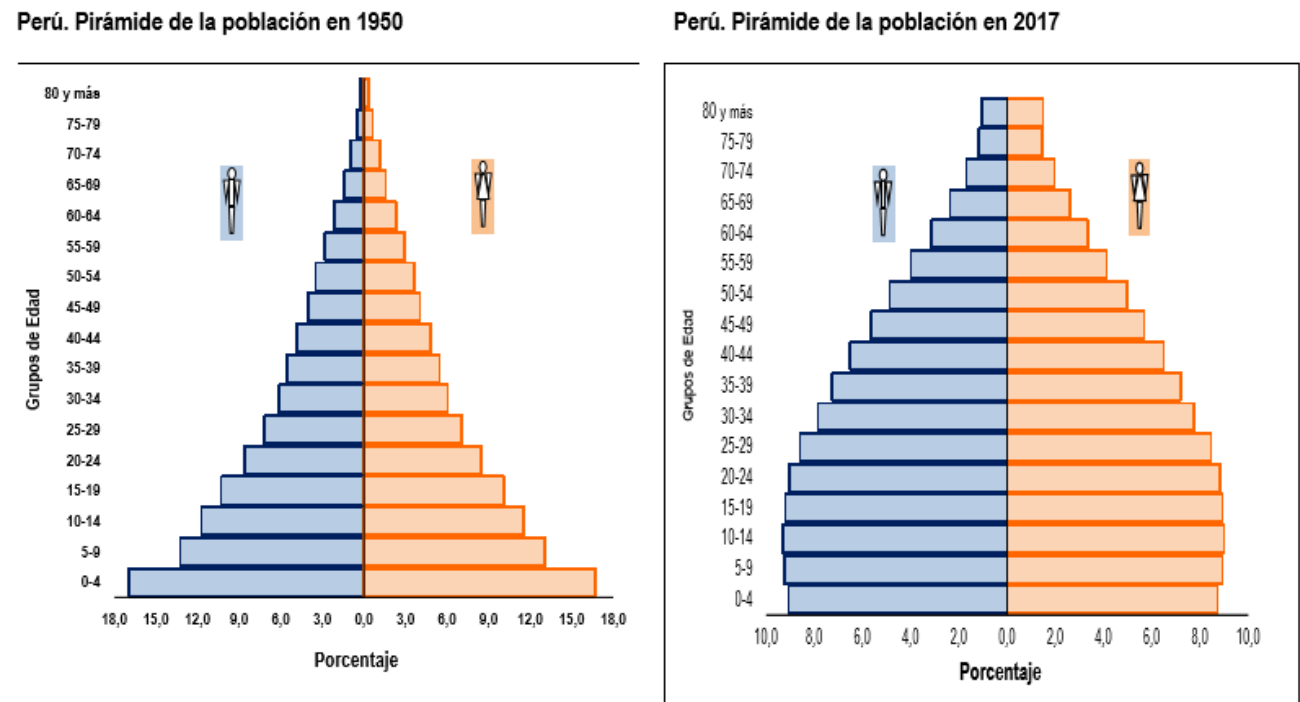

Fuente: Instituto Nacional de Estadística e Informática.

Fuente: Instituto Nacional de Estadística e Informática, 2018 
Por otro lado, los sistemas de jubilación en la región otorgan a los adultos mayores un ingreso mensual que no cubre los costos mínimos de la línea de la pobreza, un dinero que no alcanza para cubrir sus necesidades más básicas. (CEPAL, 2000)

En el Perú, según el INEI en el año 2017, el 62.4\% de la población adulta mayor no cuenta con un sistema de pensión.

En el gráfico siguiente podemos ver la distribución de la población adulta mayor según sus sistemas de pensiones.

Figura 3: Población adulta mayor en el Perú que tiene un sistema de pensiones

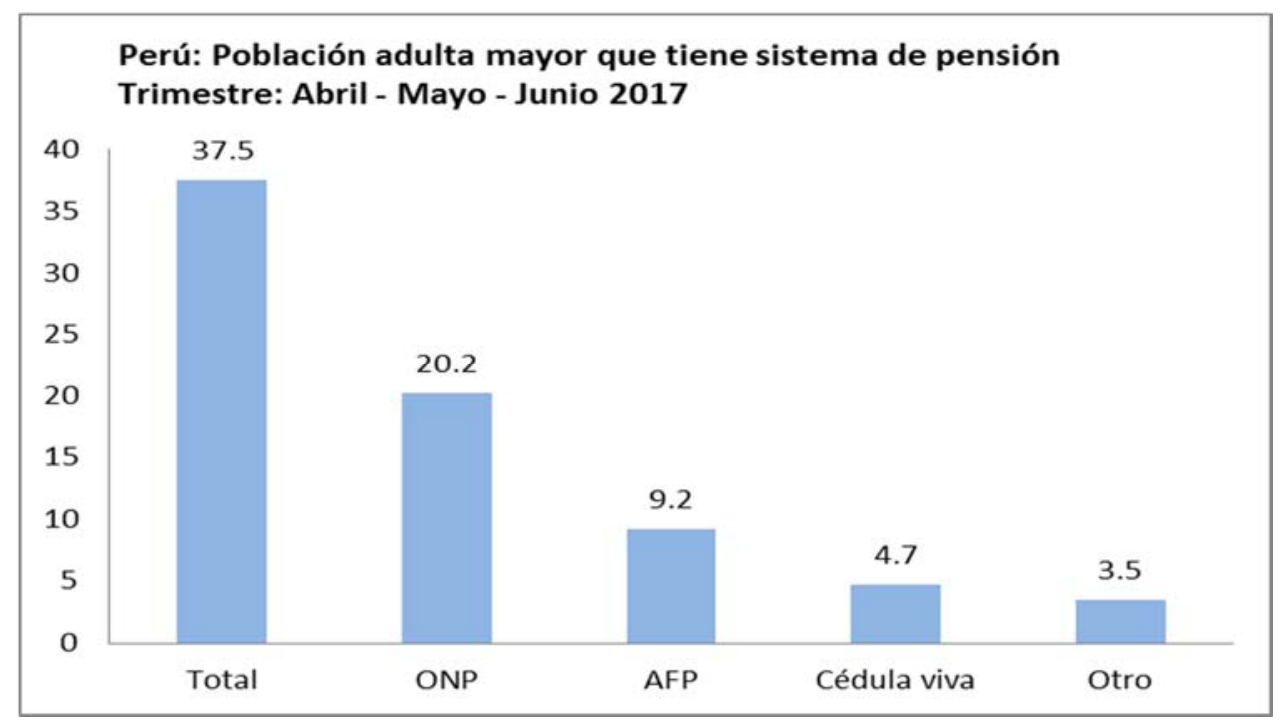

Fuente: Tomado de INEI, 2017

De lo anterior se impone una alerta frente a la situación del adulto mayor que no tiene pensión post jubilación.

Citar a García para tener un panorama de lo que sucede en el Perú es relevante en cuanto nos indica lo siguiente.

"En países como el nuestro en donde la seguridad social solo cubre a una fracción de la población adulta mayor, y ante la escasez de activos acumulados a lo largo de la vida, la subsistencia de estas personas dependerá de las transferencias familiares" "Esto conlleva a que el adulto mayor enfrente situaciones de precariedad y vulnerabilidad, y que se vea obligado en muchas ocasiones a seguir activo mediante el autoempleo con el fin de subsistir y/o de contribuir económicamente a su hogar. En este escenario de insuficiente protección social y cambios demográficos, es de esperar que en el futuro el bienestar del adulto mayor 
empeore al aumentar su número (y por lo tanto al aumentar sus necesidades) y al esperarse una declinación de su actual soporte por la reducción en las tasas de fecundidad." (García, 2012, p.8).

De lo anterior, podemos inferir que, en el Perú, llegar a ser un adulto mayor y no contar con un apoyo psicológico y económico por parte de familiares, es un gran riesgo para tener una mala vejez, una mala calidad de vida y hundirse en la pobreza.

Figura 4: Situación de mayores de 60 años en el Perú

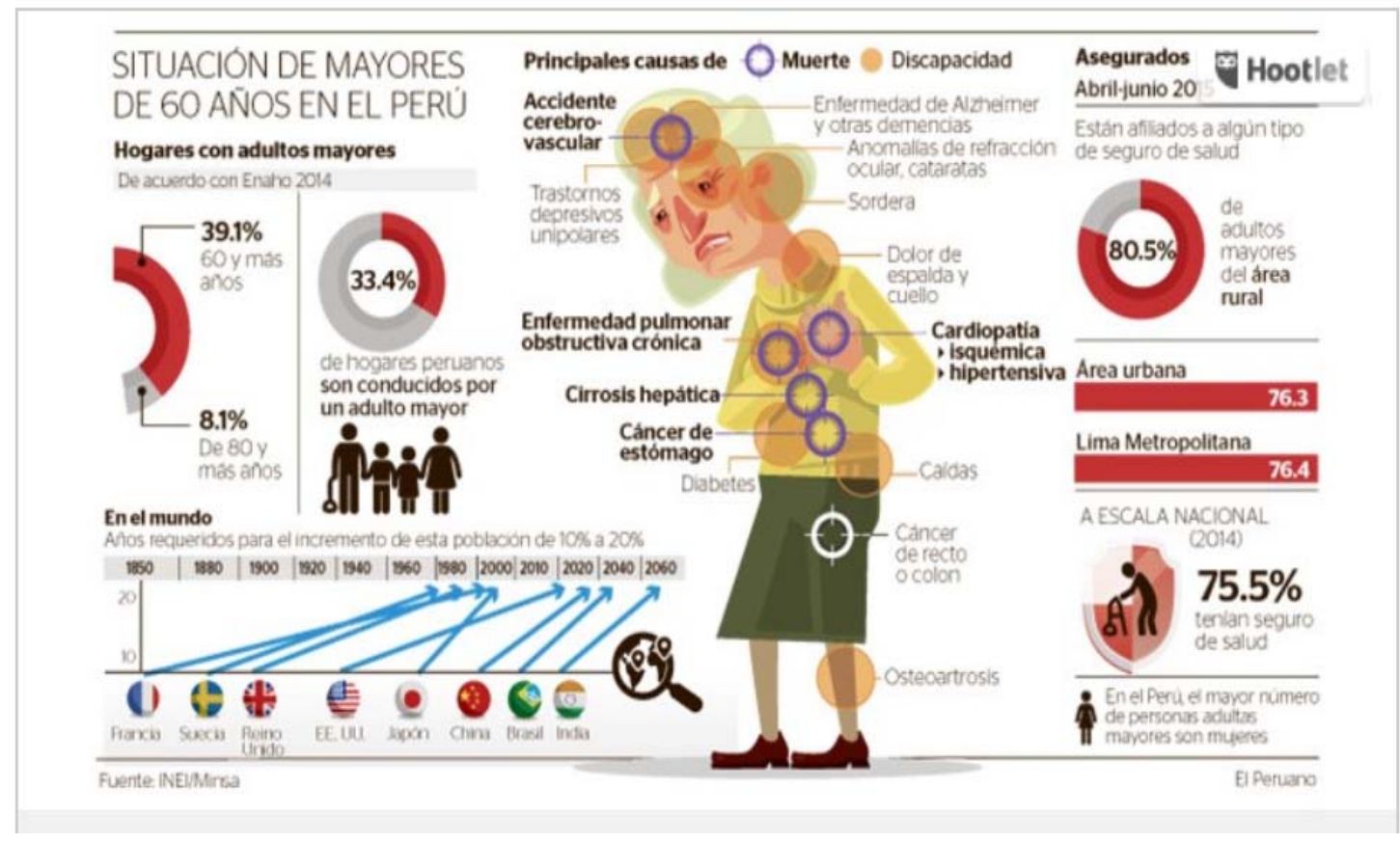

Fuente: Diario oficial del bicentenario El Peruano

En la Asamblea Mundial de las Naciones Unidas, sobre el Envejecimiento (1982), se concluyó que los Gobiernos deberían tomar o fomentar medidas para que la transición de la vida activa a la jubilación sea fácil, gradual y hacer más flexible la edad de derecho a jubilarse. Estas medidas deben incluir cursos de preparación a la jubilación y la disminución (o no) del trabajo en los últimos años de la vida profesional.

Con respecto a lo último, Agulló (2001), sostiene que la jubilación en las personas no debe ni puede ser impuesta; si o que, debe haber programas de transición para que la jubilación no produzca un cambio drástico en esta población. 


\section{Formulación del Problema}

¿Está preparado el adulto mayor para seguir aportando económicamente a la sociedad peruana, y de ser así, por qué lo hace?

¿Podrá apalancar el Estado Peruano el incremento de la esperanza de vida en el Perú?

\section{Objetivos de la Investigación}

\section{Objetivo General}

Describir la situación real del adulto mayor en el Estado Peruano y si éste se encuentra preparado para soportar el incremento de la esperanza de vida en el Perú.

\section{Objetivos Específicos}

$\checkmark$ Describir la situación del adulto mayor en el Estado Peruano frente al incremento de la esperanza de vida del Perú.

$\checkmark$ Describir las consecuencias económicas y sociales del envejecimiento poblacional en el Perú.

$\checkmark$ Exponer las políticas de Estado Peruano dirigidas al adulto mayor.

$\checkmark$ Revisar las tendencias de cultura del envejecimiento productivo. 


\section{CAPÍTULO II \\ MARCO TEÓRICO}

\section{Envejecimiento y vejez}

El envejecimiento es un tema que se empezó a tocar en este último siglo, pues antes no tenía relevancia para ninguna organización a nivel internacional; por tal razón, en este capítulo iremos viendo como el tema fue abordado por diferentes entidades.

Al hablar de envejecimiento debemos tener en cuenta que es la Organización de las Naciones Unidas, quien dio el primer paso en tomar en cuenta este tema; tal es así que se pueden encontrar registros del año 1948, donde se abordó por primera vez el tema de envejecimiento; en dicho año, la Asamblea General de la ONU, aprobó la resolución 213 (III) y decide comunicar al Consejo Económico y Social el proyecto de declaración de los derechos de la vejez. (ONU, 2017).

Desde entonces, el tema de envejecimiento ha sido estudiado de forma indirecta por algunas organizaciones interesados en temas sociales; sin embargo, desde el año 1977, la ONU tomo el tema de forma directa, es así que en dicho año se plantea la necesidad de organizar una asamblea mundial y tocar el tema de las personas mayores; siendo el año siguiente, la fecha donde se acuerda que esta asamblea se diera en el año 1982 en la ciudad de Viena.

Es a partir de esta década que el envejecimiento ha sido tratado en conferencias y eventos internacionales, de las cuales se hará mención más adelante. 
Según la Real Academia de la Lengua (RAE), ser viejo es la característica que se le da a todo ser vivo de edad avanzada. También menciona se usa el adjetivo para calificar a un objeto deslucido o estropeado por el uso. (RAE, 2018)

La palabra "vejez" se encuentra estigmatizada por los otros, los que no la están viviendo como etapa de vida, quienes le dan el valor de indeseado y lo asocian a términos de incapacidad o limitación.

Sin embargo existen otras concepciones de la vejez como parte de la vida, las cuales no son muy difundidas y se basan en los efectos que genera el tiempo en las personas, el cual hace que pasen por cada una de sus etapas en la vida, con una realidad propia donde se resalta: La madurez vital, la experiencia, el conocimiento, la perspectiva de la historia personal y social que fueron por mucho tiempo atrás valoradas y que ahora no lo son y que han terminado en conducir al adulto mayor a una grave falta de identidad (Zapata, 2015, p.190).

Según la Convención Interamericana sobre la protección de los Derechos Humanos de las Personas Mayores, se entiende por Envejecimiento al proceso gradual que se desarrolla durante el curso de vida y que conlleva cambios biológicos, fisiológicos, psico-sociales y funcionales de variadas consecuencias, las cuales se asocian con interacciones dinámicas y permanentes entre el sujeto y su medio.

Según Sarabia (2009), analiza tres conceptos de envejecimiento:

- Envejecimiento normal, sin enfermedades, de la forma típica

- Envejecimiento patológico, con enfermedades

- El envejecimiento exitoso, con satisfacción y con posibilidad de adaptarse a los cambios.

En la presente investigación resaltaremos el envejecimiento exitoso tomando en cuenta lo subjetivo que puede llegar a ser dada su dependencia de cada persona en cada caso en particular, dado que se mide por el grado de satisfacción sobre su vida. 
Ruiperez citado por Moreno (2004) afirma sobre la vejez: Toda persona debe sentirse orgullosa por haber llegado hasta allí. Además, la vejez puede ser una etapa de la vida tan positiva como cualquier otra. No es justo que se fomenten temores y sobresaltos; buscando que, los adultos mayores participen de forma activa en la sociedad disfrutando de calidad de vida.

\section{Envejecimiento poblacional}

Las sociedades pueden envejecer al aumentar la proporción de personas mayores, es decir las sociedades también podrían rejuvenecer, por lo tanto, las situaciones cambian de acuerdo al fenómeno geográfico que estén viviendo las sociedades; por otro lado, las

personas envejecen cada año que sobreviven, pues añaden un dígito a su edad cronológica. Muy por el contrario, el proceso de envejecimiento de las poblaciones es una reestructuración de las edades que modifica las relaciones entre las generaciones, lo que supone un reto que implica enfrentar con éxito las mejoras sanitarias y sociales sobre la enfermedad y la muerte. (Causapié, 2011, p.33).

Una visión positiva del envejecimiento es la postura de esta investigación que considera que al envejecimiento es un privilegio, dado su logro histórico como consecuencia del progreso de las poblaciones. (Moreno, 2004, p.188). 
Figura 5: Proporción de la población de 60 años o más en 2015 y 2050

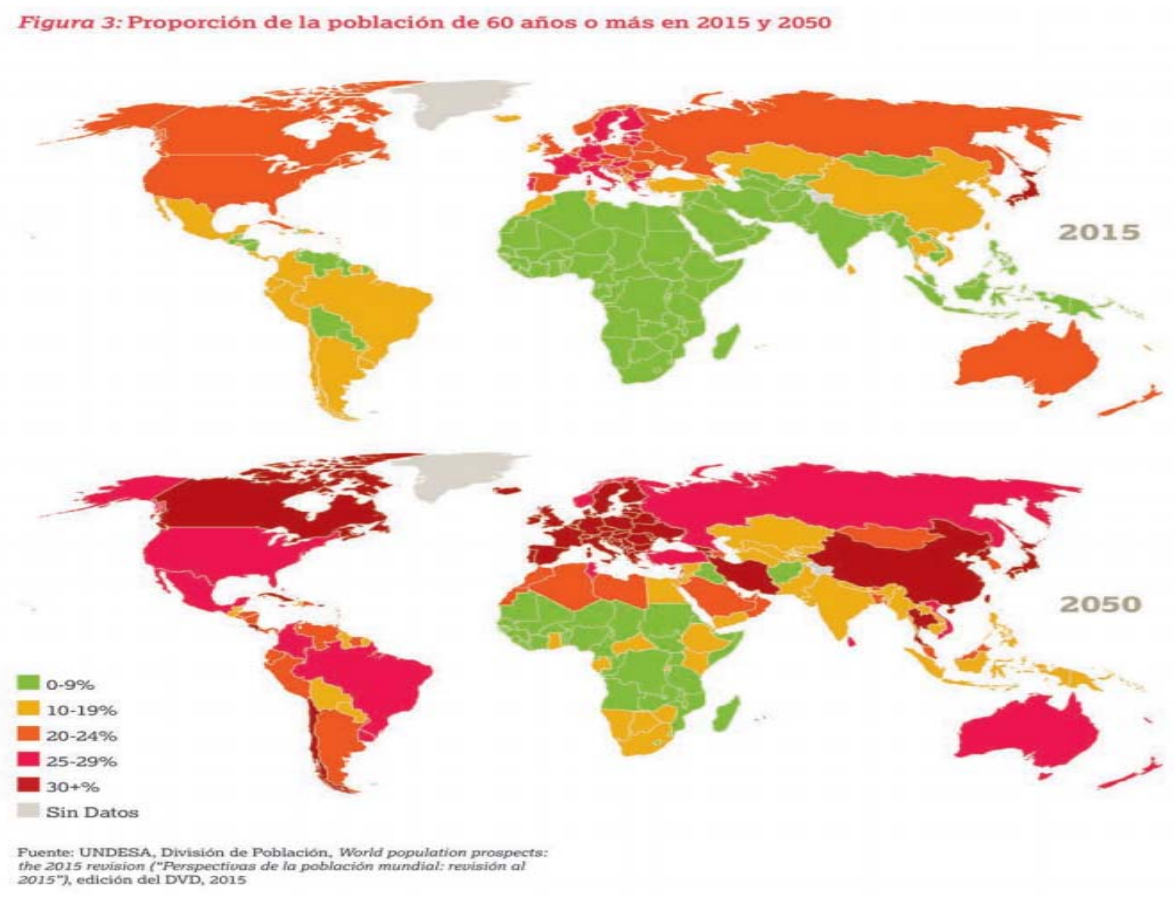

Fuente: Índice Global del Envejecimiento. Help Age International

\section{Organismos interesados en velar por el envejecimiento}

Antes de seguir con el desarrollo del tema, debemos saber que existen diversas entidades que han mostrado preocupación por el envejecimiento a nivel internacional, siento sin lugar a duda la Organización Nacional de las Naciones Unidas una de las más importantes.

\section{Organización de las Naciones Unidas (ONU)}

La ONU fue fundada el 24 de octubre de 1945 en la ciudad estadounidense de San Francisco, por 51 países, al finalizar la Segunda Guerra Mundial, con la firma de la Carta de las Naciones Unidas.

Desde su creación, ha ido tocando con pinceladas el hecho del envejecimiento y adulto mayor, los cuales son tratados desde diversas perspectivas por los diferentes órganos que lo componen y se muestran en la Tabla 1. 
Tabla 1: Organismos de las Naciones Unidas especializados en el adulto mayor

\begin{tabular}{|c|c|c|}
\hline & Entidades & Descripción \\
\hline \multirow{3}{*}{ 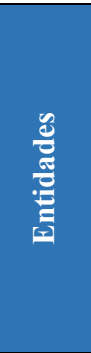 } & $\begin{array}{l}\text { Organización Internacional del } \\
\text { Trabajo (OIT) }\end{array}$ & $\begin{array}{l}\text { En el año } 1980 \text { aprobó la recomendación sobre trabajadores de edad, planteando como objetivo la creación de un trabajo digno. } \\
\text { Dentro de sus publicaciones relacionadas al adulto mayor esta "Una sociedad inclusiva para una población que envejece: el desafío } \\
\text { del empleo y la protección social". }\end{array}$ \\
\hline & $\begin{array}{l}\text { Organización Mundial de la Salud } \\
\qquad(\mathrm{OMS})\end{array}$ & $\begin{array}{l}\text { Promueve proyectos relacionados con el envejecimiento y las personas mayores a través de su programa de "envejecimiento y ciclo } \\
\text { vital". Este organismo promueve el envejecimiento activo y saludable. }\end{array}$ \\
\hline & $\begin{array}{c}\text { Organización de las Naciones Unidas } \\
\text { para la agricultura y alimentación } \\
\text { (FAO) }\end{array}$ & $\begin{array}{l}\text { El envejecimiento rural como un elemento decisivo del cambio demográfico de las regiones en desarrollo, este fenómeno puede } \\
\text { tener efectos negativos como la falta de mano de obra en el campo. Dentro de los documentos emitidos con respecto al tema de } \\
\text { estudio, publicó "envejecimiento de la población y desarrollo rural". }\end{array}$ \\
\hline \multirow{5}{*}{ 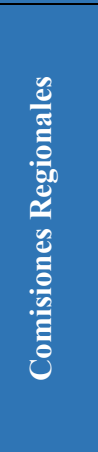 } & $\begin{array}{l}\text { Comisión económica para Europa } \\
\text { (CEPE) }\end{array}$ & $\begin{array}{l}\text { Dentro de sus aportes con respecto al envejecimiento, este organismo organizó en Berlín entre los días } 11 \text { y } 13 \text { de setiembre del } \\
2002 \text {, la conferencia ministerial sobre el envejecimiento, la que se desarrolló posteriormente a la asamblea de Madrid }\end{array}$ \\
\hline & $\begin{array}{l}\text { Comisión económica para África } \\
\text { (CEPA) }\end{array}$ & $\begin{array}{l}\text { Organismo que en el año } 2000 \text { celebro el Addis Abeba, en la que se toma en serio la sostenibilidad de las estructuras sociales en una } \\
\text { sociedad que envejece. (Naciones Unidas, 2003). }\end{array}$ \\
\hline & $\begin{array}{l}\text { Comisión económica para América y } \\
\text { el Caribe (CEPAL) }\end{array}$ & $\begin{array}{l}\text { Organismo que tiene como dependencia al Centro Latinoamericano y Caribeño de Demografía (CELADE), quien se encarga } \\
\text { directamente de los temas relacionados con el envejecimiento, adicionalmente planteo } 2 \text { proyectos concretos, "redes de apoyo } \\
\text { familiar y comunitario a los adultos mayores" y "impacto de genero de la reforma de pensiones en América Latina" }\end{array}$ \\
\hline & $\begin{array}{l}\text { Comisión económica y social para } \\
\text { Asia y el pacífico (CESPAP) }\end{array}$ & $\begin{array}{l}\text { Es la comisión más grande de la ONU, integrado por } 60 \text { miembros asociados, abarcando al } 60 \% \text { de la población mundial. Por lo } \\
\text { tanto, la mayor población que envejece (Naciones Unidas, 2003). }\end{array}$ \\
\hline & $\begin{array}{l}\text { Comisión económica y social para } \\
\text { Asia Occidental (CESPAO) }\end{array}$ & $\begin{array}{l}\text { Comisión que organizó la reunión regional preparatoria de la segunda asamblea mundial sobre el envejecimiento en febrero 2002, } \\
\text { fruto de la cual nació el "plan árabe de acción sobre el envejecimiento hasta el año } 2012\end{array}$ \\
\hline \multirow{3}{*}{ 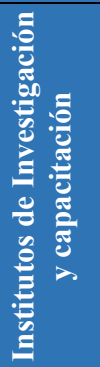 } & $\begin{array}{l}\text { Instituto internacional de } \\
\text { investigaciones y capacitaciones para } \\
\text { la promoción de la mujer } \\
\text { (INSTRAW) }\end{array}$ & $\begin{array}{l}\text { Instituto que se encarga de la promoción de la igualdad de género, quien en los últimos años tomo como tema de observación los } \\
\text { aspectos de género en el envejecimiento y proceso mundiales }\end{array}$ \\
\hline & $\begin{array}{l}\text { Instituto internacional sobre } \\
\text { envejecimiento (INIA) }\end{array}$ & $\begin{array}{l}\text { Instituto especializado en temas del envejecimiento; dentro de sus objetivos están el facilitar la implementación del plan de acción } \\
\text { internacional sobre envejecimiento de Viena, así como colmar las carencias sobre la capacitación profesional continua en el } \\
\text { envejecimiento. La principal publicación de este organismo es BOLD, una revista trimestral con información sobre últimas } \\
\text { investigaciones relacionadas con el envejecimiento }\end{array}$ \\
\hline & $\begin{array}{l}\text { Instituto de las Naciones Unidas para } \\
\text { el desarrollo Social (UNRISD) }\end{array}$ & $\begin{array}{l}\text { Instituto que organizó una conferencia bajo el título "envejecimiento, desarrollo y protección social" con el objetivo de destacar las } \\
\text { principales cuestiones relacionadas con el envejecimiento de la población }\end{array}$ \\
\hline
\end{tabular}

\section{Fuente: Elaboración Propia.}


Tabla 2: Eventos internacionales sobre el envejecimiento poblacional

\begin{tabular}{|c|c|c|}
\hline Entidades & Fechas & Descripción \\
\hline $\begin{array}{l}\text { Asamblea internacional sobre el } \\
\text { envejecimiento. Viena } 1982\end{array}$ & Viena 1982 & $\begin{array}{l}\text { En esta asamblea se trató sobre los principales problemas que aqueja a la población mayor de } 60 \text { años, con sus grandes consecuencias tanto para } \\
\text { el desarrollo general a nivel nacional como para el bienestar y la seguridad de estas personas, lo cual ya está afectando a los países desarrollados } \\
\text { y afectara en un futuro no lejano a los demás países }\end{array}$ \\
\hline $\begin{array}{l}\text { Conferencia internacional sobre población } \\
\text { y desarrollo }\end{array}$ & $\begin{array}{l}5 \text { y } 13 \text { de setiembre de } \\
1994\end{array}$ & $\begin{array}{l}\text { El tema de educación, salud e integridad a la sociedad, proponiendo brindar las herramientas necesarias para aumentar la autonomía de este grupo } \\
\text { poblacional (adulto mayor), mejorar los accesos al sistema de salud como de seguridad económica y social, así como también resaltar que la familia } \\
\text { debe ser responsables con sus familiares adultos mayores. }\end{array}$ \\
\hline $\begin{array}{l}\text { Cumbre mundial sobre el desarrollo social } \\
\quad \text { - Copenhague } 1995\end{array}$ & $\begin{array}{l}6 \text { y } 12 \text { de marzo de } \\
1995\end{array}$ & $\begin{array}{l}\text { Multiplicar los esfuerzos para proteger a las personas mayores, planteando como requisito para el cumplimiento, fortalecer los sistemas de apoyo } \\
\text { a las familias, mejorar la situación de los adultos, sobre todo si no cuentan con el apoyo familiar, velar por la satisfacción de sus necesidades } \\
\text { básicas, facilitar el acceso a los servicios sociales y de salud }\end{array}$ \\
\hline $\begin{array}{l}\text { Declaración de Montevideo sobre } \\
\text { políticas de protección integral al } \\
\text { envejecimiento y a la vejez saludable }\end{array}$ & $\begin{array}{l}31 \text { de julio y } 2 \text { de } \\
\text { agosto de } 1997\end{array}$ & $\begin{array}{l}\text { Se formularon las recomendaciones sobre la seguridad social, los servicios de atención médica, las relaciones intergeneracionales y el } \\
\text { envejecimiento activo, recomendando eliminar las barreras que impiden que los adultos mayores se mantengan productivos; así mismo, promueve } \\
\text { la educación y/o capacitación constante en el transcurso de toda su vida. }\end{array}$ \\
\hline $\begin{array}{l}25^{\circ} \text { Conferencia Sanitaria Panamericana } \\
\text { de la OPS }\end{array}$ & $\begin{array}{l}21 \text { y } 25 \text { de setiembre } \\
\text { de } 1998\end{array}$ & $\begin{array}{l}\text { En esta conferencia se plantea que, sin un buen estado de salud, las personas no podrán gozar de una vejez decente, pues las enfermedades que } \\
\text { adquieran traerán repercusiones sobre su vida y su entorno. }\end{array}$ \\
\hline $\begin{array}{l}\text { Proclamación del "año internacional de la } \\
\text { persona adulta mayor" }\end{array}$ & $\begin{array}{l}\text { Viena-1982, el } 14 \text { de } \\
\text { diciembre de } 1990\end{array}$ & Asamblea General, en su resolución $45 / 106$, proclamó el $1^{\circ}$ de octubre como el Día Internacional de las Personas de Edad \\
\hline $\begin{array}{l}\text { Foro andino sobre políticas para adultos y } \\
\text { adultas mayores }\end{array}$ & Lima en 1999 & $\begin{array}{l}\text { Se establece que los estados miembros conformen comités intersectoriales con la participación de la sociedad civil, para la concertación de políticas, } \\
\text { planes y programas que ayuden a mejorar las condiciones de vida de los adultos mayores, señalándose como responsable de la implementación de } \\
\text { este acuerdo al ministerio de la mujer y desarrollo social }\end{array}$ \\
\hline $\begin{array}{l}\text { Segunda asamblea mundial sobre el } \\
\text { envejecimiento de Madrid }\end{array}$ & $\begin{array}{l}8 \text { y } 12 \text { de abril del } \\
2002\end{array}$ & $\begin{array}{l}\text { Se celebra el aumento de la esperanza de vida; se plantea retos para aumentar la oportunidad de las personas en aprovechar. La OMS, en el año } \\
\text { 2002, dio a conocer el documento Envejecimiento activo, definiéndolo como "el proceso de optimización de las oportunidades de salud, } \\
\text { participación y seguridad con el fin de mejorar la calidad de vida de las personas a medida que envejecen". }\end{array}$ \\
\hline $\begin{array}{c}\text { Primera conferencia regional } \\
\text { intergubernamental para la } \\
\text { implementación del plan de acción de } \\
\text { Madrid sobre el envejecimiento }\end{array}$ & $\begin{array}{l}19 \text { y } 21 \text { de noviembre } \\
\text { del } 2003\end{array}$ & $\begin{array}{l}\text { Reconocer y difundir los derechos de los adultos mayores, así como también, promover la igualdad en todos los aspectos de su vida, ofrecer } \\
\text { empleos decentes y seguir desarrollándose intelectualmente; por otro lado, resalta que este grupo de personas debe contar con un seguro social, de } \\
\text { salud y cobertura de pensiones; en general fomentar una vejez saludable }\end{array}$ \\
\hline $\begin{array}{l}\text { Segunda conferencia regional } \\
\text { intergubernamental sobre el } \\
\text { envejecimiento en Brasilia }\end{array}$ & $\begin{array}{l}4 \text { y } 6 \text { de diciembre del } \\
2007\end{array}$ & $\begin{array}{l}\text { En esta conferencia, se proponen intercambiar la experiencia de las diferentes regiones de los países de América latina y el caribe con respecto a } \\
\text { la implementación del plan de acción de Madrid }\end{array}$ \\
\hline $\begin{array}{l}\text { Informe del Grupo de Trabajo de } \\
\text { Composición Abierta sobre el } \\
\text { Envejecimiento }\end{array}$ & $\begin{array}{l}5 \text { y el } 7 \text { de julio de } \\
2017\end{array}$ & $\begin{array}{l}\text { Establecido por la Asamblea General en su resolución } 65 / 182 \text {, con el propósito de incrementar la protección de los derechos humanos de las } \\
\text { personas de edad }\end{array}$ \\
\hline
\end{tabular}

\section{Fuente: Elaboración propia}


Desde los años 80 , el tema del envejecimiento ha sido tratado en diversos eventos internacionales, siento los más importantes mencionados en la Tabla 2, y que se han desarrollado en diferentes países, en diferentes momentos y con el objetivo en común de exponer las diferentes problemáticas que atraviesan los adultos mayores.

A continuación, pasaremos a revisar conceptos importantes en los que definiremos cuáles son las características principales de la población adulto mayor.

\section{Adulto mayor}

Según la Organización Mundial de la Salud, las personas de 60 a 74 años son consideradas de edad avanzadas; las personas de 75 a 90 años, se les considera viejas o ancianas; y a los que sobrepasan los 90 años, se les denomina grande viejos o grandes longevos; por tanto, a toda persona mayor de 60 años se le llama de forma indistinta, adulto mayor o tercera edad. Así mismo se indica que en el año 2015, este grupo de personas representaba el $12 \%$ de la población del planeta y se espera que, en el año 2050 , supere la cifra, llegando a representar el $22 \%$ de la población global; por otro lado hace referencia que en el año 2020, el número de personas mayores de 60 años superará al número de niños menores de 5 años. (OMS, 2018)

En el Perú y según la Ley 30490, ley de las personas adultas mayores, en su artículo 2 menciona: "Entiéndase por persona adulta mayor a aquella que tiene 60 o más años de edad.”

Siendo este último, el concepto o definición que consideraremos para el desarrollo de la presente investigación. 


\section{Nivel educativo, empleo y productividad en los adultos mayores}

A raíz del envejecimiento poblacional en los países surgen nuevas necesidades, entre ellas la demanda de educación, empleo y ocupación a lo largo de la vida, buscando desarrollar a la persona de forma integral como "proyecto inacabado" nutriéndolo en el campo laboral y atendiendo sus necesidades contemporáneas de esta forma estipular que toda persona tiene el derecho a seguir desarrollando su vida por medio de la educación y de la salud. (Dome, 2016, p.109).

\section{Educación}

La Convención Interamericana sobre la Protección de los Derechos Humanos de las Personas Mayores, proclamada por la Organización de los Estados Americanos afirma que: "La persona mayor tiene derecho a la educación en igualdad de condiciones con otros sectores de la población y sin discriminación”.

La educación es un factor relevante para cambiar la percepción negativa de la vejez, y citamos a Moreno para resaltar su importancia.

“A través de la educación, la actividad y el uso de las nuevas tecnologías, se puede alcanzar una mejor calidad de vida, que irá permitiendo un buen envejecer y dando base al nuevo modelo de envejecimiento que ya se está imponiendo al comenzar el nuevo milenio. El modelo tradicional ya no es viable, ya que está basado en un concepto deficitario de vejez, que solo contabiliza pérdidas y declinación; instalado aún en el imaginario social, en forma de prejuicios e ideas erróneas, que es necesario desprenderse, para posicionarse en ese proceso y desarrollar al máximo las potencialidades que todo ser humano tiene y que no se pierden porque se envejece" (Moreno, 2004, p.193).

En el Perú el nivel educativo alcanzando por la población adulta mayor según

INEI: "El 14,8\% de la población adulta mayor no cuenta con un nivel educativo o solo 
tiene nivel inicial, el 40,8\% alcanzó a estudiar primaria; el 23,3\% secundaria y el 21,0\%, nivel superior".

En cuanto al alfabetismo: "El 17,8\% de la población de 60 y más años de edad no sabe leer ni escribir. Esta situación es más elevada en las mujeres, el 26,1\% de adultas mayores son analfabetas, siendo tres veces más alta que en sus pares los hombres. (INEI, 2017).

\section{Actividad económica y trabajo en el adulto mayor}

Diversos autores distinguen características particulares en la demanda de trabajo y en la oferta que visualiza el mercado laboral para los adultos mayores de manera muy peculiar, y los obliga a que se les estudien por separado. Los siguientes investigadores citados por García afirman:

- Peracchi y Welch (1994) analizan la realidad de Estados Unidos y hallan que los bajos salarios de los adultos mayores llevan a que estos se retiren muy pronto de la vida laboral.

- Börsch-Supan (2000) en Alemania los aportes de la seguridad social hacen que disminuya la población adulta mayor que trabaja. Sin embarco en países subdesarrollados como el Perú y sus cifras altas de adultos mayores sin un sistema de pensiones muchos de ellos optan por alternativas de trabajo que les permitan obtener algún ingreso.

- Marfan, que en un estudio realizado en Chile se encontró que los trabajadores con más preparación académica desean laborar por mucho más tiempo que aquellos que recibieron menor educación. (García, 2012, p.10).

García cita además textualmente:

"Existen importantes prejuicios por parte de las empresas por contratar a personas adultas mayores, pensando que son menos productivos, menos adaptables y menos dispuestos a aceptar las nuevas tecnologías que los jóvenes. El informe de la OECD señala además que las empresas podrían preferir la contratación de jóvenes pagándoles salarios menores. Asimismo, existen pocos incentivos para capacitar 
a los empleados adultos mayores, pensando que su vida laboral es corta y por lo tanto los rendimientos de esta inversión serían pequeños. (García, 2012, p.10).

Desde otra perspectiva donde podamos tener en cuenta otro tipo de aportaciones del adulto mayor donde los identificamos como consumidores, poseedores de bienes y rentas, colaboradores con la familia, voluntarios, etc. No se puede encerrar a todos los adultos mayores jubilados como inactivos, pues así se muestran en las encuestas.

La concepción meramente economista y/o monetarista de que las personas adultas mayores son "inactivas" y que ya no pueden realizar un trabajo remunerado es muy limitada. (Agulló, 2001. p.60)

Es en esta última concepción de Agulló en la que se enfocará la presente investigación. Apoyando esta última teoría indicaremos que es un gran mito "Las personas mayores no trabajan" y es una gran realidad "La jubilación es un lujo que pocas personas mayores en países de bajo y mediano ingreso se permiten”.

Tal es el caso del señor Genaro reyes, un mercader de 74 años, entrevistado en Lima, Perú, quien indica “A pesar de ser hombre, a veces lloro porque siento tanta rabia porque no puedo ganar suficiente dinero para comprar medicinas que mi esposa necesita para mejorar. Nadie me quiere emplear porque dicen que soy muy viejo y no le soy útil" o la señora Gregoria Zeballos Quispe, una vendedora de flores, quien comenta lo siguiente “Me levanto al amanecer y junto todas las flores que puedo cargar. Camino 10km hasta el mercado local para venderlas. Usualmente traigo a casa alrededor de 5 soles (US\$ 1.80). Este dinero antes era suficiente pero ahora no alcanza para comprar nada. En los últimos tres meses no he comido más que maíz cocido y algunos vegetales que puedo hacer crecer en mi huerto" (Help Age International).

Según la ONU más del 70 por ciento de las mujeres de 60 años a más sigue trabajando y considerando que las estadísticas no incluyen a la informalidad ni la actividad no remunerada supone que es esta cifra todavía más grande (Kelly, 2018, p.6) 
En el Perú la Población Económicamente Activa (PEA) representan el 58,0\%, de los adultos mayores en el país siendo el porcentaje de los hombres mayor que el de las mujeres 70,2\% y 46,8\%, respectivamente. (INEI, 2017).

En el Perú los adultos mayores trabajan hasta que sus fuerzas se lo permitan, porque en el mejor de los casos sus pensiones no alcanzan para mantener un acorde nivel de vida o porque en el peor no cuentan con un sistema de pensiones. Cita textualmente Ramos: "En el Perú, una cuarta parte de la población de 60 años más, trabaja o busca trabajo, y los hombres en una proporción tres veces mayor al de las mujeres". (Ramos, 2009, p.26).

Tabla 3: Población adulta mayor por condición de actividad - Perú 2017

\begin{tabular}{|c|c|c|c|c|c|c|c|c|c|}
\hline \multirow[t]{2}{*}{ Condición de actividad } & \multicolumn{3}{|c|}{ Abr-May-Jun 2016} & \multicolumn{3}{|c|}{ Abr-May-Jun 2017 PI } & \multicolumn{3}{|c|}{$\begin{array}{c}\text { Variación } \\
\text { (Puntos porcentuales) }\end{array}$} \\
\hline & Total & Hombre & Mujer & Total & Hombre & Mujer & Total & Hombre & Mujer \\
\hline Población de 60 a más & 100,0 & 100,0 & 100,0 & 100,0 & 100,0 & 100,0 & & & \\
\hline PEA & 57,3 & 71,1 & 44,7 & 58,0 & 70,2 & 46,8 & 0,7 & $-0,9$ & 2,1 \\
\hline NO PEA & 42,7 & 28,9 & 55,3 & 42,0 & 29,8 & 53,2 & $-0,7$ & 0,9 & $-2,1$ \\
\hline
\end{tabular}

P/ Preliminar.

Fuente: Instituto Nacional de Estadistica e Informática - Encuesta Nacional de Hogares.

Fuente: Tomado de INEI 2017

Para tener una observación clara de cuáles son las actividades o los rubros en los que se ocupan las personas adultas mayores mostraremos la siguiente tabla donde se pueden observar a los adultos mayores en el Perú en el segundo trimestre del 2017 económicamente activos y de acuerdo con el rubro en el que se encuentran laborando. 
Tabla 4: Población adulta mayor económicamente activa ocupada según actividad - Perú 2017.

\begin{tabular}{|c|c|c|c|c|c|c|c|c|c|}
\hline \multirow[t]{2}{*}{ Ramas de actividad } & \multicolumn{3}{|c|}{ Abr-May-Jun 2016} & \multicolumn{3}{|c|}{ Abr-May-Jun 2017 Pl } & \multicolumn{3}{|c|}{$\begin{array}{c}\text { Variación } \\
\text { (Puntos porcentuales) }\end{array}$} \\
\hline & Total & Hombre & Mujer & Total & Hombre & Mujer & Total & Hombre & Mujer \\
\hline Total & 100,0 & 100,0 & 100,0 & 100,0 & 100,0 & 100,0 & & & \\
\hline Agricultura/Pesca/Mineria & 13,8 & 16,5 & $9,8 \mathrm{a} /$ & 15,1 & 17,5 & $11,8 \mathrm{a} /$ & 1,3 & 1,0 & 2,0 \\
\hline Manufactura & 8,8 & 9,1 & $8,2 \mathrm{a} /$ & 9,8 & $12,7 \mathrm{a} /$ & 5,7 al & 1,0 & 3,6 & $-2,5$ \\
\hline Construcción & $6,1 \mathrm{a} /$ & $10,2 \mathrm{a} /$ & 0,0 & $5,8 \mathrm{a} /$ & $9,8 \mathrm{a} /$ & $0,2 \mathrm{a} /$ & $-0,3$ & $-0,4$ & 0,2 \\
\hline Comercio & 28,0 & 20,3 & 39,6 & 27,1 & 19,7 & 37,4 & $-0,9$ & $-0,6$ & $-2,2$ \\
\hline Transporte y Comunicaciones & 7,0 al & $11,3 \mathrm{a} /$ & $0,5 \mathrm{a}$ & 5,7 & 9,7 & $0,2 \mathrm{a} /$ & $-1,3$ & $-1,6$ & $-0,3$ \\
\hline Alojamiento y Servicios de Comida & 9,7 & $5,6 \mathrm{a} /$ & 15,9 & 8,7 & $2,2 \mathrm{al}$ & 17,8 & $-1,0$ & $-3,4$ & 1,9 \\
\hline Enseñanza & 6,0 al & $6,5 \mathrm{a} /$ & $5,1 \mathrm{a} /$ & $6,2 \mathrm{a} /$ & $6,0 \mathrm{al}$ & $6,6 \mathrm{a} /$ & 0,2 & $-0,5$ & 1,5 \\
\hline Otros Servicios 1/ & 20,7 & 20,6 & $20,9 \mathrm{a} /$ & 21,6 & 22,4 & 20,5 & 0,9 & 1,8 & $-0,4$ \\
\hline
\end{tabular}

1/ Comprende Intermediación Financiera, Actividad Inmobiliaria, Empresariales y de alquiler, Actividades de Servicios Sociales y de salud. a/ Comprende a estimadores con coeficiente de variación mayor a $15 \%$ considerados como referenciales.

Fuente: Instituto Nacional de Estadistica e Informática - Encuesta Nacional de Hogares.

Fuente: Tomado de INEI 2017

\section{Productividad en el adulto mayor}

Los adultos mayores alargan la permanencia en sus empleos para mantener un ingreso monetario que a la vez les de calidad de vida en esta etapa y es necesario considerando que no se ha previsto que lleguen a tener otros ingresos económicos a esa edad. (Milán, 2010, p.94)

Los adultos mayores permanecen en la fuerza laboral y después de haberse jubilado regresan por necesidad más que por elección y esto se refleja en la relación porcentual que existe entre la participación de la fuerza laboral y los ingresos de las pensiones. Además, cita textualmente: "Se sabe que el estado de salud y la participación en la fuerza laboral dependen, en una medida no trivial, del nivel educativo de los adultos mayores" (Albalá, 2005, p. 316-317)

En el Perú el 27,2\% de los hogares, en cifras del 2017, tiene como jefe/a un adulto mayor, existiendo incluso más mujeres que hombres adultos mayores como cabezas de 
hogar, resaltando más en el área rural donde el $41,6 \%$ de los hogares conducidos por mujeres adultas mayores. (INEI, 2017)

\section{Contribución no remunerada de los adultos mayores}

Actualmente podemos hablar de una importante proporción de adultos mayores con una esperanza de vida mayor al comparado con las generaciones anteriores que además de contar con vitalidad se encuentran jubilados, pero están activos.

En especial la contribución de la mujer adulta en la familia, primero porque la incidencia de supervivencia en la calidad de vida es mayor y también por su rol de género donde se les asigna la labor doméstica haciendo su labor en esta etapa de súper importancia. Sin embargo, existe la creencia social que considera que el trabajo y la vejez son términos opuestos, imposibles de reconciliar. (Miralles, 2011. P.138-141)

Las personas mayores que dedican trabajo no remunerado en el hogar ocupan su tiempo libre post jubilación y esto se refleja en un gran beneficio económico para las familias, que se no gastan en servicios domésticos, a pesar de que son servicios invalorados y lamentablemente no destacados socialmente.

Ahora las mujeres y los hombres jubilados comparten roles en el cuidado de los nietos y apoyo de los hijos, donde las mujeres son las que mayormente asumen esta responsabilidad.

Se resalta que no siempre es satisfactorio para los adultos mayores hacerse cargo del cuidado de otras personas inclusive los nietos, y tampoco lo es para las madres hacer cargo a sus madres de sus hijos sin embargo es la estrategia que toman las mujeres jóvenes para mezclar trabajo y familia. (Agulló, 2001, P.491)

En las conclusiones de su trabajo de investigación sobre las personas adultas mayores y su contribución a la lucha contra la pobreza, Ramos resaltó que: "La presencia 
de un adulto mayor está asociada con una mayor asistencia escolar de los niños del hogar" con la importancia de resaltar que se incrementa en $3.6 \%$ si el adulto mayor es mujer y no trabaja fuera del hogar. (Ramos, 2009).

Y para reforzar la información anterior sabemos que "Un estudio en el Perú encontró que las mujeres mayores pasan un promedio de por lo menos 12 horas diarias en labores domésticas, trabajo de campo o cuidando a niños o animales.” (Kelly, 2018, p.13).

Figura 6: Contribución económica del adulto mayor al hogar

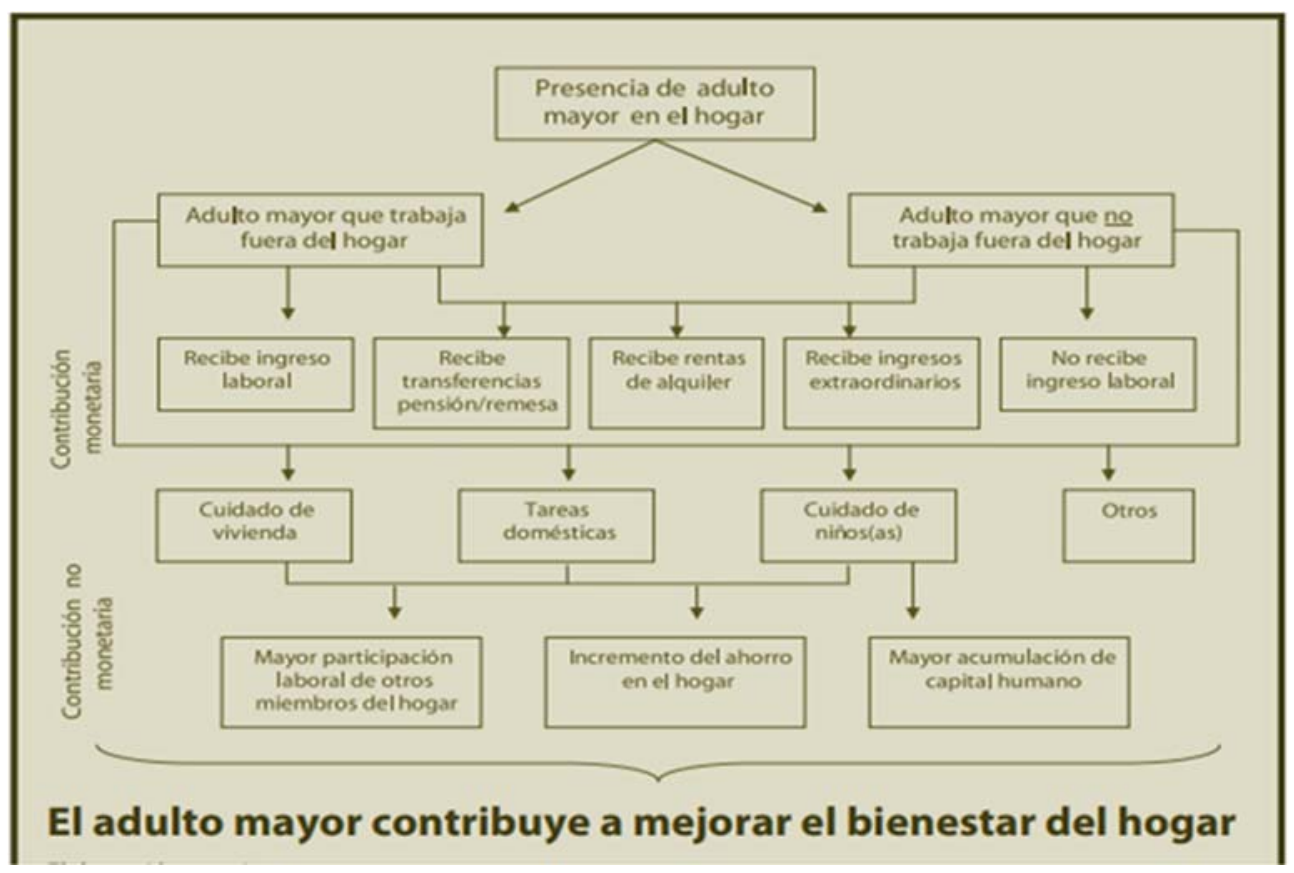

Fuente: Ramos, 2009

\section{Calidad de vida}

La OMS define la calidad de vida como "la percepción personal de un individuo de su situación de vida, dentro del contexto cultural y de valores en que vive, y en relación con sus objetivos, expectativas, valores e intereses” (Moreno, 2004).

Citar a Sarabia para expresar el siguiente concepto en el que se va a profundizar: 
"El envejecimiento es en sí mismo un proceso cuya calidad está directamente relacionada con la forma como la persona satisface sus necesidades a través de todo su ciclo vital. La satisfacción de las necesidades de la especie humana es lo que condiciona la llamada "calidad de vida" y ésta es, a su vez, el fundamento concreto de bienestar social." (Sarabia 2009, p.172)

El concepto de bienestar y/o de felicidad es relativo, como lo es de la misma forma el concepto de calidad de vida pues se condiciona aspectos físicos como sociales, espirituales, médicos, etc. Pero sobre todo porque tiene que ver con el valor que la persona haga sobre sí mismo. Por lo anterior podemos decir que la calidad de vida es subjetiva, pero tiene que ver con la objetividad que envuelve cada persona. (Rubio, 2015, p.3)

En el adulto hay tres importantes factores de mayor preponderancia en la calidad de vida: las condiciones de salud, la situación económica y el apoyo social que la persona reciba. Diversas investigaciones concluyen que no es la edad la que conduce a la desvinculación social sino otras circunstancias asociadas como la mala salud, la perdida de las amistades o la reducción de los ingresos (Spitzer, 2011, p.16)

\section{Concepto de esperanza de vida}

La esperanza de vida al nacer es el número promedio de años que se espera viviría un recién nacido, si en el transcurso de su vida estuviera expuesto a las tasas de mortalidad específicas por edad y por sexo prevalentes al momento de su nacimiento, para un año específico, en un determinado país, territorio o área geográfica. (OMS, 2005).

Aunque el aumento de la esperanza de vida representa un triunfo, el envejecimiento de la población plantea diversos retos a las familias, a las comunidades y a las sociedades en aspectos como el crecimiento económico, la seguridad económica en la vejez, la organización de los sistemas de atención a la salud y la solidez de los sistemas de apoyo familiar. La tasa de soporte a la vejez, definida como el número de adultos en edad laboral por persona mayor de la población, se encuentra ya en niveles bajos en la mayoría de los países de las regiones más desarrolladas y se espera que siga descendiendo 
en los próximos decenios, lo que garantiza la presión fiscal sobre los sistemas de apoyo a las personas mayores. En entornos donde los sistemas de seguridad social son limitados, las personas mayores están mucho más expuestas a la pobreza. (ONU, 2014).

Analizando unos estudios más específicos, encontramos que la esperanza de vida al nacer en España en el año 2013 fue de 83,1 años (80,1 en hombres y 86,0 en mujeres). Respecto al año anterior, la esperanza de vida al nacer en 2013 aumentó en 0,4 años en el conjunto de la población, 0,5 en hombres y 0,2 en mujeres. Como ocurre en buena parte de los países desarrollados, la evolución de la esperanza de vida al nacimiento en España es muy favorable. (Ministerio de sanidad servicios sociales e igualdad, 2015).

En el Perú, para el periodo 2010-2015 se ha previsto una esperanza de vida al nacer de 74,1 años, valor que, al finalizar el período de una proyección realizada hasta el año 2050, llegará a 79,1 años de vida. Igualmente, la esperanza de vida al nacer es distinta por sexo, observándose una diferencia a favor de las mujeres. (INEI, 2011).

\section{Factores que intervienen en la esperanza de vida en el Perú}

Debido al aumento de la esperanza de vida y a la disminución de la tasa de fecundidad, la proporción de personas mayores de 60 años está aumentando más rápidamente que cualquier otro grupo de edad en casi todos los países. El envejecimiento de la población puede considerarse un éxito de las políticas de salud pública y el desarrollo socioeconómico, pero también constituye un reto para la sociedad, que debe adaptarse a ello para mejorar al máximo la salud y la capacidad funcional de las personas mayores, así como su participación social y su seguridad. (OMS, 2017).

Entre los factores más resaltantes son:

- Natalidad; que mide el número de nacidos vivos, cuya proyección según el INEI es de $-23.3 \%$, es decir disminuye. 
- Fecundidad; que mide el número de hijos que en promedio tiene una mujer, que ha bajado en el Perú de 3.0 en el 2000 a 2.3 en el 2015. (INEI,2015)

- Mortalidad; que expresa el número de muertes por cada mil habitantes, en el 2016 según el INEI es de 2,3 por cada mil habitantes en el 2015 y era de 3,0 en el 2000.

A continuación, mostramos la Tabla $\mathrm{N}^{\circ} 5$ que muestra la evolución de los indicadores demográficos en el Perú anteriormente mencionados.

Tabla 5: Evolución de indicadores demográficos, Perú (1950-2100)

\begin{tabular}{lccccccc}
\hline & 1950 & 1975 & 2000 & 2025 & 2050 & 2075 & 2100 \\
\hline Tasa Global de Fecundidad & 6,85 & 5,38 & 2,8 & 2,05 & 1,75 & 1,79 & 1,89 \\
Tasa bruta de mortalidad & 21,58 & 10,86 & 5,56 & 6,22 & 8,84 & 11,99 & 13,45 \\
Esperanza de Vida al Nacer & 43,9 & 58,53 & 71,61 & 76,33 & 79,68 & 82,44 & 84,27 \\
Relación Ancianos/Jóvenes & 8,31 & 8,23 & 14,17 & 35,89 & 95,8 & 172,74 & 203,38 \\
Relación de Apoyo a Los Pad & 3,77 & 4,65 & 8,91 & 13,24 & 25,1 & 48,96 & 69,03 \\
\% personas 65+ & 3,46 & 3,56 & 4,83 & 8,76 & 17,1 & 25,7 & 29,89 \\
\% personas 80+ & 0,33 & 0,34 & 0,78 & 1,87 & 4,67 & 9,23 & 12,45 \\
\hline
\end{tabular}

Fuente: Tomado de Olivera, 2014

\section{Políticas del Estado Peruano y el adulto mayor}

\section{La ley de las personas adultas mayores (ley 30490)}

Su objetivo principal: “Establecer un marco normativo que garantice el ejercicio de los derechos de la persona adulta mayor, a fin de mejorar su calidad de vida y propiciar su plena integración al desarrollo social, económico, político y cultural de la Nación." Y se promulga para proteger y dar un marco legal a los derechos establecidos en la constitución de la república, en los tratados internacionales de las personas adultas mayores, buscando de esta manera mejorar su calidad de vida y que se desarrollen sociales 
económicamente, de forma política y cultural que les permita contribuir al respeto de su dignidad. (Congreso de la República, 2016)

\section{La dirección de las personas adultas mayores- DIPAM}

Se encarga de diseñar, monitorear, coordinar y supervisar proyectos dirigidos a las personas adultas mayores en especial de quienes sufren discriminación y/o exclusión social, es decir poblaciones en pobreza y pobreza extrema, está a cargo del Ministerio de la mujer y poblaciones vulnerables (MIMP), cuyo fin principal es el de desarrollan el Plan Nacional de Personas Adultas Mayores (PLANPAM) (MIMP, 2018).

\section{Plan nacional para las personas adultas mayores (PLANPAM)}

Es un plan a cargo del Ministerio de la mujer y poblaciones vulnerables, mediante la Dirección de personas adultas mayores de la dirección general de la familia y la comunidad, que busca definir los objetivos estratégicos, resultados e intervenciones del MIMP y que son llevados a cabo por las entidades del gobierno (MIMP, 2017).

Cabe mencionar que el último plan nacional para adultos mayores se desarrolló entre el 2013 y el 2017, y en la actualidad no se ha actualizado plan alguno. 
Tabla 6: Objetivos Estratégicos del PLANPAM

Objetivos Estratégicos del PLANPAM

\begin{tabular}{|c|c|}
\hline $\begin{array}{l}\text { Lineamientos de } \\
\text { Politica Nacional } 1\end{array}$ & Envejecimiento Saludable \\
\hline Objetivo Estratégico & $\begin{array}{l}\text { Acción Estratégica1 } \\
\text { Contar con información actualizada de investigaciones y análisis } \\
\text { estadisticos y cualitativos sobre aspectos demográficos relacionados } \\
\text { con el envejecimiento poblacional en el Perú. }\end{array}$ \\
\hline $\begin{array}{l}\text { Mejorar el bienestar } \\
\text { físico, psíquico y }\end{array}$ & $\begin{array}{l}\text { Acción Estratégica } 2 \\
\text { Incorporar el envejecimiento saludable en la agenda de salud pública. }\end{array}$ \\
\hline $\begin{array}{l}\text { social de las personas } \\
\text { adultas mayores, a } \\
\text { través del incremento }\end{array}$ & $\begin{array}{l}\text { Acción Estratégica } 3 \\
\text { Diseñar e implementar intervenciones preventivo - promocionales sobre } \\
\text { envejecimiento saludable. }\end{array}$ \\
\hline $\begin{array}{l}\text { calidad de los servicios } \\
\text { socio-sanitarios, la } \\
\text { garantía de una }\end{array}$ & $\begin{array}{l}\text { Acción Estratégica } 4 \\
\text { Fortalecer las capacidades de las/los cuidadora/es de personas adultas } \\
\text { mayores. }\end{array}$ \\
\hline $\begin{array}{c}\text { asistencia alimentaria y } \\
\text { nutricional, y la } \\
\text { generación de } \\
\text { oportunidades para } \\
\text { una vida armónica }\end{array}$ & $\begin{array}{l}\text { Acción Estratégica } 5 \\
\text { Contar con información actualizada sobre investigaciones, estadisticas y } \\
\text { datos cualitativos de la situación de salud integral (física y mental) de } \\
\text { las PAM. }\end{array}$ \\
\hline
\end{tabular}

Fuente: Ministerio de la mujer y poblaciones vulnerables

\section{Pensión 65}

Programa social dirigido a las personas adultas mayores que cumplen ciertos requisitos como no contar con una pensión de jubilación y ser de extrema pobreza, rige desde octubre del 2011 busca darle un nivel mínimo de ingresos y evitar la pobreza extrema en los adultos mayores. (MINP, 2018)

Según el INEI:

"El 23,7\% de la población de 65 y más años de edad se beneficia del programa social Pensión 65. Comparado con similar trimestre del 2016, la proporción de la población beneficiaria se mantiene en los mismos niveles. Según área de residencia, el $60,3 \%$ de los/as adultos/as mayores del área rural acceden a este programa social, mientras en el área urbana el 17,3\% y en Lima Metropolitana el 1,6\%.” (INEI, 2017) 
Figura 7: Población beneficiaria del programa pensión 65, según área de residencia

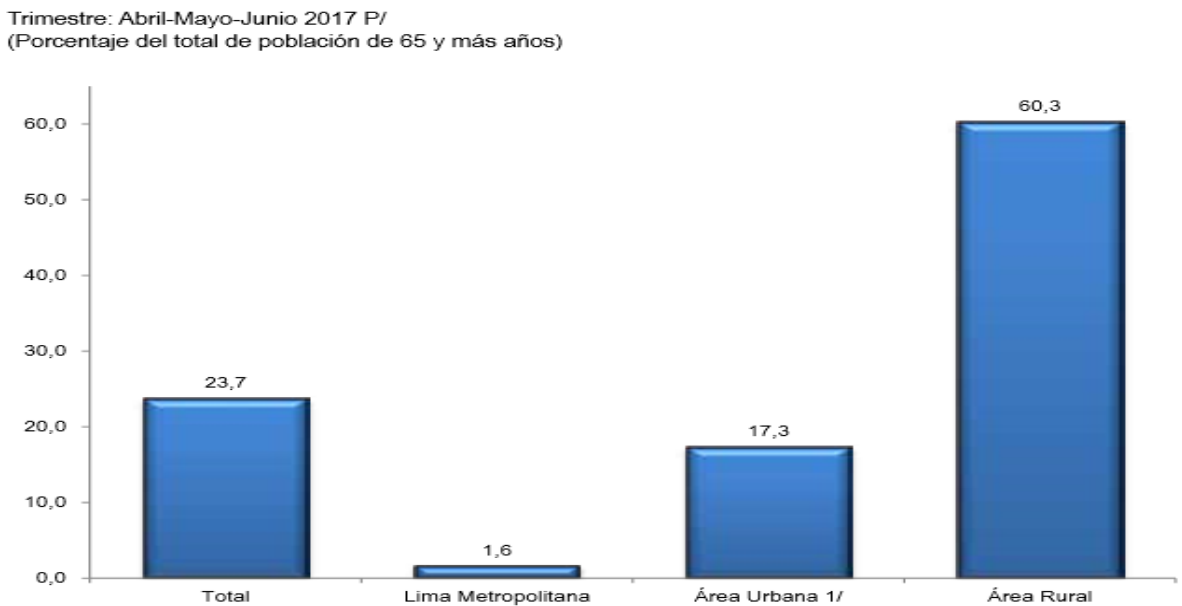

Fuente: Tomado del INEI, 2017

\section{Sistema de pensiones en el Perú}

Según el diccionario de la Real Academia, «jubilar» significa «dispensar o eximir de su trabajo a un empleado por enfermedad o ancianidad; se le suele atribuir una remuneración llamada "haber pasivo" o “jubilación”». (Real Academia de la Lengua, 2018)

Actualmente en la sociedad la jubilación es conceptualizada como el inicio que conduce a la vejez e incluso asemeja y se confunde con la misma. (Agulló, 2001, p.57)

En la región existen los sistemas contributivos de seguridad social que protegen y prestan pensiones de retiro mediante programas de vejez, invalidez y muerte. También encontramos los no contributivos que brindan prestaciones monetarias y no monetarias durante la vejez a través de programas de asistencia social mediante mecanismos de reparto. (Bernal, 2008, p.12)

La mayoría de los sistemas de seguridad social de la región funcionan mediante mecanismos de reparto, cuyo financiamiento proviene de las contribuciones que realizan los empleados y en dependencia del país de los empleadores y el gobierno. Los beneficios 
(prestaciones) o pensiones otorgadas se definen de acuerdo con la remuneración a la edad del retiro y el período de tiempo durante el cual el empleado contribuyó financieramente.

En Canadá y en Argentina la seguridad social tiene un alcance universal con programas que aseguran una pensión mínima a toda la población como una prestación básica. (Suarez, 2005, p.421)

De acuerdo con la tendencia de crecimiento de la población adulta mayor se espera que sea difícil sostener el proceso y notable resaltarlo en el caso específico del Perú donde la tercera parte de la PEA trabaja de informal por lo mismo el no acceso a la seguridad social es alto. Quienes no tienen acceso a la formalidad optan por los acuerdos familiares donde los más jóvenes se hacen cargo de los adultos mayores sin embargo esto sería insostenible si las tendencias demográficas se mantienen. (Olivera, 2014, p.79).

En el Perú:

"El sistema pensionario en Perú está compuesto por dos subsistemas principales: el del Decreto Ley No. 19990, denominado Sistema Nacional de Pensiones (SNP), que es administrado por el Estado y opera teóricamente bajo un régimen financiero de reparto; y el Sistema Privado de Pensiones (SPP), administrado por entidades privadas denominadas Administradoras Privadas de Fondos de Pensiones (AFP), que se caracteriza por tener un régimen financiero de cuentas individuales donde cada trabajador ahorra para obtener una pensión. (Bernal, 2008, p.27)

Para tener una idea más clara en el Perú según el INEI:

"De la población adulta mayor, el 37,6\% está afiliado a un sistema de pensión. En el trimestre abril-mayo-junio 2017, el $20,2 \%$ está afiliado a la Oficina de Normalización Previsional (ONP), seguido por el 9,2\% de afiliados a las Administradoras de Fondos de Pensiones (AFP) y el 4,7\% a la Cédula viva." (INEI, 2017, p.13).

Se resalta que en el Perú el sistema es de orden contributivo para los trabajos formales y el cual resulta opcional para los trabajadores ya que se puede optar por el público o por el régimen privado con la diferencia que el público financia las actuales pensiones y el privado se acumula en una cuenta personal que será retribuida en una futura pensión. (Bernal, 2008, p.28) 


\section{Acceso al sistema de salud para los adultos mayores}

Los adultos mayores realizan aportes a la sociedad, a sus familias, comunidad de muchas formas, pero siempre dependiente de conservar buena salud. Enfocarnos en que los adultos mayores no pierdan su capacidad física y mental hará que las consecuencias del crecimiento de la población del adulto mayor sean mucho menos negativas (ONU, 2015.p3)

Rivera citado por Moreno (2004) indica: "No hay duda de que la variable salud es la de mayor peso en la percepción de bienestar de los ancianos y, que los déficits de salud constituyen el primer problema para ellos” (Moreno, 2004, p.192)

En el Perú los adultos mayores se ubican en tres grupos los que cuentan con ESSALUD y SIS, los que se atienden en prestadores privados y los que no están afiliados y que desconocen o no ejercen sus derechos. Un problema resaltante es el incremento de las tasas de los seguros privados al incrementar la edad que hace que haya una menor ocurrencia de participación de los adultos mayores en este grupo.

Por esta razón, en términos de atenciones de salud, los principales proveedores institucionales de atenciones para los adultos mayores son la red de establecimientos de EsSalud y la red pública del Ministerio de Salud. (García, 2012, p.17)

EsSalud por su lado cuenta con algunos servicios específicos para adultos mayores como los Centros del adulto mayor y el Programa de atención domiciliaria (PADOMI):

"PADOMI es un servicio brindado por EsSalud y orientado a los pacientes afiliados a este seguro que se vean imposibilitados de trasladarse a los centros de salud debido a encontrarse en situación de dependencia funcional temporal o permanente entre los cuales comprende a los AM con más de 80 años. El servicio comprende la realización de visitas médicas al domicilio del paciente, así como también la atención de emergencias domiciliarias que impliquen procedimientos de complejidad menor. Del mismo modo el servicio comprende la asignación de un médico de cabecera y la realización de visitas de otros profesionales de la salud tales como enfermeras, fisioterapeutas, y psicólogos." (Olivera, 2014 p.94).

Del total de la población adulta mayor de 60 y más años de edad, el 79,2\% tiene

algún seguro de salud, sea público o privado. Destaca la cobertura de afiliación a algún 
seguro de salud de los residentes en el área rural con el 82,8\%, ubicándose luego Lima Metropolitana con el 79,1\%, seguida por el área urbana con 76,9\%.

Y según el tipo de seguro de salud: "el 41,6\% de los/as adultos/as mayores acceden solo al Seguro Integral de Salud (SIS) y el 30,9\%, a EsSalud. Comparando con similar trimestre del año anterior, la proporción de asegurados con el SIS se incrementó en 2,9 puntos porcentuales y, en cambio, la de EsSalud disminuyó en 2,9 puntos porcentuales." (INEI, 2017).

Figura 8: Flujo de fondos del sistema de salud peruano.

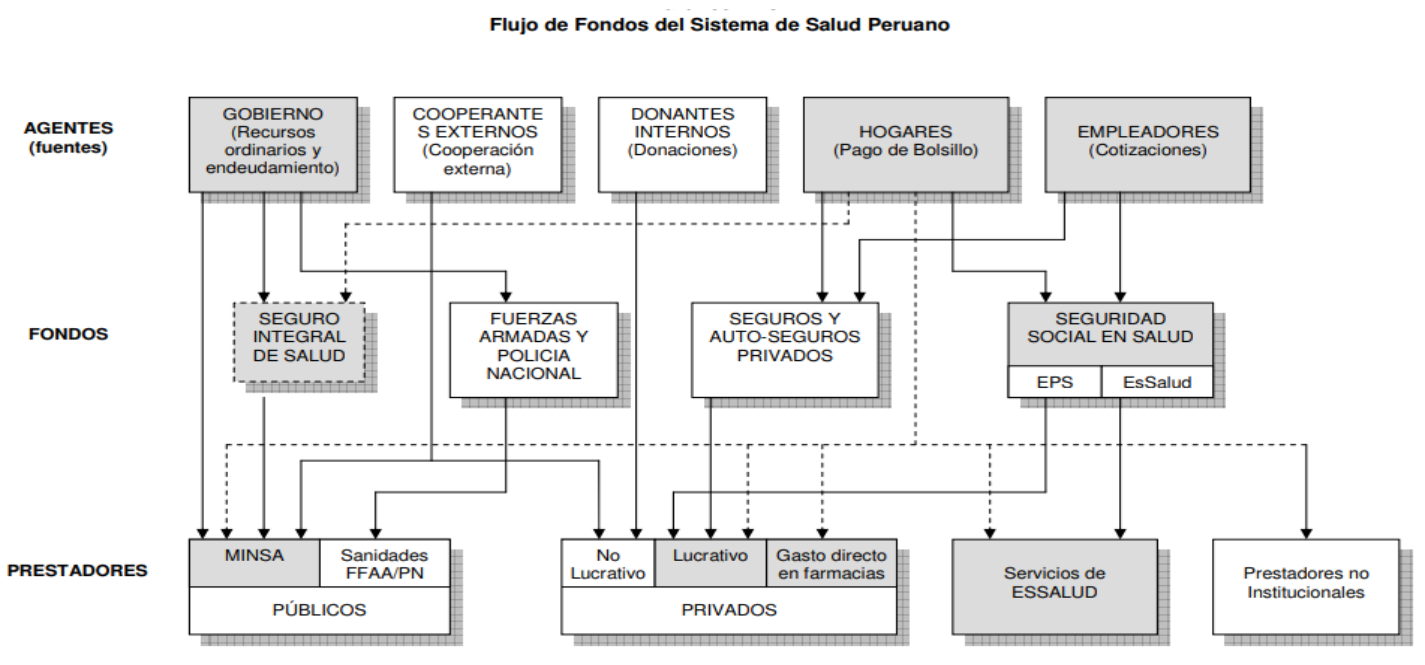

Fuente: Tomado de García, 2012

Se resaltará en este punto la importancia del acceso a la salud de los adultos mayores en el Perú como un factor determinante para un envejecimiento productivo.

Se cita a Moreno:

"En la vejez, hay desgaste, declinación en la energía física, aumenta la susceptibilidad a las enfermedades e incapacidades, pero no es una enfermedad. Es un proceso multifacético de maduración y declinación, un proceso gradual, natural, universal e inexorable. No es más que el estado final del ciclo vital normal" (Moreno, 2004, p.188). 


\section{Cultura del envejecimiento productivo}

La cultura del envejecimiento productivo tiene como objeto ampliar la esperanza de vida saludable para que los adultos mayores logren seguir contribuyendo de forma activa.

La convención interamericana sobre la protección de los derechos humanos de las personas adultas mayores define envejecimiento activo y saludable como: "El proceso por el cual se optimizan las oportunidades de bienestar físico, mental y social, de participar en actividades sociales, económicas, culturales, espirituales y cívicas, y de contar con protección, seguridad y atención” (MINSA, 2012).

Se define al envejecimiento activo como: "el proceso de optimización de las oportunidades de salud, participación y seguridad con el fin de mejorar la calidad de vida de las personas a medida que envejecen”. (OMS, 2018)

Un concepto que resulta importante para nuestra investigación referir:

"Cuando las sociedades consideran a los viejos como una carga que todos deben llevar a cuesta, los ancianos, respondiendo a esta expectativa social, se transforman en sujetos de necesidades y demandantes de servicios. Se formulan políticas sociales "para y por" los mayores. Contrariamente, considerar a los mayores como un "recurso" da lugar al intercambio y la participación como sujetos activos, el desarrollo de las potencialidades, y no se omiten deberes y derechos con toda la sociedad. Los mayores son parte de la sociedad" (Zolotow, 2002).

Úrsula Lehr, citada por Moreno (2004) considera como prioridad preventiva a la actividad, no sólo física sino mental como en pro de conseguir una vejez exitosa. Considera que los adultos mayores mentalmente activos, más sociables consiguen llegar a la vejez con bienestar psicofísico y por lo mismo con calidad de vida. Resalta además a la actividad grupal como soporte emocional con lo que se comparte estilos de vida en similitud de condiciones donde el entablar nuevas redes sociales, nuevas amistades que compensa la etapa de la vejez llena por lo general de pérdidas. (Moreno, 2004, p.194) 


\section{Plan de acción internacional}

Para mejorar la calidad de vida de los adultos mayores la Organización Panamericana de la Salud (OPS) ha establecido estrategias para que los países puedan diseñar sus planes de acción y se basan en principios de las Naciones Unidas las cuáles son: la independencia, la participación, el cuidado, la autorrealización y la dignidad. (OPS, 2018)

Resalta también la OPS las cuatro áreas críticas que son:

- Colocar a la salud y las personas mayores en las políticas públicas

- Lograr la idoneidad de los sistemas de salud para afrontar los retos asociados al envejecimiento de la población

- La capacitación de recursos humanos, principalmente del personal de salud, los propios adultos mayores, y personas encargadas de su cuidado.

- Generar la información necesaria para lograr intervenciones con base a experiencias exitosas. (OPS, 2018).

\section{Personas mayores y su desarrollo}

El fomentar una sociedad más equitativa refuerza el desarrollo y apoya a las contribuciones, debemos identificar que los adultos mayores contribuyen de diferentes formas y excluirlos en el proceso mengua el crecimiento de la sociedad en su conjunto.

Para tener un ejemplo el hecho de que un adulto mayor necesite asistencia en domicilio lleva muchas veces a que una mujer inclusive una niña o un miembro de su familia se ocupe de su asistencia y no pueda o deje de trabajar o estudiar. Es evidente darse cuenta de que el descuidar a los adultos mayores tiene consecuencias que van más allá de ellos como individuos. (ONU, 2015.p17). 


\section{Rol de la familia en el envejecimiento productivo y creación de un entorno propicio}

La proporción de personas adultas mayores aumenta siempre con el pasar de los años, actualmente en los países europeos más del $40 \%$ de las mujeres mayores de 65 viven solas. En Japón como una sociedad tradicional se acostumbra que los padres de edad avanzada vivan con sus hijos; sin embargo, estas tradiciones son cada vez menos y esta reducción hace que se limite las oportunidades de disfrutar de atención recíproca o compartir los bienes, muchas veces esto hace que aumente el riesgo de pobreza.

Sin embargo, muchos adultos mayores prefieren vivir en su propio hogar aún si están solas lo que los expone a mayores riesgos de aislamiento y suicidio. (ONU, 2015.p13).

En el contexto médico, la calidad de vida alcanza mayor importancia, pero es en la vejez donde tiene mayor magnitud, y se hace sobre todo necesaria la intervención del apoyo social y familiar para que los adultos mayores puedan seguir desarrollándose en su máximo potencial que se debe expresar en el apoyo material y afectivo de los familiares de distintos grados.

Al respecto Ramos nos indica que:

"El peso de su alimentación, de su cuidado cada vez más clamoroso cuando no puedan valerse por sí mismos para resolver sus necesidades más elementales, los gastos de salud que se incrementan cuando se acumulan enfermedades crónicas y degenerativas, recaen totalmente sobre los hombros de las familias pobres, contribuyendo aún más a hundirlos en las personas adultas mayores y su contribución a la lucha contra la pobreza" (Ramos, 2014, p.57). 
Figura 9: El adulto mayor y su aporte económico a la sociedad peruana

\section{Adulto mayor}

Según la OMS, las personas mayores de 60 años se les llama de forma indistinta, adulto mayor.

Proyección de población mayor de 60 años

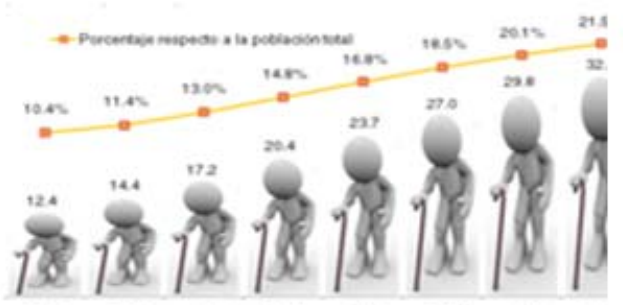

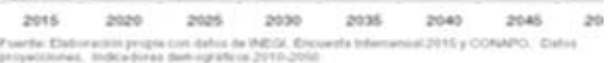

Esperanza de vida (año)

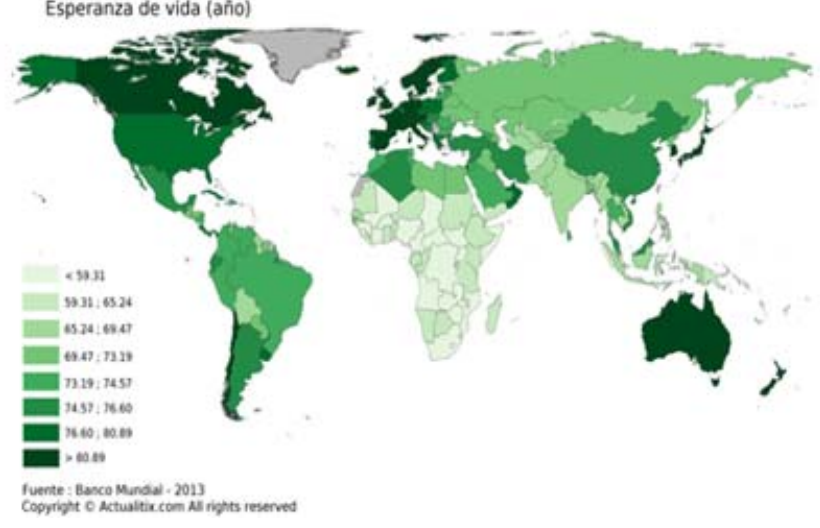

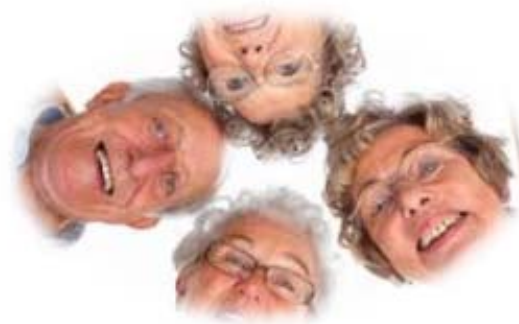

Sistema de pensiones

De la población adulta mayor, solo el $34.5 \%$ cuenta con un sistema de pensiones.

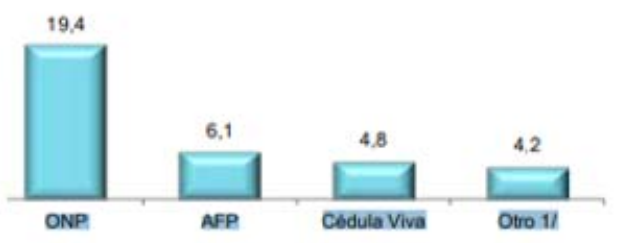

\section{Pensión 65}

Solo el $\mathbf{2 7} \%$ de la población adulta mayor, se beneficia de este programa.

\section{pensión65 MIDIS聶}

Actividad económica

Los adultos mayores que están incluidos en la Población económicamente activa (PEA) representan el $58,3 \%$, siendo mayor el porcentaje de hombres que de mujeres, $71,7 \%$ y $46.5 \%$. Los adultos mayores que no forman parte de la Población Económicamente activa (NO PEA), representan el $41,7 \%$.

Envejecimiento activo

Proceso de optimización de las oportunidades de salud, participación y seguridad con el fin de mejorar la calidad de vida a medida que envejecemos.

ENVEJECIMIENTO ACTIVO iftitition

\section{Contribución no remunerada}

Actualmente, los paises desarrollados ya están resaltando el aporte que ofrecen los adultos mayores y sobre todo el aporte no monetario, pues en muchos lugares los adultos ofrecen sus servicios para compartir experiencias, orientar a los jóvenes y en otros casos ayudan a los hijos con el cuidado de los nietos, lo cual genera una disminución de los gastos familiares.

\section{Fuente: Elaboración Propia}




\section{CAPÍTULO III METODOLOGÍA DE LA INVESTIGACIÓN}

En el presente capítulo, se explicará la metodología de investigación aplicada; así como también las herramientas utilizadas para la recolección de información necesaria del grupo poblacional en estudio.

\section{Planteamiento de la investigación:}

\section{Propósito de la investigación.}

La siguiente investigación tiene como propósito describir y analizar la situación actual del adulto mayor en el Perú durante el periodo marzo - abril del 2018, e identificar lo que este grupo poblacional representa para el Estado Peruano, mediante una investigación de enfoque cualitativo.

\section{Tipo de investigación.}

El tipo de investigación que se realizará es etnográfica y descriptiva, pues se explora la situación del adulto mayor en el Perú y se buscará interpretar desde el punto de vista de los participantes, los adultos mayores activos, desde el punto de vista de los expertos y sobre todo de los casos de los adultos mayores vulnerables como grupo social que serán observados; así mismo, se podría decir que es de aspecto cualitativo, debido a 
que esta investigación se realizará con pequeñas muestras para comprender la realidad y características relevantes de una población, que como ya se mencionó se clasificará en 3 subgrupos.

\section{Preguntas de la investigación.}

En esta investigación intentaremos responder las siguientes interrogantes:

- ¿Cuál es la situación del adulto mayor en el Perú?

- ¿Cuáles son las consecuencias económicas y sociales de la vulnerabilidad en los adultos mayores?

- ¿Cuáles de las políticas de estado peruano dirigidas a los adultos mayores, y cuál es el conocimiento que tienen de las mismas las poblaciones vulnerables?

- ¿Cuáles son los factores relevantes para el envejecimiento activo en los adultos mayores?

\section{Contexto}

\section{Descripción del contexto interno y externo}

Para la investigación y recopilación de información se han considerado 03 grupos de estudio quienes están involucrados directa e indirectamente con el tema; siendo 02 de ellos los que están relacionados de forma directa, perteneciendo al grupo de estudio adulto mayor que viva en la ciudad de lima:

- El primer grupo estará conformado por un grupo de especialistas en el tema de envejecimiento y lo que se hace en favor de este grupo etario.

- El segundo grupo estará conformado por personas adultas mayores que a pesar de haber pasado los 60 años, continúan aportando económicamente a la sociedad peruana. 
- El tercer grupo estará conformado por personas adultas mayores que en la actualidad no aportan de forma económica al estado peruano y adicionalmente representan una carga para el estado y/o su familia.

Con primer grupo, los especialistas se entablarán entrevistas grabadas con preguntas abiertas que lleven a profundizar temas de opiniones, políticas públicas y/o iniciativas privadas de las instituciones a los que los entrevistados pertenezcan.

Con el segundo grupo, la obtención de datos se realizará mediante entrevistas grabadas a profundidad, con preguntas abiertas donde se hablará de la persona en sí, sus opiniones y sus diferentes aspectos.

Con el tercer grupo, el caso de los dependientes se realizará una observación y pequeñas preguntas del estado o calidad de vida que presentan, la cual será registrada en la bitácora y audios, que servirán para complementar o ampliar la perspectiva de los investigadores.

\section{Muestra}

\section{Descripción de la muestra}

Para la presente investigación se han considerado 28 entrevistas que fueron clasificados de la siguiente manera:

Tabla 7: Segmentos de la muestra

\begin{tabular}{|l|c|}
\hline \multicolumn{1}{|c|}{ Segmentos para la entrevista } & No de entrevistas $^{\circ}$ \\
\hline Especialistas de Sector & 5 \\
\hline Adultos mayores aportantes & 8 \\
\hline Casos Etnográficos/adultos mayores vulnerables & 15 \\
\hline Total & $\mathbf{2 8}$ \\
\hline
\end{tabular}

Fuente: Elaboración Propia 
Siendo una investigación cualitativa de tipo etnográfica, responde a la necesidad de obtener diversas perspectivas del entorno de un adulto mayor y como se ve frente a la sociedad y el estado.

La población de esta investigación está conformada por el grupo etario adulto mayor, basándonos en la definición adoptada por la OMS (persona mayor de 60 años de edad).

Nuestra muestra estará dividida en 03 segmentos o categorías:

- Especialista, persona que sea reconocido como experto en los temas que correspondan al adulto mayor y su calidad de vida. (5 entrevistas).

- Adulto mayor aportante, persona que sea mayor de 60 años y actualmente se encuentre trabajando, tenga un negocio propio o sea un profesional destacado. ( 8 entrevistas).

- Adultos mayores vulnerables, no aportantes, casos etnográficos, persona que sea mayor de 60 años y actualmente no se encuentren trabajando, adicionalmente represente una carga para sus familiares. (15 casos).

\section{Diseño o abordaje principal (recolección de datos)}

\section{Identificación de la estructura de la entrevista}

La búsqueda o recolección de información se obtendrá mediante entrevistas a profundidad no estructurada, las cuales se realizarán a las 03 categorías descritas en el punto 3.3.1; así mismo, toda la información será documentada o registrada en nuestra bitácora, así como también uno de los investigadores siempre estará atento ante posibles rasgos que no se puedan captar mediante el audio sino la observación, para de esa forma recrear el verdadero escenario donde se realizó.

Las entrevistas se realizarán entre los meses de marzo y abril del 2018 


\section{Guía de preguntas de la entrevista}

Buenos días (tardes, noches) (nombre del entrevistado), nosotros somos Sarita Katiuska Macedo Salazar y el joven Alan Mata Aquiño. Somos egresados en Administración de Empresas de la UPC, nos encontramos en la elaboración de nuestra tesis de grado para poder titularnos como licenciados en administración, en la etapa de investigación, nos interesa explorar sobre la situación del adulto mayor en el Perú, como población vulnerable y destacando las tendencias del envejecimiento productivo para contrarrestar las consecuencias sociales y económicas que representa para los países el crecimiento de la población de adultos mayores. De esta manera, con su importante apoyo, experiencias y puntos de vista, intentaremos profundizar al respecto, por lo que de antemano estamos muy agradecidos.

Le resaltamos enfáticamente que todo lo que nos diga, será anónimo, estrictamente confidencial y absolutamente profesional si así lo desea. Iremos tomando nota mientras conversamos y si no le incomoda, preferiríamos grabar la entrevista, pues además debemos de entrevistar a otras personas y no es posible recordarlo todo. De esta forma, podremos conversar con mayor comodidad y evitar confundir o mezclar algún tipo de información que nos brinden los diferentes entrevistados.

Asimismo, deseamos contarle que luego de analizar las entrevistas, se tratará la información estadísticamente. Si alguna frase se torna particularmente descriptiva, será transcrita, pero siempre de forma anónima aludiendo a un número de entrevistas si así lo prefiere. Por último, nos comprometemos a entregar los resultados de esta investigación a quienes hayan colaborado con su tiempo si así lo desean.

Es para nosotros importante destacar que no tenemos vínculo alguno con ninguna organización. La relación con la investigación es absolutamente responsabilidad nuestra, es decir, no medían recursos de ninguna institución o empresa. La idea es conocer su 
opinión y puntos de vista. Por lo tanto, no hay respuestas correctas o incorrectas. Usted puede elegir no contestar alguna pregunta si así lo desea. De igual forma, considérese libre de conversar sobre aquellos temas, situaciones, actitudes, conductas de su trabajo o de su vida personal que le parezcan importantes y relevantes.

\section{Segmentos}

Debido a que necesitamos varias expectativas o puntos de vista para plantear y respaldar nuestra teoría, se han determinado los siguientes segmentos:

- Especialista (5 expertos reconocidos en temas de adulto mayor)

- Adultos mayores aportante (8 entrevistas validadas)

- Adulto mayor no aportante (15 entrevistas validadas)

Cada segmento contará con su propia bitácora de entrevista, lo cual ayudará a esquematizar el procesamiento de la información.

Tabla 8: Principales características de los adultos mayores independientes, aportantes, y de los adultos mayores, como población vulnerable.

\begin{tabular}{|c|c|c|}
\hline & Entrevistas a Profundidad & Casos Etnográficos \\
\hline Situación Laboral & Profesional/Independiente/Negocio Propio & No Trabaja \\
\hline Aporte Económico & Aporta & No aporta \\
\hline Sistema de Salud & Seguro Privado/EPS & Essalud/SIS \\
\hline Protección Social & Contributivo & No contributivo \\
\hline
\end{tabular}

Fuente: Elaboración propia

\section{Categorías}

Las categorías por explorar no serán relevantes en la misma magnitud para cada segmento, pues los enfoques serán distintos o complementarios; por lo tanto, estudiaremos las siguientes categorías: 
- Situación económica del adulto mayor

- Consecuencias económicas y sociales del envejecimiento

- Políticas del Estado Peruano

- Envejecimiento productivo

\section{El instrumento de investigación: Diseño y descripción del instrumento (Entrevista)}

El instrumento que se utilizará en esta investigación será la entrevista a profundidad, ya que nos permitirá explorar diferentes realidades y perspectivas de cada uno de los entrevistados en cada segmento definido previamente; a esta entrevista, le acompañara la observación, pues se registrarán los cambios o respuestas corporales ante las diversas preguntas que realicemos, los cuales serán registrados en nuestra bitácora. 


\section{Bitácoras}

\section{Bitácora - especialistas}

\begin{tabular}{|c|c|c|}
\hline Categoría & Sub categoría & $\begin{array}{l}\text { Segmento 1: } \\
\text { Especialista en el Sector }\end{array}$ \\
\hline \multirow{4}{*}{$\begin{array}{l}\text { Situación del } \\
\text { adulto mayor }\end{array}$} & Envejecimiento y vejez & ¿Qué se sabe de la población adulta mayor en el mundo? \\
\hline & \multirow{2}{*}{$\begin{array}{l}\text { Envejecimiento poblacional } \\
\text { en el Perú }\end{array}$} & $\begin{array}{l}\text { ¿Cuál considera usted que es el principal problema que enfrenta } \\
\text { el adulto mayor en el Perú? }\end{array}$ \\
\hline & & ¿Por qué se le podría considerar población vulnerable? \\
\hline & Adulto mayor & $\begin{array}{l}\text { ¿Cuál es el aporte que realiza su organización a la situación del } \\
\text { adulto mayor? }\end{array}$ \\
\hline \multirow{6}{*}{$\begin{array}{l}\text { Consecuencias } \\
\text { económicas y } \\
\text { sociales del } \\
\text { envejecimiento }\end{array}$} & \multirow[b]{2}{*}{ Nivel educativo } & $\begin{array}{l}\text { ¿Qué tendencia se está siguiendo en el Mundo sobre la } \\
\text { educación en los adultos mayores? }\end{array}$ \\
\hline & & $\begin{array}{l}\text { OEA: " La persona mayor tiene derecho a la educación en } \\
\text { igualdad de condiciones con otros sectores de la población y } \\
\text { sin discriminación" ¿Conoce si en el país existe políticas al } \\
\text { respecto? }\end{array}$ \\
\hline & Actividad y trabajo & $\begin{array}{l}\text { Le menciono que hay autores que consideran a la fragilidad e } \\
\text { inactividad de los adultos mayores como un gran mito. ¿Qué } \\
\text { opina al respecto? }\end{array}$ \\
\hline & Contribución no remunerada & $\begin{array}{l}\text { Los adultos mayores realizan diferentes actividades no } \\
\text { remuneradas, ¿qué se sabe al respecto? ¿Sería posible que nos } \\
\text { brinde algunos ejemplos o cifras? }\end{array}$ \\
\hline & Calidad de vida & $\begin{array}{l}\text { Se sabe que los adultos mayores son un grupo que se encuentra } \\
\text { lejos de ser un grupo homogéneo dado que es diferente ser } \\
\text { mayor de } 60 \text { y ser mujer o hombre, con pensión o sin pensión, } \\
\text { pobre, o de extrema pobreza. Se trabaja calidad de vida en base } \\
\text { a estas diferencias. Conoce de políticas públicas basadas en } \\
\text { calidad de vida }\end{array}$ \\
\hline & Esperanza de vida & $\begin{array}{l}\text { Siendo el envejecimiento poblacional un éxito en las mejoras } \\
\text { sanitarias. ¿Qué retos visualiza usted va enfrentar el Estado } \\
\text { Peruano en los próximos años? }\end{array}$ \\
\hline \multirow{6}{*}{$\begin{array}{l}\text { Políticas del } \\
\text { Estado } \\
\text { Peruano }\end{array}$} & Ley 30490 & $\begin{array}{l}\text { La Ley } 30490 \text {, la ley de los adultos mayores se promulgó con } \\
\text { el objetivo principal de propiciar la integración del adulto } \\
\text { mayor al desarrollo social, económico, político y cultural de la } \\
\text { nación. }\end{array}$ \\
\hline & $\begin{array}{l}\text { Plan nacional para las } \\
\text { personas adultas mayores }\end{array}$ & $\begin{array}{l}\text { ¿Cuáles son los programas dirigidos al adulto mayor que se } \\
\text { proponen a través de la organización a la que usted representa? }\end{array}$ \\
\hline & DIPAM & $\begin{array}{l}\text { Tiene conocimientos de planes dirigidos a personas adultas } \\
\text { mayores en situación de pobreza o pobreza extrema }\end{array}$ \\
\hline & Pensión 65 & $\begin{array}{l}\text { ¿Considera al programa social pensión } 65 \text { como un éxito de } \\
\text { políticas públicas? }\end{array}$ \\
\hline & $\begin{array}{c}\text { Sistema de pensiones en el } \\
\text { Perú }\end{array}$ & $\begin{array}{l}\text { Según INEI, solo el } 37.6 \% \text { de adultos mayores en el Perú, está } \\
\text { afiliado a un sistema de pensiones. ¿Qué se está haciendo al } \\
\text { respecto? }\end{array}$ \\
\hline & Acceso al sistema de salud & $\begin{array}{l}\text { ¿Considera usted que el sistema de salud y de acceso a estos, } \\
\text { por parte del adulto mayor es el óptimo? Se atrevería a dar } \\
\text { sugerencias de cambio bajo su experiencia. }\end{array}$ \\
\hline \multirow{3}{*}{$\begin{array}{l}\text { Envejecimiento } \\
\text { Productivo }\end{array}$} & Adultos y su desarrollo & $\begin{array}{l}\text { Bajo su experiencia qué podría hacer mejor el Estado Peruano } \\
\text { para fomentar el desarrollo social, económico de los adultos } \\
\text { mayores }\end{array}$ \\
\hline & Rol de la familia & $\begin{array}{l}\text { ¿Cuál es el rol que forma la familia, no solo para los adultos } \\
\text { mayores vulnerables, dependientes sino para quienes buscan } \\
\text { envejecer de forma exitosa? }\end{array}$ \\
\hline & Fomento de salud & $\begin{array}{l}\text { ¿Cuáles son las últimas mejoras en el sistema de salud que se } \\
\text { hayan enfocado al adulto mayor? }\end{array}$ \\
\hline
\end{tabular}




\section{Bitácora aportantes}

\begin{tabular}{|c|c|c|}
\hline Categoría & Sub categoría & $\begin{array}{l}\text { Segmento 2: } \\
\text { Adultos mayores aportantes }\end{array}$ \\
\hline \multirow{3}{*}{$\begin{array}{l}\text { Situación del } \\
\text { adulto mayor }\end{array}$} & $\begin{array}{l}\text { Envejecimiento y } \\
\text { vejez }\end{array}$ & \\
\hline & $\begin{array}{l}\text { Envejecimiento } \\
\text { poblacional en el } \\
\text { Perú }\end{array}$ & $\begin{array}{l}\text { ¿Qué opina de que se considere en el Perú que una persona que llega a tener más } \\
\text { de } 60 \text { años ya es inactiva? }\end{array}$ \\
\hline & Adulto mayor & $\begin{array}{l}\text { ¿Cuáles cree usted que son las características físicas, sociales, económicas que } \\
\text { caracterizan la etapa de vida que está viviendo? }\end{array}$ \\
\hline \multirow{6}{*}{$\begin{array}{l}\text { Consecuencias } \\
\text { económicas y } \\
\text { sociales del } \\
\text { envejecimiento }\end{array}$} & \multirow{2}{*}{ Nivel educativo } & ¿Cuál es su grado de instrucción alcanzado? \\
\hline & & ¿Le gustaría seguir estudiando? Tiene algún proyecto al respecto \\
\hline & Actividad y trabajo & $\begin{array}{l}\text { Nos podría describir: ¿Cuál es su ocupación, profesión? ¿Actualmente a qué se } \\
\text { dedica? }\end{array}$ \\
\hline & $\begin{array}{l}\text { Contribución no } \\
\text { remunerada }\end{array}$ & $\begin{array}{l}\text { ¿Qué actividades realiza que podría considerar como un trabajo no remunerado? } \\
\text { ¿Esta actividad a quién beneficia? ¿Por qué lo hace? (iniciativa, obligación) }\end{array}$ \\
\hline & Calidad de vida & $\begin{array}{l}\text { ¿Cuál es la percepción personal de su situación de vida? En relación con sus } \\
\text { objetivos, expectativas, valores. ¿Está a gusto, se siente bien al respecto? }\end{array}$ \\
\hline & Esperanza de vida & $\begin{array}{l}\text { ¿Cómo se imagina que será su vida en los próximos años? ¿Tendrá algún reto que } \\
\text { enfrentar: (social, económico, de salud)? }\end{array}$ \\
\hline \multirow{6}{*}{$\begin{array}{c}\text { Políticas del } \\
\text { Estado Peruano }\end{array}$} & Ley 30490 & $\begin{array}{l}\text { Conoce de algunas de las políticas de Estado Peruano para contribuir con el } \\
\text { desarrollo de las personas adultas mayores }\end{array}$ \\
\hline & $\begin{array}{l}\text { Plan nacional para } \\
\text { las personas adultas } \\
\text { mayores }\end{array}$ & $\begin{array}{l}\text { Considera usted que el Estado Peruano le ha brindado herramientas de desarrollo } \\
\text { económico, social para la salud. }\end{array}$ \\
\hline & DIPAM & \\
\hline & Pensión 65 & \\
\hline & $\begin{array}{l}\text { Sistema de pensiones } \\
\text { en el Perú }\end{array}$ & $\begin{array}{l}\text { ¿Contribuye usted a un sistema de pensiones? ¿Qué opinión le merece que el } \\
\text { estado mediante ley determina el tiempo en que las todas las personas deben } \\
\text { jubilarse? }\end{array}$ \\
\hline & $\begin{array}{l}\text { Acceso al sistema de } \\
\text { salud }\end{array}$ & ¿Cuenta usted con algún tipo de seguro de salud? \\
\hline \multirow{3}{*}{$\begin{array}{l}\text { Envejecimiento } \\
\text { Productivo }\end{array}$} & $\begin{array}{c}\text { Adultos y su } \\
\text { desarrollo }\end{array}$ & ¿Cómo se visualiza usted? ¿Tiene algún proyecto? \\
\hline & Rol de la familia & ¿Cuál es el rol que cumple la familia en su desempeño y actividad del día a día? \\
\hline & Fomento de salud & $\begin{array}{l}\text { ¿Qué considera usted que necesita para mejorar su estado de salud, o considera } \\
\text { que su estado de salud actual es el óptimo? }\end{array}$ \\
\hline
\end{tabular}




\section{Bitácora no aportantes}

\begin{tabular}{|c|c|c|}
\hline $\begin{array}{c}\text { Categorías/ } \\
\text { Entrevistados }\end{array}$ & Sub categorías & Segmento No aportantes \\
\hline \multirow{3}{*}{$\begin{array}{l}\text { Observaciones } \\
\text { durante la } \\
\text { entrevista }\end{array}$} & $\begin{array}{l}\text { Consecuencias } \\
\text { económicas y } \\
\text { sociales del } \\
\text { envejecimiento }\end{array}$ & $\begin{array}{l}\text { Nos podría indicar si el Sr. (a) tenía algún oficio u ocupación. ¿Cuál era? } \\
\text { Si su grado de dependencia lo permite, el señor (a) realiza algún tipo de } \\
\text { actividad } \\
\text { ¿Cuál es la situación del señor (a), satisface sus principales necesidades: } \\
\text { salud, económicas, sociales (cultiva amistades, mantiene una vida social) }\end{array}$ \\
\hline & $\begin{array}{c}\text { Políticas del } \\
\text { Estado Peruano }\end{array}$ & 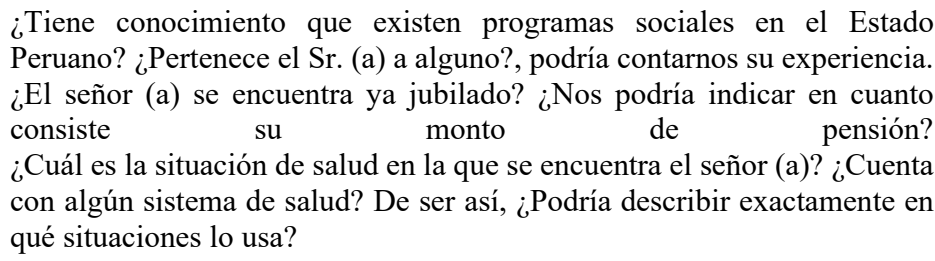 \\
\hline & $\begin{array}{c}\text { Envejecimiento } \\
\text { Productivo }\end{array}$ & $\begin{array}{l}\text { ¿Cómo considera usted que el señor (a) puede mejorar su situación? } \\
\text { ¿Quién es la persona responsable del cuidado del cuidado del Señor (a)? } \\
\text { ¿Si no estuviera esa persona a cargo que actividad desarrollaría? ¿Recibe } \\
\text { apoyo de algún otro familiar? }\end{array}$ \\
\hline
\end{tabular}

\section{Procedimiento (Procesamiento de la información).}

Se trabaja en función a los segmentos y categorías

Se analiza:

- Agrupamiento

- Aspectos comunes

- Aspectos distintivos

Luego de realizar dicho agrupamiento se ejecuta una técnica de escrutinio para el análisis. Posteriormente se aplican las técnicas de procesamiento a través de una matriz por categorías (tabla 14.10 de Sampieri). Cuando las categorías ya han sido respondidas satisfactoriamente, se cierra la investigación. 


\section{Matriz de segmentos y categorías}

\begin{tabular}{|c|c|c|c|}
\hline Categoría & Especialista & Aportante & No Aportante \\
\hline \multirow{3}{*}{ 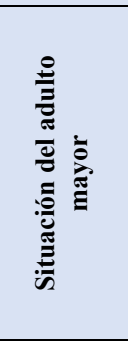 } & $\begin{array}{l}\text { ¿Qué se sabe de la población adulta mayor en el } \\
\text { mundo? }\end{array}$ & $\begin{array}{l}\text { ¿Qué opina de que se considere en el Perú que una } \\
\text { persona que llega a tener más de } 60 \text { años ya es } \\
\text { inactivo? }\end{array}$ & \\
\hline & $\begin{array}{l}\text { ¿Cuál considera usted que es el principal problema que } \\
\text { enfrenta el adulto mayor en el Perú? }\end{array}$ & $\begin{array}{l}\text { ¿Cuáles cree usted que son las características físicas, } \\
\text { sociales, económicas que caracterizan la etapa de vida } \\
\text { que está viviendo? }\end{array}$ & \\
\hline & ¿Por qué se le podría considerar población vulnerable? & & \\
\hline \multirow{6}{*}{ 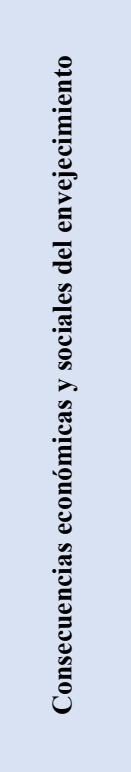 } & $\begin{array}{l}\text { ¿Qué tendencia se está siguiendo en el Mundo sobre la } \\
\text { educación en los adultos mayores? }\end{array}$ & $\begin{array}{l}\text { ¿Cuál es su grado de instrucción alcanzado? ¿Le } \\
\text { gustaría seguir estudiando? Tiene algún proyecto al } \\
\text { respecto }\end{array}$ & $\begin{array}{l}\text { Nos podría indicar si el Sr. (a) tenía algún } \\
\text { oficio u ocupación. ¿Cuál era? }\end{array}$ \\
\hline & $\begin{array}{l}\text { OEA: " La persona mayor tiene derecho a la educación } \\
\text { en igualdad de condiciones con otros sectores de la } \\
\text { población y sin discriminación" ¿Conoce si en el país } \\
\text { existe políticas al respecto? }\end{array}$ & $\begin{array}{l}\text { Nos podría describir: ¿Cuál es su ocupación, } \\
\text { profesión? ¿Actualmente a qué se dedica? }\end{array}$ & $\begin{array}{l}\text { Si su grado de dependencia lo permite, } \\
\text { el señor (a) realiza algún tipo de actividad }\end{array}$ \\
\hline & $\begin{array}{l}\text { Los adultos mayores realizan diferentes actividades no } \\
\text { remuneradas, ¿qué se sabe al respecto? ¿Sería posible } \\
\text { que nos brinde algunos ejemplos o cifras? }\end{array}$ & $\begin{array}{l}\text { ¿Cuál es la percepción personal de su situación de } \\
\text { vida? En relación con sus objetivos, expectativas, } \\
\text { valores. ¿Está a gusto, se siente bien al respecto? }\end{array}$ & \\
\hline & \multirow{2}{*}{$\begin{array}{l}\text { Se sabe que los adultos mayores son un grupo que se } \\
\text { encuentra lejos de ser un grupo homogéneo dado que es } \\
\text { diferente ser mayor de } 60 \text { y ser mujer o hombre, con } \\
\text { pensión o sin pensión, pobre, o de extrema pobreza. Se } \\
\text { trabaja calidad de vida en base a estas diferencias. } \\
\text { Conoce de políticas públicas basadas en calidad de vida }\end{array}$} & $\begin{array}{l}\text { ¿Cómo se imagina que será su vida en los próximos } \\
\text { años? ¿Tendrá algún reto que enfrentar: (social, } \\
\text { económico, de salud)? }\end{array}$ & \\
\hline & & & \\
\hline & $\begin{array}{l}\text { Siendo el envejecimiento poblacional un éxito en las } \\
\text { mejoras sanitarias. ¿Qué retos visualiza usted va a } \\
\text { enfrentar el Estado Peruano en los próximos años? }\end{array}$ & & \\
\hline \multirow{4}{*}{ 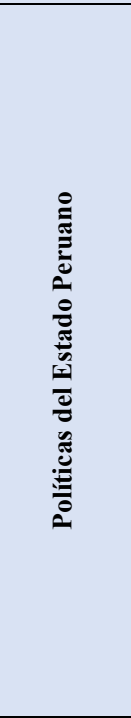 } & $\begin{array}{l}\text { La Ley } 30490 \text {, la ley de los adultos mayores se } \\
\text { promulgó con el objetivo principal de propiciar la } \\
\text { integración del adulto mayor al desarrollo social, } \\
\text { económico, político y cultural de la nación. }\end{array}$ & $\begin{array}{l}\text { Conoce de algunas de las políticas de Estado Peruano } \\
\text { para contribuir con el desarrollo de las personas } \\
\text { adultas mayores }\end{array}$ & $\begin{array}{l}\text { ¿Tiene conocimiento que existen } \\
\text { programas sociales en el Estado } \\
\text { Peruano? ¿Pertenece el Sr. (a) a alguno?, } \\
\text { podría contarnos su experiencia. } \\
\end{array}$ \\
\hline & $\begin{array}{l}\text { ¿Considera al programa social pensión } 65 \text { como un } \\
\text { éxito de políticas públicas? }\end{array}$ & ¿Cuenta usted con algún tipo de seguro de salud? & $\begin{array}{l}\text { ¿Cuenta con algún sistema de salud? De } \\
\text { ser así, ¿Podría describir exactamente en } \\
\text { qué situaciones lo usa? } \\
\end{array}$ \\
\hline & $\begin{array}{l}\text { Según INEI, solo el } 37.6 \% \text { de adultos mayores en el } \\
\text { Perú, está afiliado a un sistema de pensiones. ¿Qué se } \\
\text { está haciendo al respecto? }\end{array}$ & & \\
\hline & $\begin{array}{l}\text { ¿Considera usted que el sistema de salud y de acceso a } \\
\text { estos, por parte del adulto mayor es el óptimo? Se } \\
\text { atrevería a dar sugerencias de cambio bajo su } \\
\text { experiencia. }\end{array}$ & & \\
\hline \multirow{3}{*}{ 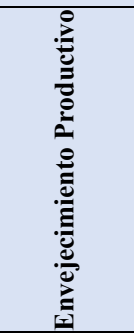 } & $\begin{array}{l}\text { Bajo su experiencia qué podría hacer mejor el Estado } \\
\text { Peruano para fomentar el desarrollo social, económico } \\
\text { de los adultos mayores }\end{array}$ & ¿Cómo se visualiza usted? ¿Tiene algún proyecto? & $\begin{array}{l}\text { ¿Cómo considera usted que el señor (a) } \\
\text { puede mejorar su situación? }\end{array}$ \\
\hline & $\begin{array}{l}\text { ¿Cuál es el rol que forma la familia, no solo para los } \\
\text { adultos mayores vulnerables, dependientes sino para } \\
\text { quienes buscan envejecer de forma exitosa? }\end{array}$ & $\begin{array}{l}\text { ¿Cuál es el rol que cumple la familia en su desempeño } \\
\text { y actividad del día a día? }\end{array}$ & $\begin{array}{l}\text { ¿Quién es la persona responsable del } \\
\text { cuidado del cuidado del Señor (a)? ¿Si no } \\
\text { estuviera esa persona a cargo que } \\
\text { actividad desarrollaría? }\end{array}$ \\
\hline & $\begin{array}{l}\text { ¿Cuáles son las últimas mejoras en el sistema de salud } \\
\text { que se hayan enfocado al adulto mayor? }\end{array}$ & $\begin{array}{l}\text { ¿Qué considera usted que necesita para mejorar su } \\
\text { estado de salud, o considera que su estado de salud } \\
\text { actual es el óptimo? }\end{array}$ & ¿Recibe apoyo de algún otro familiar? \\
\hline
\end{tabular}




\section{Matriz de descripción de contexto interno y externo de la}

\section{muestra}

\section{Muestra - Especialistas}

\begin{tabular}{|c|c|c|}
\hline$E$ & CONTEXTO INTERNO & CONTEXTO EXTERNO \\
\hline E 1 & $\begin{array}{l}\text { Dr. Carlos L.V.B } \\
\text { Jefe del servicio de Geriatría del Hospital Central de } \\
\text { aeronáutica Lima - Perú. } \\
\text { Presidente de la sociedad peruana de Geriatría y } \\
\text { Gerontología del Perú. } \\
\text { Consultor en temas geriátricos (Congreso de la } \\
\text { República - Ministerio de Salud). } \\
\text { El entrevistado se muestra contento, se tomó una foto } \\
\text { con nosotros y solicitó le mostremos los resultados de } \\
\text { la investigación, pues es un tema de su interés. }\end{array}$ & $\begin{array}{l}\text { La entrevista se llevó a cabo en las } \\
\text { instalaciones del Hospital Central } \\
\text { Geriátrico FAP, la cual está ubicada en la } \\
\text { calle Las Tiendas - Surquillo. } \\
\text { Este lugar es de fácil acceso pues se } \\
\text { encuentra a } 1 \text { cuadra de la Av. Aramburú y } \\
\text { se encuentra en una zona comercial. }\end{array}$ \\
\hline E 2 & $\begin{array}{l}\text { Lic. Ysela J.P.R } \\
\text { Lic. En Psicología, ejerciendo en la práctica privada. } \\
\text { Integrante de la Asociación Peruana de } \\
\text { Neuropsicología. } \\
\text { Actualmente ejecutando investigación neurocognitiva } \\
\text { en el adulto mayor. } \\
\text { La especialista, a medida que avanza la entrevista se } \\
\text { va mostrando cómoda y relajada, agradeció que se le } \\
\text { considerara para esta investigación y que sería } \\
\text { interesante se pueda compartir el resultado al final pues } \\
\text { ella se encuentra haciendo una investigación en esta } \\
\text { población adulta para su doctorado. }\end{array}$ & $\begin{array}{l}\text { La entrevista se ejecutó en los consultorios } \\
\text { del Centro Médico CAFAE-SE, el cual está } \\
\text { ubicado en la Av. Tudela y Varela } 102 \text { San } \\
\text { Isidro. Este lugar es de fácil acceso, pues } \\
\text { colinda con la Av. Camino Real y está a } 1 \\
\text { cuadra del centro comercial Dasso o a } 3 \\
\text { cuadras del Ovalo Gutiérrez. }\end{array}$ \\
\hline E 3 & $\begin{array}{l}\text { Mg. Elia Luna del Valle directora de la Dirección del } \\
\text { Adulto Mayor del Ministerio de la Mujer y Poblaciones } \\
\text { Vulnerables. } \\
\text { La entrevista se realizó en el despacho privado de la } \\
\text { entrevistada. } \\
\text { La directora se muestra contenta al saber del tema que } \\
\text { trata nuestro trabajo, por lo que nos brinda consejos, } \\
\text { así como también, nos da material para seguir } \\
\text { profundizando en nuestra investigación. Nos felicita en } \\
\text { reiteradas veces por la tesis y se ofrece ayudar en todo } \\
\text { lo posible. }\end{array}$ & $\begin{array}{l}\text { La entrevista se realizó en la oficina del } \\
\text { Adulto Mayor del Ministerio de La Mujer, } \\
\text { ubicado en el Jr. Camaná } 616 \text {, cercado de } \\
\text { Lima. Este lugar es de fácil acceso, sin } \\
\text { embargo, el tráfico dificulta y aplaza los } \\
\text { tiempos de llegada. }\end{array}$ \\
\hline E 4 & $\begin{array}{l}\text { Dra. Rosa Mercedes Rincón Huamán- directora del } \\
\text { Centro de Atención Residencial Geriátrico Ignacia } \\
\text { Rudolfo Viuda de Canevaro. } \\
\text { En el inicio de la entrevista se muestra bastante tensa, } \\
\text { por lo que decide no estar sola y llama al coordinador } \\
\text { (psicólogo) a participar de la entrevista, sin antes volver } \\
\text { a preguntar sobre la finalidad de la entrevista por lo que } \\
\text { se vuelve a recalcar que dicha entrevista solo tiene } \\
\text { fines académicos. } \\
\text { Se observa que, a nivel que avanzamos con las } \\
\text { preguntas, la entrevistada se va relajando. } \\
\text { La directora y el coordinador de psicología acceden a } \\
\text { que podamos entrevistar adultos mayores vulnerables } \\
\text { como parte de nuestra investigación. }\end{array}$ & $\begin{array}{l}\text { La entrevista se realiza en la oficina de la } \\
\text { directora, en las instalaciones del Hogar } \\
\text { Canevaro, ubicado en el Jr. Madera } 265 \text { - } \\
\text { Rímac. } \\
\text { Este centro es considerado como uno de } \\
\text { los más importantes albergues a nivel } \\
\text { nacional, puesto que en el residen cerca de } \\
500 \text { adultos mayores. }\end{array}$ \\
\hline
\end{tabular}


Dra. María Edith Baca Psicóloga Salubrista - Consultora Nacional de la OPS. La Dra. Baca nos comenta que todo el día y todos los días reciben personas o está en reuniones; sin embargo, se siente gustosa de atendernos, pues la primera cita que se concertó nos tuvo que cancelar por motivos de viaje.
La entrevista se llevó a cabo en las instalaciones de la OPS (Organización Panamericana de la Salud) sede Perú, ubicada la calle Los Pinos 251 Urb. Camacho La Molina, en la oficina de la entrevistada.

\section{Muestra - Aportantes}

\begin{tabular}{|c|c|c|}
\hline$E$ & CONTEXTO INTERNO & CONTEXTO EXTERNO \\
\hline E 1 & $\begin{array}{l}\text { Mg. Dolores G.P. } \\
\text { Gerente General Farmacia Universal. } \\
\text { Integrante de la Cámara de Comercio del Perú, } \\
\text { comisión de mujeres emprendedoras de la Cámara de } \\
\text { Comercio, Organización Mundial de Mujeres } \\
\text { Empresarias. } \\
\text { Ofrecer sugerencias hacia políticas de estado. } \\
\text { Al concluir la entrevista, nos da las gracias por hacer } \\
\text { partícipe de esta investigación y solicita que al final se } \\
\text { le muestre los resultados, a lo cual gustosos } \\
\text { accedimos. }\end{array}$ & $\begin{array}{l}\text { La entrevista se realizó en las instalaciones de } \\
\text { la Farmacia Universal - Sede Central, ubicada } \\
\text { en la Av. Emancipación } 799 \text { - cercado. } \\
\text { El lugar es de fácil acceso; sin embargo, la } \\
\text { congestión vehicular puede perjudicar este } \\
\text { acceso. } \\
\text { Fuimos atendidos en la sala de reuniones, } \\
\text { puesto que siendo las } 8: 00 \text { p.m. era el lugar } \\
\text { disponible sin interferir sus labores y sin que } \\
\text { nadie nos interrumpiese. }\end{array}$ \\
\hline E 2 & $\begin{array}{l}\text { Sr. Luis M.O.H } 69 \text { años } \\
\text { Tesorero empresa CAFAE-SE. } \\
\text { Estudios técnicos en la escuela superior de } \\
\text { administración pública del ministerio de economía y } \\
\text { finanzas. } \\
\text { Al concluir la entrevista, se muestra satisfecho e indica } \\
\text { que ojalá nos haya podido ayudar en la investigación. }\end{array}$ & $\begin{array}{l}\text { La entrevista se realizó en las instalaciones de } \\
\text { la empresa CAFAE-SE, ubicada en la Av. } \\
\text { Tudela y Varela } 102 \text { - San Isidro, Este lugar es } \\
\text { de fácil acceso, pues colinda con la Av. } \\
\text { Camino Real y está a } 1 \text { cuadra del centro } \\
\text { comercial Dasso o a } 3 \text { cuadras del Ovalo } \\
\text { Gutiérrez. La entrevista se realizó en la oficina } \\
\text { del entrevistado, quien nos brindó unos } \\
\text { minutos de su tiempo, pues indica que tiene } \\
\text { mucha carga laboral. }\end{array}$ \\
\hline E 3 & $\begin{array}{l}\text { Sra. Luz A.R.H. } 60 \text { años } \\
\text { Auxiliar administrativo CAFAE-SE. } \\
\text { Secretariado ejecutivo - estudios técnicos } \\
\text { Al concluir la entrevista, agradece la consideración para } \\
\text { entrevistarla. }\end{array}$ & $\begin{array}{l}\text { La entrevista se realizó en las instalaciones de } \\
\text { la empresa CAFAE-SE - San Isidro, Este lugar } \\
\text { es de fácil acceso, pues colinda con la Av. } \\
\text { Camino Real y está a } 1 \text { cuadra del centro } \\
\text { comercial Dasso o a } 3 \text { cuadras del Ovalo } \\
\text { Gutiérrez. La entrevista se realizó en un } \\
\text { ambiente disponible para lo cual la } \\
\text { entrevistada tuvo que dejar encargado su } \\
\text { puesto, debido a que la entrevista se realizó en } \\
\text { su jornada laboral. }\end{array}$ \\
\hline E 4 & $\begin{array}{l}\text { Sr. Andrés R.E.Q } 64 \text { años } \\
\text { Jefe del departamento Online, ingeniería electrónica - } \\
\text { Casino Atlantic City - Miraflores. } \\
\text { Ingeniero electrónico } \\
\text { Al concluir la entrevista, agradece la consideración para } \\
\text { la entrevista y solicita se compartan los resultados. }\end{array}$ & $\begin{array}{l}\text { La entrevista se realizó en las instalaciones del } \\
\text { Casino Atlantic City, ubicada en la Av. Alfredo } \\
\text { Benavidez } 430 \text { - Miraflores. Este lugar es de } \\
\text { fácil acceso pues es una de las avenidas } \\
\text { principales del distrito de Miraflores. } \\
\text { La entrevista se realizó en la oficina del } \\
\text { entrevistado, segundo piso del casino. }\end{array}$ \\
\hline E 5 & $\begin{array}{l}\text { Sr. Guillermo L.R } 65 \text { años } \\
\text { Director técnico, profesor, academia de futbol. } \\
\text { Al concluir la entrevista, nos da las gracias y agradece } \\
\text { a Dios por el día. }\end{array}$ & $\begin{array}{l}\text { La entrevista se realizó en la academia de } \\
\text { futbol que dirige el entrevistado, el cual está } \\
\text { ubicado dentro de la Universidad Nacional } \\
\text { Agraria La Molina, lugar de muy fácil acceso, } \\
\text { aunque un poco distante del centro de la } \\
\text { ciudad. }\end{array}$ \\
\hline E 6 & $\begin{array}{l}\text { Sra. María Esther S.O. } 62 \text { años } \\
\text { Técnica Enfermera en el Club Lima Cricket. }\end{array}$ & $\begin{array}{l}\text { La entrevista se realizó previa cita, en la } \\
\text { comodidad de su hogar. }\end{array}$ \\
\hline
\end{tabular}




\begin{tabular}{|l|l|l|}
\hline E 7 & $\begin{array}{l}\text { Sra. Gloria Leonor S.L. 62 años } \\
\text { Contadora Pública Colegiada. }\end{array}$ & $\begin{array}{l}\text { La entrevista se realizó previa cita, en la } \\
\text { comodidad de su hogar. }\end{array}$ \\
\hline E 8 & $\begin{array}{l}\text { Sra. Imelda T. P. 67 años } \\
\text { Docente Universitaria UNMSM }\end{array}$ & $\begin{array}{l}\text { La entrevista se realizó en las instalaciones de } \\
\text { la UNMSM, ubicada en el cruce de las Av. } \\
\text { Universitaria y la Av. Venezuela, Lima. }\end{array}$ \\
\hline
\end{tabular}

\section{Muestra - No Aportantes}

\begin{tabular}{|c|c|c|}
\hline$E$ & CONTEXTO INTERNO & CONTEXTO EXTERNO \\
\hline $\begin{array}{c}E \\
1-15\end{array}$ & $\begin{array}{l}\text { La muestra está compuesta por } 14 \text { residentes del área } \\
N^{\circ} 9 \text { del Hogar Canevaro, esta muestra fue elegida al } \\
\text { azar. } \\
\text { Los entrevistados se mostraron muy colaborativos y } \\
\text { trataron de responder de la mejor forma que podían, } \\
\text { siempre agradeciendo que los tomen en consideración. }\end{array}$ & $\begin{array}{l}\text { La entrevista se realizó en las instalaciones } \\
\text { del área } N^{\circ} 9 \text { del Hogar Canevaro } \\
\text { (habitaciones, cafetín, patio y área } \\
\text { recreativa). } \\
\text { El lugar está ubicado en el Jr. Madera } 265 \\
\text { - Rímac, siendo de fácil acceso. }\end{array}$ \\
\hline
\end{tabular}

\section{Matriz de Procesamiento de Información}

\section{Análisis de aspectos positivos $y$ negativos para el segmento 1:}

\section{Especialista}

\begin{tabular}{|c|c|}
\hline ASPECTOS POSITIVOS & ASPECTOS NEGATIVOS \\
\hline \multicolumn{2}{|c|}{$\begin{array}{l}\text { ASPECTOS POSITIVOS } \\
\text { SEGMENTO 1: Especialistas } \\
\end{array}$} \\
\hline $\begin{array}{l}\text { - Existe interés en el tema del adulto mayor y } \\
\text { resaltan el gran valor que estos representan } \\
\text { en la sociedad. } \\
\text { - La esperanza de vida en el Perú se ha } \\
\text { incrementado. } \\
\text { - Desde sus puestos de trabajo, plantean } \\
\text { mejoras para mejorar la calidad de vida de } \\
\text { este grupo ocupacional. } \\
\text { - Realizan charlas orientadas al cuidado físico } \\
\text { y psicológico del adulto mayor. } \\
\text { - Piensan que los adultos mayores poseen } \\
\text { muchas cualidades valiosas dentro de ellas } \\
\text { la experiencia. } \\
\text { Resaltan que el grupo etario de nuestro } \\
\text { estudio está en pleno crecimiento, lo cual se } \\
\text { atribuye a las mejoras en salud. } \\
\text { En las entrevistas se percibió cierta molestia } \\
\text { o impotencia por no tener los medios para } \\
\text { hacer más por este grupo de personas. }\end{array}$ & $\begin{array}{l}\text { - Están preocupados porque no existe un plan } \\
\text { de acción concreto que afronte el crecimiento } \\
\text { de la población en estudio. } \\
\text { - Piensan que si las políticas de estado no } \\
\text { cambian (si existiesen) o no se } \\
\text { implementan, la situación de los adultos } \\
\text { mayores empeorará aún más. } \\
\text { - Indican que las propuestas que sus } \\
\text { organismos realizan llegan hasta el } \\
\text { congreso o ministerio, pero no avanzan } \\
\text { más. } \\
\text { Indican que las funciones en los ministerios } \\
\text { son aisladas, lo cual no permite avanzar en } \\
\text { los proyectos, debería haber una cohesión } \\
\text { entre los ministerios. } \\
\text { En los sistemas de salud existe un gran } \\
\text { vacío en los recursos para la atención de } \\
\text { los adultos mayores. }\end{array}$ \\
\hline
\end{tabular}


- Indican que un gran problema para lograr un buen envejecimiento es el acceso a la salud (existe mucha burocracia) y la atención no es descentralizada.

- Existe una falta de reconocimiento (por parte de la sociedad y la familia) a las labores no remuneradas que realizan los adultos mayores, por ejemplo, cuidar a los nietos o hacer labores domésticas.

- Existen necesidades de los adultos mayores que no están siendo atendidos.

- Hay vulnerabilidad de los derechos de este grupo etario.

- La calidad de vida para la mayoría de las personas de este grupo etario es una utopía.

\section{Análisis de aspectos positivos y negativos para el segmento 2: Aportantes}

\section{ASPECTOS POSITIVOS $\quad$ ASPECTOS NEGATIVOS}

\section{SEGMENTO 2: Aportantes}

- Los entrevistados se sienten bien de salud y vigorosos para realizar sus actividades.

- Los entrevistados refieren no sentirse viejos, sino dicen ser los nuevos jóvenes.

- En sus tiempos libres, realizan actividades no remuneradas, tenga que ver con la familia o grupos comunitarios a los que pertenecen.

- La mayoría indica que realiza deporte.

- Ven el futuro con optimismo, por lo que tienen planes a realizar en el futuro.

- Indican que dejaran de trabajar cuando ellos sientan que es hora de parar, pero no para descansar en casa sino para pasar más tiempo con sus familias y desarrollar actividades pospuestas (viajes, negocios propios, etc.).

- Cuentan con un seguro privado.

- Aportan a una AFP u ONP.

- Indican que la familia es un pilar y motivo para seguir adelante.

- Los entrevistados refieren sentirse satisfechos con lo que hasta ahora han logrado.

- La mayoría indica tener una vida social muy activa, puesto que participan de reuniones sociales, donde se reúnen con sus pares.

- Indican que el trabajo es básico para mantenerse activos, que sin ellos no se sentirían completos.

- La mayoría indica querer seguir estudiando, pero no buscando fines remunerativos, sino como desarrollo personal.

- En la mayoría de los casos, su día empieza entre las 5:00 a.m. a 6:00 a.m. con un poco de ejercicios para luego dirigirse a sus centros de trabajo.
- Sólo uno menciona haberse beneficiado de un plan o proyecto realizado por el estado, adicionalmente indican no conocer ninguno.

- No sienten que el país se preocupe por ellos (adultos mayores).

- En algunos casos señalan que en sus trabajos es complicado acceder a los permisos para realizar terapias.

- Refieren que la jubilación no debe ser por obligación (de acuerdo con la edad) sino de acuerdo con sus capacidades. 


\section{Análisis de aspectos positivos y negativos para el segmento 3: No}

\section{Aportantes}

\begin{tabular}{|c|c|}
\hline ASPECTOS POSITIVOS & ASPECTOS NEGATIVOS \\
\hline \multicolumn{2}{|c|}{ SEGMENTO 3: No Aportantes } \\
\hline $\begin{array}{l}\text { - Los entrevistados en el área de recreación, } \\
\text { se veían contentos. } \\
\text { - Los entrevistados cuentan con al menos } 3 \\
\text { alimentos y una cama donde descansar. } \\
\text { - Todos los entrevistados cuentan con SIS. }\end{array}$ & $\begin{array}{l}\text { - La mayoría de los casos refieren no tener } \\
\text { familia, por lo que no cuentan con un apoyo } \\
\text { económico y afectivo. } \\
\text { - En la mayoría de los casos, cuando se } \\
\text { realizaban preguntas sobre aspectos } \\
\text { económicos, se evidenciaba tristeza y en } \\
\text { algunos casos llegaban al llanto. } \\
\text { - En la mayoría de los casos nos indicaron que } \\
\text { no cuentan con pensión, aunque un par de } \\
\text { casos mencionó que habían hecho trámites } \\
\text { para cobrar su pensión, pero ellos no reciben } \\
\text { nada. } \\
\text { Se puede evidenciar que el estado de salud } \\
\text { en general es frágil, pues se evidencia un } \\
\text { estado nutricional inadecuado, lo que los } \\
\text { vuelve vulnerables } \\
\text { enfermedades. } \\
\text { En ante muchas } \\
\text { realizar sus actividades básicas (higiene } \\
\text { personal), necesitan el apoyo de otra } \\
\text { persona. } \\
\text { Algunos casos reportan que están allí porque } \\
\text { los secuestraron, sin embargo, al no contar } \\
\text { con familia se resignaron a estar en este } \\
\text { lugar. } \\
\text { En todos los casos, no se ha podido } \\
\text { identificar que alguno tenga estudios } \\
\text { superiores, incluso estudios básicos. } \\
\text { No se ha podido evidenciar que alguno de los } \\
\text { entrevistados haya trabajado de manera } \\
\text { formal en el transcurso de su vida. } \\
\text { Existe mucho escepticismo de parte de las } \\
\text { autoridades del hogar Canevaro con respecto } \\
\text { a realizar estudios con las personas que } \\
\text { residen en dicho lugar. }\end{array}$ \\
\hline
\end{tabular}




\section{CAPITULO IV}

\section{ANALISIS DE DATOS}

El objetivo principal de esta tesis es describir la situación real del adulto mayor en

el Estado Peruano y si éste se encuentra preparado para soportar el incremento de la esperanza de vida en el Perú; por tal razón, concluimos lo siguiente: 


\section{Conclusiones}

- El adulto mayor no se encuentra preparado para seguir aportando económicamente a la sociedad. Los adultos mayores en el Perú no conocen los términos y fundamentos de la Ley de personas mayores que les da derechos en la sociedad, no conocen de las Políticas de Estado y en su mayoría no sienten que el estado haya aportado de alguna manera en su desarrollo personal ni en su desarrollo económico. Nuestra sociedad está envejeciendo de manera moderada en comparación con otras ciudades del mundo, en donde ya se infiere al envejecimiento poblacional como la transformación social más importante del siglo XXI y eso se determina gracias al incremento de la esperanza de vida, a la disminución de la mortandad y otros factores menos relevantes como el ingreso de la mujer en el trabajo formal. Acompañar este proceso de envejecimiento poblacional en el país debería ser una prioridad en la ejecución e implementación de las políticas de estado, sin embargo podemos observar que si bien existen instituciones de gobierno como la oficina del adulto mayor a cargo del Ministerio de la Mujer, lineamientos e iniciativas de adhesión a convenciones internacionales, políticas a través de programas de subvención y leyes basadas en respaldar los derechos de las personas mayores y el fenómeno de crecimiento de la población en el Perú, no son una prioridad en las políticas de gobierno, y lo que se establece no se implementa de forma suficiente, no alcanza en su totalidad la magnitud del problema y que además, no ha sido capaz el Estado Peruano de afrontar las diversas demandas y necesidades de las personas adultas mayores en este momento, por lo que en el futuro podemos claramente identificar un colapso, un caos, y un desabastecimiento en la atención de las necesidades de los adultos mayores.

- Cumpliendo con nuestro objetivo número 2 se observa que es relevante centrarse en que los adultos mayores no pierdan su capacidad física y mental para que las consecuencias del crecimiento de la población sean mucho menos negativas. Sin embargo, podemos observar que el mayor problema del adulto mayor en el Perú es el acceso a la salud. Actualmente vivimos una saturación del sistema de salud con poco acceso a la atención médica y a los medicamentos necesarios para la atención de 
enfermedades de base o también llamadas enfermedades crónicas, que originan y son el inicio de complicaciones posteriores que llevan a los adultos mayores a ser completamente dependientes. Actualmente los dos grandes prestadores de salud son el público y el privado, ya mencionamos el desabastecimiento y falta de acceso del sector público, por otro lado, en el sector privado la situación es todavía más difícil, pues a mayor edad de la persona, es mayor es el costo de la atención. Entonces tenemos un sistema que por un lado no se abastece y que por el otro llega a ser altamente oneroso. La implementación del Sistema Integrado de Salud (SIS) por parte del gobierno ha representado un avance para el acceso a la salud de la población a nivel nacional, sin embargo, tiene todavía deficiencias en su implementación, difusión y alcance de las poblaciones de extrema pobreza. Y hablando de forma específica de la población adulta mayor, el SIS sólo funciona para atenciones básicas cuando las necesidades de salud del adulto mayor deben ser atendidas de forma integral dado que normalmente son portadores de más de una enfermedad a la vez.

- Se observa que no existe una cultura de prevención en la población peruana. Evidenciamos en esta investigación que los adultos mayores vulnerables trabajaron de manera informal, y las cifras de afiliación a un sistema de pensiones en el Perú lo evidencian, pues sólo el 37. 5\% de la actual población adulta mayor en el Perú tiene una pensión. (Gráfico 3). Al no existir una cultura de previsión, conlleva a que el número de personas adultas no preparadas se incremente de manera abrupta, trayendo consigo consecuencias del tipo económico, social y familiar:

- Económicas, se incrementa el número de personas adultas mayores pobres o en extrema pobreza, que no acceden a un sistema de pensiones y que se vuelven una carga muy fuerte para el estado.

- Sociales, se crea una falsa percepción o estereotipo de lo que es la vejez, la sociedad los muestra como personas que no son capaces de contribuir o valerse por sí mismos, sino al contrario, los catalogan como un estorbo o un problema de la sociedad. Esta percepción equivocada hace que se vulneren sus derechos más básicos de educación, salud y trabajo.

- Familiares, debido a la falta de educación y concientización de lo valerosas que son las experiencias de las personas mayores, muchas familias tratan de deshacerse de sus familiares más longevos, abandonándolos o haciéndolos sentir 
ausentes. En otros casos la falta de poder adquisitivo para cubrir las necesidades básicas de la manutención de un adulto mayor trae una carga económica familiar que lleva a las familias a la pobreza. La familia juega un rol importante en la vida de los adultos mayores, puesto que son el pilar para soportar todo a lo que la sociedad lo expone; además se ha catalogado como un agente motivador de superación, tanto personal como profesional para las personas mayores.

- Las organizaciones gubernamentales vinculadas a la solución de los problemas de los adultos mayores centralizan sus esfuerzos en el establecimiento de lineamientos, políticas, diseño de programas y desarrollo de investigaciones de esta población; sin embargo, su implementación en el sistema es insuficiente y deficiente. Uno de los programas sociales más difundidos es el de Pensión 65, destacado por los expertos como un programa de transferencia económica que no soluciona problemas de fondo y dirigido básicamente a sacar a los adultos mayores de la pobreza extrema, que impacta en poca proporción de la población y que no ofrece calidad de vida. El punto 2.7.4 se destaca que 62.4 por ciento de la población adulta mayor en el Perú no tiene acceso un sistema de pensiones por lo que no recibe ningún tipo de pensión. Al respecto de este problema de gran envergadura que afecta a la mayor parte de la población adulta mayor, el Estado Peruano parece estar haciendo nada al respecto. La investigación no identifica un plan de acción del estado peruano que busque reducir esta cifra. No hay una política de estado que fomente un aporte contributivo a un sistema de pensiones ni de iniciativas de modificación de la ley de aportaciones para dar mayores opciones de acceso. En este punto el rol de la familia es clave y fundamental pues son ellos los que asumen el apoyo económico y de sustentación a los adultos mayores siendo esto un punto de quiebre pues en el futuro sería imposible de sostener dado el cambio demográfico de edades en la población peruana. Observamos entonces de forma muy clara que la implementación de las políticas del Estado Peruano es insuficiente.

- Se observa que el envejecimiento productivo es posible en cuanto la vejez no es sinónimo de fragilidad. Se observa que el envejecimiento puede llegar a ser productivo y económicamente activo. Los especialistas del sector hacen hincapié en separar el concepto de fragilidad y desasociarla de los adultos mayores. Nuestro segmento de aportantes en su totalidad se muestra en desacuerdo con la postura de inactividad con que se les vincula a los mayores de 60 y más del 50 por ciento de 
nuestra muestra etnográfica de población vulnerable se encuentra físicamente en posibilidad de continuar con alguna actividad u ocupación. Se observa que los actuales adultos mayores frágiles y/o vulnerables lo son a partir de que están siendo desatendidos en sus necesidades básicas de acuerdo a las características físicas y psicológicas de esta población, pero también por la suma de una serie de factores como la falta de previsión de la vejez como etapa de vida, pero sobre todo por el estereotipo arraigado y discriminatorio en el Perú y en el mundo de inactividad y fragilidad de las personas mayores. En el subcapítulo 2.1 analizamos el concepto de envejecimiento donde se evidencia que la palabra vejez se encuentra estigmatizada difundiendo un concepto errado de las personas mayores donde no se les valora ni se les reconoce, pero sobre todo donde se vulnera sus derechos más básicos como el acceso a la educación y a un trabajo digno.

- Las personas mayores son activas, se observa en la presente investigación y el INEI reporta que un 58 por ciento de la población adulta mayor es económicamente activa. Resaltamos que la informalidad, así como la contribución no económica de los adultos mayores no está en medición y es casi imposible medir el impacto no contributivo que realizan a través de diversas actividades. Se observa que después de los 60 años, los adultos mayores realizan actividades no remuneradas, ya sea en el ámbito familiar y/o social en el que se desenvuelven. Existe una falta de concientización acerca de la valoración de los adultos mayores, tal como lo hacen las sociedades europeas, donde llegar a ser mayor es símbolo de éxito y experiencia, la cual es muy valorada por la sociedad y más aún por la familia. A lo anterior podemos observar que el nivel educativo juega un rol importante en el mantenimiento de la actividad y productividad de los adultos mayores. La educación o grado de instrucción es un factor determinante para tener una vejez digna que ayude a sobrellevar el futuro. La educación en los adultos mayores influye directamente en el tipo de trabajo que desarrollaran durante su vida económicamente activa. La formación académica crea en los adultos mayores una conciencia del futuro y de prevención para la vejez. Podemos observar que considerar a las personas mayores de 60 años como inactivos es un error sobre todo si se hace basado en un estereotipo arraigado de no actividad y fragilidad de este grupo. No se tiene en consideración la experiencia y por consiguiente la productividad que esta causa. Existen factores importantes que determinan la capacidad cognitiva y física que se desarrollan de forma diferente en las personas dependiendo del estilo de 
vida que llevaron durante su vida. Tal como mencionamos en el subcapítulo 2.5.2 actividad económica y trabajo, la jubilación es un lujo que pocas personas mayores en países de bajos y medianos ingresos se pueden permitir. 


\section{Recomendaciones}

- Mejorar de forma integral el acceso a la salud de los adultos mayores desde el enfoque del concepto de salud planteado por la OMS, donde no sólo es ausencia de enfermedad sino un estado absoluto de bienestar físico, mental y social. Los adultos mayores necesitan acceder a controles de personas adultas mayores sanas dónde las enfermedades crónicas o de base tengan un seguimiento personalizado continúo. Nos parece oportuno imitar la cartilla de control del niño sano dónde se puede llevar un control del avance, deterioro o puntos críticos de control de la salud de las personas mayores. Considerar además que los adultos mayores son capaces de aprender técnicas de autocuidado y fomentar en esta población la conservación de sus capacidades físicas y cognitivas. Sumado a lo anterior la creación de un ente regulador en el precio, venta y acceso de los medicamentos es importante, pues es base fundamental de los tratamientos degenerativos y crónicos. En el país no existe un órgano regulador de las medicinas y sus genéricos, siendo un vacío legal aprovechado por muchos laboratorios y cadenas farmacéuticas.

- Proponer diversos mecanismos de aporte a un sistema de pensiones. Que se diversifique el acceso, tal como hace el Estado por ejemplo con los programas mi vivienda donde la población cuenta con diversas opciones de ahorro y bonos de buen pagador que permite sobre todo a las nuevas familias acceder a una vivienda propia. Citamos una propuesta de Bernal:

- "Planes de Pensión por 1 y Pensión por 2. Se trata de esquemas de aporte y beneficio definido, dirigidos a trabajadores que actualmente se encuentran fuera del sistema y tienen bajos niveles de ingresos, mediante los que se garantizaría un porcentaje de la pensión mínima en función a los años de aportes realizados a una cuenta individual de capitalización. Para garantizar estos niveles e incentivar la aportación, la pensión autofinanciada sería complementada con un bono.” (Bernal, 2008, p.14) 
- Si partimos del concepto de (Ramos, 2009) donde se indica que no son una población homogénea donde es diferente ser mayor de 60 y ser mujer o hombre, o donde la diferencia es mayor si se cuenta con pensión o sin pensión. Se debe implementar normas que ayuden y den opciones de aportaciones más flexibles, encontrar alternativas para adultos mayores que no completaron el periodo de aportaciones en el sistema público. Promover el empleo formal, destacando la importancia de contribuir a un sistema de pensiones como un plan de jubilación necesario. Desarrollar en las personas adultas un estado de conciencia del futuro, y tener en cuenta las aportaciones, la jubilación y la vejez como una etapa de la vida.

- Desarrollar una cultura de valoración y respeto a las personas adultas mayores. Empezar por empoderar a esta población con la difusión de sus derechos, es importante que ellos conozcan que existen leyes, organizaciones y entidades que los protegen en sus derechos más básicos. Resaltar de forma importante el aporte que nos da la experiencia y los años vividos, no sólo rescatará a los adultos mayores del estereotipo de vejez, sino que creará conciencia en las personas de la necesidad de planeación de la vejez como una etapa de vida a la que se debe llegar de la mejor manera. En este camino de valoración es importante mantener y reforzar los vínculos familiares, cambiando el estereotipo del adulto mayor actual (carga familiar) a un estereotipo más dinámico, valioso y productivo. Considerando sobre todo el rol de la familia, como unidad de una sociedad más fuerte.

- Difundir en el Estado Peruano la importancia de la educación y su rol protagónico en la vida, no sólo de los adultos mayores sino en general de toda la población en el Perú y en el mundo, por lo que la educación debe tomar el rol protagónico en las políticas del Estado Peruano. Integrar a los adultos mayores en el desarrollo de planes de acción dirigidos al adulto mayor en el aspecto de auto sostenibilidad, autocuidado y educación entre pares, considerando que muchos adultos mayores están en capacidad de ayudar a otros con edades avanzadas o en situación vulnerable, integrarlos y hacerlos parte de la solución teniendo en cuenta que en los próximos 10 años el número de pobladores pertenecientes a este grupo etario crecerá en un $50 \%$ aproximadamente con respecto a la población actual. 
Tabla 9: Matriz de consistencia

\begin{tabular}{|c|c|c|c|c|c|}
\hline PROBLEMAS & OBJETIVOS & VARIABLES & METODOLOGÍA & CONCLUSIONES & $\begin{array}{c}\text { RECOMENDACI } \\
\text { ONES }\end{array}$ \\
\hline $\begin{array}{l}\text { Problema principal } \\
\text { ¿Está preparado el adulto } \\
\text { mayor para seguir } \\
\text { aportando } \\
\text { económicamente a la } \\
\text { sociedad peruana, y de ser } \\
\text { así, por qué lo hace? } \\
\text { Problemas secundarios }\end{array}$ & $\begin{array}{l}\text { Objetivo general } \\
\text { Describir la situación real del } \\
\text { adulto mayor en el Estado } \\
\text { Peruano y si éste se encuentra } \\
\text { preparado para soportar el } \\
\text { incremento de la esperanza de } \\
\text { vida en el Perú. } \\
\text { Objetivos específicos } \\
\text { 1. Describir la situación del adulto } \\
\text { mayor en el Estado Peruano } \\
\text { frente al incremento de la } \\
\text { esperanza de vida del Perú. } \\
\text { 2. Describir las consecuencias } \\
\text { económicas y sociales del } \\
\text { envejecimiento poblacional en el } \\
\text { Perú. } \\
\text { 3. Exponer las políticas de Estado } \\
\text { Peruano dirigidas al adulto } \\
\text { mayor. } \\
\text { 4. Revisar las tendencias de cultura } \\
\text { del envejecimiento productivo. }\end{array}$ & $\begin{array}{l}\text { - Situación del } \\
\text { adulto mayor. } \\
\text { - Consecuencias } \\
\text { económicas y } \\
\text { sociales del } \\
\text { envejecimiento. } \\
\text { - Políticas del } \\
\text { estado peruano } \\
\text { - Envejecimiento } \\
\text { productivo }\end{array}$ & 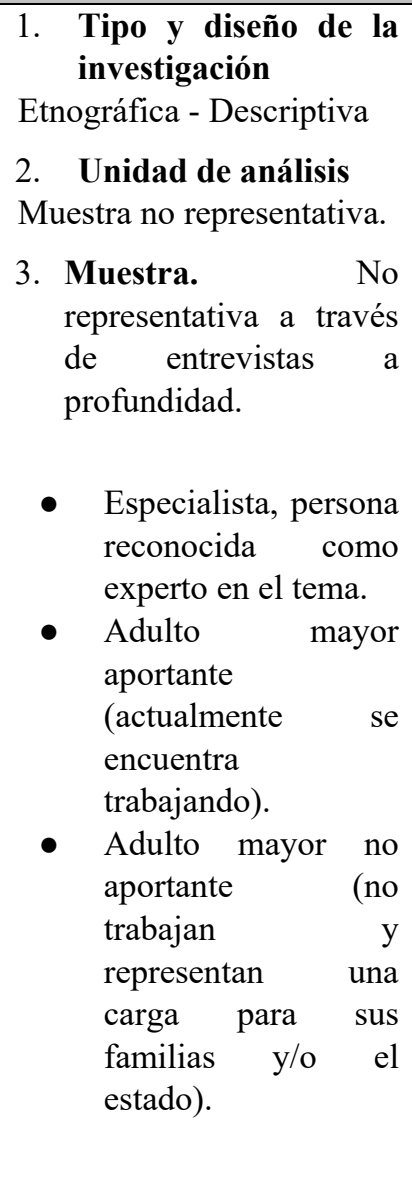 & $\begin{array}{l}\text { C1- El adulto mayor no se } \\
\text { encuentra preparado para seguir } \\
\text { aportando económicamente al } \\
\text { Estado Peruano y este no ha sido } \\
\text { capaz de enfrentar las demandas } \\
\text { actuales de la población adulta } \\
\text { mayor. } \\
\text { C2.- La capacidad física de los } \\
\text { adultos mayores es relevante para } \\
\text { minorizar las consecuencias } \\
\text { negativas del envejecimiento } \\
\text { C3.- No existe una política de } \\
\text { previsión de las personas en el } \\
\text { Perú, no planifican su vejez. } \\
\text { C3.- La implementación de las } \\
\text { políticas del Estado Peruano son } \\
\text { insuficientes. } \\
\text { C4.- El envejecimiento productivo } \\
\text { es posible. } \\
\text { C4.- Las personas mayores son } \\
\text { activos y su nivel educativo juega } \\
\text { un rol importante. }\end{array}$ & $\begin{array}{l}\text { R1- Mejorar de forma } \\
\text { integral el acceso a la } \\
\text { salud de los Adultos } \\
\text { mayores desde el enfoque } \\
\text { de salud de la OMS. } \\
\text { R2- Proponer diversos } \\
\text { mecanismos de aporte a un } \\
\text { sistema de pensiones. Que } \\
\text { se diversifique el acceso. } \\
\text { R3- Desarrollar una } \\
\text { cultura de valoración y } \\
\text { respeto a las personas } \\
\text { adultas mayores que } \\
\text { empodere a esta. } \\
\text { R4- Imponer en el Estado } \\
\text { Peruano la importancia de } \\
\text { la educación y su rol } \\
\text { protagónico en la vida, no } \\
\text { sólo de los mayores sino } \\
\text { en general de toda la } \\
\text { población en el Perú. }\end{array}$ \\
\hline
\end{tabular}




\section{BIBLIOGRAFIA}

Agulló Tomás Silveria. Mayores, actividad y trabajo en el proceso de envejecimiento y jubilación: Una aproximación psico-sociológica. Premio ex aequo de Investigación IMSERSO 2000. Instituto de Migraciones y Servicios Sociales. Primera Edición, 2001.

Albala C, Lebrão ML, León Díaz EM, Ham-Chande R, Hennis AJ, Palloni A, et al. Encuesta Salud, Bienestar y Envejecimiento (SABE): metodología de la encuesta y perfil de la población estudiada. Rev Panam Salud Pública. 2005;17 (5/6):307-22.

Bernal Noelia, Muñoz Angel, Perea Hugo, Tejada Johanna, Tuesta David. Una mirada al Sistema Privado de Pensiones. Diagnósticos y Propuestas. BBVA. Lima, 2018

Causapié, P., Balbontin, A., Porras, M., y Mateo, A. (Coord.) (2011). Libro blanco Envejecimiento Activo. Ministerio de Sanidad, Política Social e Igualdad. Secretaría General de Política Social y Consumo. Instituto de Mayores y Servicios Sociales (IMSERSO) Instituto Nacional de Estadística e Informática. Situación de la Población Adulta Mayor Abril-Mayo-Junio. Setiembre 2017.

CELADE. Centro Latinoamericano y Caribeño de Demografía. Encuentro latinoamericano y caribeño sobre las personas de edad. Publicación de las Naciones Unidas. Santiago de Chile, agosto de 2000

Congreso de la República del Perú. Ley 30490. Ley de la Persona Adulta Mayor. Junio del 2016. Lima, Perú. Recuperado de: http://busquedas.elperuano.pe/normaslegales/ley-dela-persona-adulta-mayor-ley-n-30490-1407242-1/

Convención Interamericana sobre la protección de los derechos humanos de las personas mayores (2018) Recuperado de: http://www.oas.org/es/sla/ddi/tratados_multilaterales_interamericanos_a-

70_derechos_humanos_personas_mayores.asp

Diario Ofícial del bicentenario el Peruano, artículo de Garay Rojas Karina. El 25\% de la población peruana será adulto mayor para el 2050, Lima, Junio del 2017. Recuperado de http://www.elperuano.com.pe/noticia-el-25-de-poblacion-peruana-sera-adultomayor-para-2050-56500.aspx

Diccionario de la Real Academia de la Lengua 2018. Recuperado de: http://dle.rae.es/?id=bnRGe0W

Dome C. y Erausquin C. (2016). Los docentes frente a las violencias en las escuelas: problemas complejos y escisión de las intervenciones. Memorias VIII Congreso Internacional de Investigación y Práctica Profesional en Psicología, (1) 89-93.

García Núñez, Luis. Desprotección en la Tercera Edad: ¿Estamos preparados para enfrentar el envejecimiento de la población? Pontificia Universidad Católica del Perú. Mayo, 2012

HelpAge International. Índice Global del Envejecimiento. Londres 2015 Recuperado de: http://www.helpage.org/silo/files/gawi-2015-resumen-ejecutivo-.pdf

Hernandez Sampieri, Roberto. Metodología de la Investigación. Mc Graw Hill Education. Sexta Edición. México D.F. 2014

Instituto Nacional de Estadística e Informática (INEI) (2017) Situación de la población adulta mayor. Abril - Mayor - Junio del 2017. Informe técnico no 3. Setiembre del 2017. Recuperado de: https://www.inei.gob.pe/media/MenuRecursivo/boletines/03-informetecnico-n03_adulto-abr-may-jun2017.pdf

Kaztman, Rubén (2000), Notas sobre la medición de la vulnerabilidad social Montevideo, Universidad Católica del Uruguay, Serie Documentos de Trabajo del IPES / Colección Aportes Conceptuales No2 
Kelly Annie. Fuerza laboral olvidada: Las personas mayores y su derecho al trabajo digno. HelpAge International. 2018

Milán León, Beatriz. Factores asociados a la participación laboral de los adultos mayores mexiquenses. Universidad Autónoma de la ciudad de México. 2010.

Ministerio de la Mujer y Poblaciones Vulnerables. Plan Nacional de Personas Adultas MayoresPLANPAM 2012-2017. Primera edición, julio 2013 Lima, Perú. Recuperado de: https://www.mimp.gob.pe/files/mimp/especializados/boletines_dvmpv/cuaderno_5_dv mpv.pdf

Ministerio de Sanidad, Servicios Sociales e Igualdad. Esperanzas de vida en España, 2014. Madrid, 2016. Recuperado de: https://www.msssi.gob.es/estadEstudios/estadisticas/inforRecopilaciones/ESPERANZ AS_DE_VIDA_ESP_2014.pdf

Miralles, Ivanna. Envejecimiento Productivo: Las contribuciones de las personas mayores desde la cotidianidad. N ${ }^{\circ}$ 16, vol. XV, Verano 2011, Santiago del Estero, Argentina

Miró G, Carmen A. Transición demográfica y envejecimiento demográfico. Centro de Estudios Latinoamericanos (CELA). Justo Arasomena, Panamá. 2003.

Moreno Moreno Julia. Mayores y Calidad de Vida. Universidad de Huelva. Potugal 2004

Olivera Javier y Clausen Jhonatan. Las características del adulto mayor peruano y las políticas de protección social. Facultad de Economía. Pontificia Universidad Católica del Perú. Lima 2014

Organización de las Naciones Unidas (ONU). La situación demográfica en el mundo 2014. Informe Conciso. New York 2014. Recuperado de: http://www.un.org/en/development/desa/population/publications/pdf/trends/Concise $\%$ 20Report\%20on\%20the\%20World\%20Population\%20Situation\%202014/es.pdf

Organización Mundial de la Salud (OMS) 2018. El Abrazo mundial, envejecimiento y ciclo de vida. Manual. Ginebra, Suiza 2001. Recuperado de: http://www.who.int/ageing/publications/alc_elmanual.pdf

Organización Mundial de la Salud. Informe mundial contra el envejecimiento y la salud. 1 Ginebra 27, Suiza. 2015. Recuperado de: http://apps.who.int/iris/bitstream/handle/10665/186466/9789240694873_spa.pdf;jsessi onid=7C914341645431F2AD333C5FAD018CD4?sequence $=1$

Organización Panamericana de la Salud (2018), OPS Recuperado de: https://www.un.org/development/desa/ageing/resources/international-year-of-olderpersons-1999/principles/los-principios-de-las-naciones-unidas-en-favor-de-laspersonas-de-edad.html

Prieto, María Belén Formiga, Nidia. Envejecimiento y Vulnerabilidad Sociodemográfica: El Caso de Bahía Blanca, Argentina.

Ramos Padilla Miguel Angel, Vera-Tudela Traverso David, Cárdenas García Santillán María Katia. Las personas adultas mayores y su contribución a la lucha contra la pobreza. Ministerio de la Mujer y Desarrollo Social. Lima, noviembre del 2009.

Rubio Olivares, Doris Yisell; Rivera Martínez, Lilliam; Borges Oquendo, Lourdes de la Caridad; González Crespo, Fausto Vladimir "Calidad de vida en el adulto mayor" VARONA, núm. 61, julio-diciembre, 2015, pp. 1-7 Universidad Pedagógica Enrique José Varona La Habana, Cuba.

Sarabia Cobo Carmen María. Envejecimiento exitoso y calidad de vida. Su papel en las teorías del envejecimiento. Revista Rincón Científico. Gerokomos .2009

Spitzer Chang Heidi. Propuesta de servicios de apoyo al uso del tiempo libre de adultos mayores de niveles socioeconómicos A2 Y B1 en Lima Metropolitana. Universidad Católica del Perú. 2011. Lima Perú. 
Suárez Rubén, Pescetto Claudia. Revi-sta Interamericana de Educación de Adultos. Sistemas de protección social para el adulto mayor en América Latina y el Caribe. Organización Panamericana de la Salud, Washington, D.C., Estados Unidos de América. 2005

United Nations, Department of Economic and Social Affairs, Population Division (2017). World Population Prospects: The 2017 Revision, Key Findings and Advance Tables. Working Paper No. ESA/P/WP/248.

Viveros Madariaga, Alberto. Envejecimiento y vejez en América Latina y el Caribe: Políticas públicas y las acciones de la sociedad. Centro Latinoamericano y Caribeño de Demografía (CELADE). Santiago de Chile. 2001

Zapata Arias Hernán. Adulto Mayor: Participación e Identidad. Red de Revistas Científicas de América Latina y el Caribe, España y Portugal. Sistema de Información Científica. Universidad Autónoma del Estado de México, 2015.

Zolotow, David. Los devenires de la ancianidad. Buenos Aires - México - Lumen Humanitas, 2002 


\section{ANEXOS}

\section{Bitácoras - Categoría especialistas}

\begin{tabular}{|c|c|c|}
\hline $\begin{array}{l}\text { Categorías/ } \\
\text { Entrevistados }\end{array}$ & \multicolumn{2}{|c|}{$\begin{array}{l}\text { presidente de la sociedad peruana de Geriatría y Gerontología del Perú. Jefe del servicio de Geriatría del Hospital } \\
\text { Central de aeronáutica Lima - Perú. }\end{array}$} \\
\hline Contexto Interno & \multicolumn{2}{|c|}{$\begin{array}{c}\text { El Doctor Vela nos recibió en las instalaciones del Hospital Central Geriátrico FAP luego que terminara sus consultas, lo } \\
\text { esperamos pues tenía paciente incluso que lo visitaban sin previa cita, le indicamos que solo demoraría media hora, se } \\
\text { muestra con predisposición, a gusto con la entrevista, le contamos como hemos llegado a él y se alegra de que su } \\
\text { nombre sea reconocido como una especialista en temas del adulto mayor. }\end{array}$} \\
\hline Contexto externo & \multicolumn{2}{|c|}{ La entrevista se llevó a cabo en las instalaciones del Hospital Central Geriátrico FAP - Surquillo. } \\
\hline \multirow{4}{*}{$\begin{array}{l}\text { Situación del adulto } \\
\text { mayor }\end{array}$} & $\begin{array}{l}\text { ¿Qué se sabe de la población adulta } \\
\text { mayor en el mundo? }\end{array}$ & $\begin{array}{l}\text { Transición demográfica, crecimiento de este grupo poblacional, inversión de } \\
\text { pirámide, doble carga de enfermedad y se hacen más vulnerables, hay adultos } \\
\text { mayores robustos y frágiles, hay diferencias grandes entre la población peruana } \\
\text { y la extranjera (España). } 1 \text { de cada } 4 \text { familias tiene a su cargo a } 01 \text { adulto mayor, } \\
\text { algunos colaboran con las actividades del hogar, el adulto mayor (robusto) que } \\
\text { aún es productivo. Fragilidad es un síndrome geriátrico (no buena salud, no } \\
\text { buena alimentación, etc.) sarcopenia (pérdida de masa muscular, fuerza). Es lo } \\
\text { que vuelve más vulnerables a los adultos mayores. Muchos de los adultos } \\
\text { llegan a ser el sustento de la familia. }\end{array}$ \\
\hline & $\begin{array}{l}\text { ¿Cuál considera usted que es el principal } \\
\text { problema que enfrenta el adulto mayor } \\
\text { en el Perú? }\end{array}$ & $\begin{array}{l}\text { En el Perú, aun la familia acoge a los adultos mayores, falta de aseguramiento, } \\
\text { acceso a la seguridad social, la salud es un tema medular en los adultos } \\
\text { mayores, saturación de sistema salud, poco acceso a los servicios. SIS sistema } \\
\text { con muchos problemas (corrupción, auditoria, acceso), los requisitos que } \\
\text { solicitan son los que limitan el acceso. Restricciones para seguros privados EPS } \\
\text { (incrementan con la edad). Acceso a una salud integral (sistema que no } \\
\text { funciona, un sistema que está copado y un sistema que no lo deja entrar). } \\
\text { Llevando los gastos a las familias. Con respecto a los derechos del adulto mayor } \\
\text { se ha avanzado, pero falta reglamentar para salvaguardar los derechos del } \\
\text { adulto. Mejorar calidad de atención en los servicios médicos. Leyes de atención } \\
\text { prioritaria, leyes que exoneran impuestos a esta población. Existen pocos } \\
\text { profesionales (geriatras) en el Perú. }\end{array}$ \\
\hline & $\begin{array}{l}\text { ¿Por qué se le podría considerar } \\
\text { población vulnerable? }\end{array}$ & Define a la población frágil (adultos mayores con más factores de riesgos). \\
\hline & $\begin{array}{l}\text { ¿Cuál es el aporte que realiza su } \\
\text { organización a la situación del adulto } \\
\text { mayor? }\end{array}$ & $\begin{array}{l}\text { Generar espacios académicos e investigación en geriatría y gerontología. } \\
\text { Apoyo y consejo al estado en temas que se le considera experto (en el congreso } \\
\text { y colegio médico). Educación al adulto mayor en temas de autocuidado de su } \\
\text { salud. }\end{array}$ \\
\hline \multirow{4}{*}{$\begin{array}{l}\text { Consecuencias } \\
\text { económicas y } \\
\text { sociales del } \\
\text { envejecimiento }\end{array}$} & $\begin{array}{l}\text { ¿Qué tendencia se está siguiendo en el } \\
\text { Mundo sobre la educación en los adultos } \\
\text { mayores? }\end{array}$ & $\begin{array}{l}\text { Los adultos no son valorados por todo lo que pueden aportar, el estereotipo } \\
\text { que tiene la sociedad está equivocado, lo representa como alguien que no se } \\
\text { vale por sí mismo. Existe un estereotipo social equivocado del viejito que no es } \\
\text { capaz por valerse por sí mismo. El fenómeno de viejísimo que es discriminatorio } \\
\text { con el adulto mayor. Son personas que merecen nuestro mejor respeto. } \\
\text { Tendencia de educación entre pares. Capacitación comunitaria en temas de } \\
\text { adulto mayor, autocuidado. }\end{array}$ \\
\hline & $\begin{array}{l}\text { OEA: " La persona mayor tiene derecho } \\
\text { a la educación en igualdad de } \\
\text { condiciones con otros sectores de la } \\
\text { población y sin discriminación" ¿Conoce } \\
\text { si en el país existe políticas al respecto? }\end{array}$ & $\begin{array}{l}\text { Hay programa de alfabetización para adultos mayores lo cual está a cargo del } \\
\text { MINEDU, conozco de los CIAMS; de terapistas ocupacionales. }\end{array}$ \\
\hline & $\begin{array}{l}\text { Le menciono que hay autores que } \\
\text { consideran a la fragilidad e inactividad de } \\
\text { los adultos mayores como un gran mito. } \\
\text { ¿Qué opina al respecto? }\end{array}$ & $\begin{array}{l}\text { Existen métodos para pronosticar la fragilidad de un adulto mayor. Los autores } \\
\text { que mencionan están anclados en el pasado. Existe la fragilidad incluso la pre- } \\
\text { fragilidad, la cual se puede medir. Fragilidad cognitiva. (Esta respuesta es nula } \\
\text { por que el doctor no entendió la pregunta o no se le supo plantear el problema) }\end{array}$ \\
\hline & $\begin{array}{l}\text { Los adultos mayores realizan diferentes } \\
\text { actividades no remuneradas, ¿qué se } \\
\text { sabe al respecto? ¿Sería posible que nos } \\
\text { brinde algunos ejemplos o cifras? }\end{array}$ & Hay adultos mayores robustos (activos), que realizan diversas actividades. \\
\hline
\end{tabular}




\begin{tabular}{|c|c|c|}
\hline & $\begin{array}{l}\text { Se sabe que los adultos mayores son un } \\
\text { grupo que se encuentra lejos de ser un } \\
\text { grupo homogéneo dado que es diferente } \\
\text { ser mayor de } 60 \text { y ser mujer o hombre, } \\
\text { con pensión o sin pensión, pobre, o de } \\
\text { extrema pobreza. Se trabaja calidad de } \\
\text { vida en base a estas diferencias. Conoce } \\
\text { de políticas públicas basadas en calidad } \\
\text { de vida }\end{array}$ & $\begin{array}{l}\text { Calidad de vida, frase mal usada por muchos. Calidad de vida está relacionada } \\
\text { con el acompañamiento en la vida del adulto mayor. Hay que acortar las } \\
\text { brechas generacionales, unificar a los nietos con los abuelos. Acercar al adulto } \\
\text { mayor al modelo más afectivo, que es respetado, de adulto robusto. La sociedad } \\
\text { castiga mientras más edad tienes menos acceso a las cosas. La imagen del } \\
\text { adulto mayor como un doctor respetado está dejando de ser así, ahora el } \\
\text { estereotipo es de un doctor joven. Los adultos mayores ya no compiten con } \\
\text { nadie, ya cumplió, sigue dando consejos, se mantiene. }\end{array}$ \\
\hline & $\begin{array}{l}\text { Siendo el envejecimiento poblacional un } \\
\text { éxito en las mejoras sanitarias. ¿Qué } \\
\text { retos visualiza usted va enfrentar el } \\
\text { Estado Peruano en los próximos años? }\end{array}$ & $\begin{array}{l}\text { El acceso al sistema de salud. La calidad del sistema de salud. La transición } \\
\text { epidemiológica, mirar a las enfermedades crónicas con cuidado. El enfoque de } \\
\text { salud pública va tener que ser el del médico de familia, para que los adultos } \\
\text { mayores no sean trasladados a los hospitales, que es el peor lugar para ello. } \\
\text { Organizar un sistema de redes. Necesitamos una decisión política que } \\
\text { magnifique de forma adecuada el gran problema que se viene. }\end{array}$ \\
\hline \multirow{6}{*}{$\begin{array}{l}\text { Políticas del Estado } \\
\quad \text { Peruano }\end{array}$} & $\begin{array}{l}\text { La Ley } 30490 \text {, la ley de los adultos } \\
\text { mayores se promulgó con el objetivo } \\
\text { principal de propiciar la integración del } \\
\text { adulto mayor al desarrollo social, } \\
\text { económico, político y cultural de la } \\
\text { nación. }\end{array}$ & $\begin{array}{l}\text { Tenemos una presión de alto poder de decisión, grupos etarios, jóvenes que } \\
\text { pujan por los espacios. Con una ley no se soluciona la problemática, sino un } \\
\text { cambio de cultura. Que se refleje en una ley, que convoque a la sociedad. La } \\
\text { ley debe estar discutida por expertos en el tema. No solo un ministerio se debe } \\
\text { encargar de los adultos mayores, sino todos los ministerios de forma global, } \\
\text { multisectorial. Propone el viceministerio del adulto mayor, porque el ministerio } \\
\text { de la mujer no tiene la capacidad resolutiva de atacar todos los problemas. } \\
\text { Identifica el principal problema del adulto mayor es la salud. En tanto más } \\
\text { selecciones poblaciones vulnerables más las segregas. }\end{array}$ \\
\hline & $\begin{array}{l}\text { ¿Cuáles son los programas dirigidos al } \\
\text { adulto mayor que se proponen a través } \\
\text { de la organización a la que usted } \\
\text { representa? }\end{array}$ & Investigación \\
\hline & $\begin{array}{l}\text { Tiene conocimientos de planes dirigidos } \\
\text { a personas adultas mayores en situación } \\
\text { de pobreza o pobreza extrema }\end{array}$ & $\begin{array}{l}\text { Pensión } 65 \text {. Lo único que ha hecho es dar un poco de dinero para que las } \\
\text { personas salgan de la extrema pobreza. }\end{array}$ \\
\hline & $\begin{array}{l}\text { ¿Considera al programa social pensión } \\
65 \text { como un éxito de políticas públicas? }\end{array}$ & El impacto que tiene es cortísimo \\
\hline & $\begin{array}{l}\text { Según INEI, solo el } 37.6 \% \text { de adultos } \\
\text { mayores en el Perú, está afiliado a un } \\
\text { sistema de pensiones. ¿Qué se está } \\
\text { haciendo al respecto? }\end{array}$ & Nada, solo un porcentaje tiene acceso a este beneficio. \\
\hline & $\begin{array}{l}\text { ¿Considera usted que el sistema de } \\
\text { salud y de acceso a estos, por parte del } \\
\text { adulto mayor es el óptimo? Se atrevería } \\
\text { a dar sugerencias de cambio bajo su } \\
\text { experiencia. }\end{array}$ & $\begin{array}{l}\text { No es el óptimo, porque no toda la población tiene acceso, se requieren } \\
\text { requisitos que la población adulta no cumple. Se deberían brindar facilidades } \\
\text { para el acceso a toda la población. }\end{array}$ \\
\hline \multirow{3}{*}{$\begin{array}{l}\text { Envejecimiento } \\
\text { Productivo }\end{array}$} & $\begin{array}{l}\text { Bajo su experiencia qué podría hacer } \\
\text { mejor el Estado Peruano para fomentar } \\
\text { el desarrollo social, económico de los } \\
\text { adultos mayores }\end{array}$ & $\begin{array}{l}\text { Leyes, programas presupuestados. Una política pública para que se destine } \\
\text { impuestos de ciertos productos para los programas que se planteen y se pueda } \\
\text { soportar el plan nacional. Porque de nada sirve el plan que no tiene } \\
\text { presupuesto }\end{array}$ \\
\hline & $\begin{array}{l}\text { ¿Cuál es el rol que forma la familia, no } \\
\text { solo para los adultos mayores } \\
\text { vulnerables, dependientes sino para } \\
\text { quienes buscan envejecer de forma } \\
\text { exitosa? }\end{array}$ & La familia es muy importante en el proceso de envejecimiento. \\
\hline & $\begin{array}{l}\text { ¿Cuáles son las últimas mejoras en el } \\
\text { sistema de salud que se hayan enfocado } \\
\text { al adulto mayor? }\end{array}$ & $\begin{array}{l}\text { Oportunidad de acceso al SIS, al menos conocen a cierto nivel, tienen acceso } \\
\text { a educación de enfermedades, vacunas. El adulto mayor es un turista en el } \\
\text { hospital, así como entra así sale. }\end{array}$ \\
\hline $\begin{array}{l}\text { Observaciones } \\
\text { después de la } \\
\text { entrevista }\end{array}$ & \multicolumn{2}{|c|}{$\begin{array}{l}\text { El entrevistado se muestra contento, se tomó una foto con nosotros y solicitó le mostremos los resultados de la } \\
\text { investigación, pues es un tema de su interés. }\end{array}$} \\
\hline $\begin{array}{l}\text { Percepción de la } \\
\text { entrevista }\end{array}$ & \multicolumn{2}{|c|}{$\begin{array}{c}\text { A nuestro parecer fue una entrevista muy productiva y a pesar de que se solicitó } 30 \text { minutos, el entrevistado se explayó } \\
\text { en las respuestas y al final la entrevista duro } 1 \text { hora. }\end{array}$} \\
\hline
\end{tabular}




\begin{tabular}{|c|c|c|}
\hline & & $\begin{array}{l}\text { Lic. Ysela J.P.R } \\
\text { Lic. En Psicología, especialista en Neuropsicología. Integrante } \\
\text { de la Asociación Peruana de Neuropsicología. Actualmente } \\
\text { ejecutando investigación neurocognitiva en el adulto mayor. }\end{array}$ \\
\hline Contexto Interno & & $\begin{array}{l}\text { La Licenciada nos cita en su consultorio en las Instalaciones de CAFAE, nos } \\
\text { cuenta de sus trabajos de investigación, y nos felicita por el tema escogido, } \\
\text { siente que hay mucho por hacer con la población adulto mayor y se ofrece para } \\
\text { ayudar en todo lo que sea necesario. }\end{array}$ \\
\hline Contexto externo & & $\begin{array}{l}\text { La entrevista se ejecutó en los consultorios del Centro Médico CAFAE-SE, San } \\
\text { Isidro. }\end{array}$ \\
\hline \multirow{4}{*}{$\begin{array}{l}\text { Situación del } \\
\text { adulto mayor }\end{array}$} & $\begin{array}{l}\text { ¿Qué se sabe de la población adulta } \\
\text { mayor en el mundo? }\end{array}$ & $\begin{array}{l}\text { La expectativa de vida ha variado, la población está crecimiento, Europa y Asia } \\
\text { preparados para el envejecimiento, en estos países cuentan con seguros es } \\
\text { aspectos de salud básica y también en la parte cognitiva, los adultos requieren } \\
\text { apoyo para mantener autonomía. Y el contraste con nuestro país, en Perú no } \\
\text { hay políticas claras, que nos lleven apalear el gran reto social que representa } \\
\text { el crecimiento de la población. La población adulto mayor no está dentro de las } \\
\text { políticas de estado }\end{array}$ \\
\hline & $\begin{array}{l}\text { ¿Cuál considera usted que es el principal } \\
\text { problema que enfrenta el adulto mayor en } \\
\text { el Perú? }\end{array}$ & $\begin{array}{l}\text { La falta de políticas de estado, el estado no debe preocuparse solo por la parte } \\
\text { económica, sino algo más integral, involucrando la salud física y mental. La } \\
\text { parte económica no cubre las necesidades del adulto mayor. El poder } \\
\text { ayudarlos a ser personas que puedan valerse por sí mismas. Las políticas no } \\
\text { han sido asesoradas por especialistas, para lograr que no sean dependientes } \\
\text { económicos. Falta de estimulación para un buen funcionamiento del cerebro. }\end{array}$ \\
\hline & $\begin{array}{l}\text { ¿Por qué se le podría considerar } \\
\text { población vulnerable? }\end{array}$ & $\begin{array}{l}\text { Porque no cuentan con asistencia del gobierno y familia para afrontar la } \\
\text { situación de riesgo a lo que están expuesto por la fragilidad de su salud. Son } \\
\text { personas que van a requerir apoyo, pero esto se puede cambiar tomando } \\
\text { medidas que no sean dependientes. }\end{array}$ \\
\hline & $\begin{array}{l}\text { ¿Cuál es el aporte que realiza su } \\
\text { organización a la situación del adulto } \\
\text { mayor? }\end{array}$ & $\begin{array}{l}\text { Investigaciones en el aspecto cognitivo. Promover actividades con el colegio } \\
\text { de psicólogos para realizar propuestas al gobierno. Pertenezco a la sociedad } \\
\text { de neuropsicología, promoviendo el cambio de las políticas del estado. }\end{array}$ \\
\hline \multirow{6}{*}{$\begin{array}{l}\text { Consecuencias } \\
\text { económicas y } \\
\text { sociales del } \\
\text { envejecimiento }\end{array}$} & $\begin{array}{l}\text { ¿Qué tendencia se está siguiendo en el } \\
\text { Mundo sobre la educación en los adultos } \\
\text { mayores? }\end{array}$ & $\begin{array}{l}\text { Entidades principalmente privadas presentan programas educativos a esta } \\
\text { población. Los programas de alfabetización no llegan a todos los adultos } \\
\text { mayores. Cambiar idea que un adulto mayor de } 60 \text { años no es capaz de } \\
\text { realizar actividades, los más aptos son las personas que han tenido mayor } \\
\text { tiempo de educación, su cerebro está apto y puede por tanto afrontar retos en } \\
\text { educación y trabajo. La capacidad cognitiva en personas de } 80,82 \text { años, } \\
\text { mantienen su capacidad y que incluso supera a los jóvenes. }\end{array}$ \\
\hline & $\begin{array}{l}\text { OEA: " La persona mayor tiene derecho a } \\
\text { la educación en igualdad de condiciones } \\
\text { con otros sectores de la población y sin } \\
\text { discriminación" ¿Conoce si en el país } \\
\text { existe políticas al respecto? }\end{array}$ & No conoce políticas al respecto \\
\hline & $\begin{array}{l}\text { Le menciono que hay autores que } \\
\text { consideran a la fragilidad e inactividad de } \\
\text { los adultos mayores como un gran mito. } \\
\text { ¿Qué opina al respecto? }\end{array}$ & $\begin{array}{l}\text { Está de acuerdo, pero está mal enfocado. Los cambios o deben ser radicales } \\
\text { porque afecta la parte emocional y cognitiva, pues de esa forma se perjudica } \\
\text { a los adultos llevándolos a la depresión. En el caso de los educadores, que } \\
\text { investigan, preparan su clase dictan a pasar solo a estar en su casa, cambiar } \\
\text { el nivel de actividad a solo estar en casa, no les ayuda sino los perjudica. } \\
\text { Desde el punto de vista cognitiva no los ayuda, se usa menos. }\end{array}$ \\
\hline & $\begin{array}{l}\text { Los adultos mayores realizan diferentes } \\
\text { actividades no remuneradas, ¿qué se } \\
\text { sabe al respecto? ¿Sería posible que nos } \\
\text { brinde algunos ejemplos o cifras? }\end{array}$ & $\begin{array}{l}\text { Realizan actividades de voluntariado en hospitales, municipalidades, } \\
\text { actividades religiosas o eventos sociales no remunerados. Contribuyen } \\
\text { buscando mantenerse activos. }\end{array}$ \\
\hline & $\begin{array}{l}\text { Se sabe que los adultos mayores son un } \\
\text { grupo que se encuentra lejos de ser un } \\
\text { grupo homogéneo dado que es diferente } \\
\text { ser mayor de } 60 \text { y ser mujer o hombre, } \\
\text { con pensión o sin pensión, pobre, o de } \\
\text { extrema pobreza. Se trabaja calidad de } \\
\text { vida en base a estas diferencias. Conoce } \\
\text { de políticas públicas basadas en calidad } \\
\text { de vida }\end{array}$ & $\begin{array}{l}\text { No conoce mucho, sabe de pensión } 65 \text { pero que no beneficia a todos, la } \\
\text { mayoría de la población no cuenta con seguro o beneficios por lo tanto no tiene } \\
\text { la calidad de vida que merece. }\end{array}$ \\
\hline & $\begin{array}{l}\text { Siendo el envejecimiento poblacional un } \\
\text { éxito en las mejoras sanitarias. ¿Qué } \\
\text { retos visualiza usted va enfrentar el } \\
\text { Estado Peruano en los próximos años? }\end{array}$ & $\begin{array}{l}\text { El reto inicia conociendo la realidad. No solo a nivel económico sino de una } \\
\text { forma más íntegra (salud). Ver a los adultos como un potencial para que } \\
\text { generen sus propios recursos hasta donde les sea posible. Se debe solicitar la } \\
\text { información de especialistas en este aspecto para ver la mejor forma de ayudar } \\
\text { al adulto mayor. }\end{array}$ \\
\hline
\end{tabular}




\begin{tabular}{|c|c|c|}
\hline \multirow{6}{*}{$\begin{array}{l}\text { Políticas del } \\
\text { Estado Peruano }\end{array}$} & $\begin{array}{l}\text { La Ley } 30490 \text {, la ley de los adultos } \\
\text { mayores se promulgó con el objetivo } \\
\text { principal de propiciar la integración del } \\
\text { adulto mayor al desarrollo social, } \\
\text { económico, político y cultural de la } \\
\text { nación. }\end{array}$ & Textualmente la ley suena bien, pero la realidad no lo respalda. No se visualiza. \\
\hline & $\begin{array}{l}\text { ¿Cuáles son los programas dirigidos al } \\
\text { adulto mayor que se proponen a través } \\
\text { de la organización a la que usted } \\
\text { representa? }\end{array}$ & $\begin{array}{l}\text { Charlas de orientación, sensibilización a las personas. Concientizar a la familia } \\
\text { y jóvenes de la importancia del contacto con los adultos mayores y } \\
\text { mantenerlos al día. Evaluación de salud mental para detectar el deterioro } \\
\text { cognitivo. }\end{array}$ \\
\hline & $\begin{array}{l}\text { Tiene conocimientos de planes dirigidos } \\
\text { a personas adultas mayores en situación } \\
\text { de pobreza o pobreza extrema }\end{array}$ & Pensión 65. \\
\hline & $\begin{array}{l}\text { ¿Considera al programa social pensión } \\
65 \text { como un éxito de políticas públicas? }\end{array}$ & $\begin{array}{l}\text { No podría catalogar como éxito, de alguna manera ayudo a personas de muy } \\
\text { pocos recursos, además solo impacto en poca población y en el aspecto } \\
\text { económico. }\end{array}$ \\
\hline & $\begin{array}{l}\text { Según INEI, solo el } 37.6 \% \text { de adultos } \\
\text { mayores en el Perú, está afiliado a un } \\
\text { sistema de pensiones. ¿Qué se está } \\
\text { haciendo al respecto? }\end{array}$ & $\begin{array}{l}\text { ¿Crees que los } 60 \text { años es la correcta para jubilarse? El estado no debería } \\
\text { poner un límite, porque hay muchos adultos que superan los } 60 \text { años pueden } \\
\text { producir, por ejemplo, nuestro premio nobel Mario Vargas Llosa. Temas } \\
\text { muchas personas que pueden demostrar capacidad, ponerles un límite es } \\
\text { influenciar de forma negativa en sus emociones. Debería haber instrumentos } \\
\text { y medidas para identificar poder medir el nivel de productividad. }\end{array}$ \\
\hline & $\begin{array}{l}\text { ¿Considera usted que el sistema de } \\
\text { salud y de acceso a estos, por parte del } \\
\text { adulto mayor es el óptimo? Se atrevería } \\
\text { a dar sugerencias de cambio bajo su } \\
\text { experiencia. }\end{array}$ & $\begin{array}{l}\text { Sistema de salud complicado y más aún los adultos mayores, el acceso no es } \\
\text { el adecuado puesto que pone en riesgo su salud, se debe priorizar asistencia } \\
\text { a domicilio. No hay evaluación para ver funcionamiento general del adulto } \\
\text { mayor para crear estrategias de contingencia. Falta de apertura por parte de } \\
\text { esta para convocar especialistas en el tema y mejorar propuestas. }\end{array}$ \\
\hline \multirow{3}{*}{$\begin{array}{l}\text { Envejecimiento } \\
\text { Productivo }\end{array}$} & $\begin{array}{l}\text { Bajo su experiencia qué podría hacer } \\
\text { mejor el Estado Peruano para fomentar el } \\
\text { desarrollo social, económico de los } \\
\text { adultos mayores }\end{array}$ & $\begin{array}{l}\text { Programas para desarrollar habilidades en el adulto para que ellos sean } \\
\text { independientes. }\end{array}$ \\
\hline & $\begin{array}{l}\text { ¿Cuál es el rol que forma la familia, no } \\
\text { solo para los adultos mayores } \\
\text { vulnerables, dependientes sino para } \\
\text { quienes buscan envejecer de forma } \\
\text { exitosa? }\end{array}$ & $\begin{array}{l}\text { La familia debe tomar más conciencia sobre la condición del adulto mayor, la } \\
\text { familia desconoce que solo es el aspecto económico es importante, pero la } \\
\text { importancia de otros aspectos (emocionales) falta educación en las familias. } \\
\text { No conocen mucho la parte cognitiva, hay que educarse en tratar al adulto } \\
\text { mayor, pero enfocados en el potencial y no en las debilidades. Tenerlos } \\
\text { relegados hace que se vayan deteriorando. }\end{array}$ \\
\hline & $\begin{array}{l}\text { ¿Cuáles son las últimas mejoras en el } \\
\text { sistema de salud que se hayan enfocado } \\
\text { al adulto mayor? }\end{array}$ & $\begin{array}{l}\text { En el ámbito neuropsicológico la información a la población, educar a los } \\
\text { futuros psicólogos. Charlas sobre factores de riesgo. }\end{array}$ \\
\hline $\begin{array}{l}\text { Observaciones } \\
\text { después de la } \\
\text { entrevista }\end{array}$ & & $\begin{array}{l}\text { La entrevistada se muestra cómoda y relajada, agradeció que se le considerara } \\
\text { para esta investigación y que sería interesante se pueda compartir el resultado } \\
\text { al final pues ella se encuentra haciendo una investigación en esta población } \\
\text { adulta para su doctorado. }\end{array}$ \\
\hline $\begin{array}{l}\text { Percepción de la } \\
\text { entrevista }\end{array}$ & & $\begin{array}{l}\text { La entrevista fue muy productiva, principalmente en temas de aprendizaje y/o } \\
\text { productividad de la población investigada. }\end{array}$ \\
\hline
\end{tabular}




\begin{tabular}{|c|c|c|}
\hline & & $\begin{array}{l}\text { Mg. Elia Luna del Valle directora de la Dirección del Adulto } \\
\text { Mayor del Ministerio de la Mujer y Poblaciones Vulnerables }\end{array}$ \\
\hline Contexto Interno & & $\begin{array}{l}\text { Se visita a la directora sin tener cita previa, pues en coordinaciones con su } \\
\text { secretaria no se llega a un acuerdo. En recepción la directora accede a pesar } \\
\text { de encontrarse celebrando su cumpleaños con sus compañeros de oficina } \\
\text { Informa solo cuenta con } 20 \text { minutos pues debe salir a una capacitación que se } \\
\text { le va dictar. }\end{array}$ \\
\hline Contexto externo & & $\begin{array}{l}\text { La entrevista se realizó en la oficina del Adulto Mayor del Ministerio de La } \\
\text { Mujer, en el despacho privado de la directora, se encontraban en el área } \\
\text { celebrando el cumpleaños de la directora. }\end{array}$ \\
\hline \multirow{4}{*}{$\begin{array}{l}\text { Situación del } \\
\text { adulto mayor }\end{array}$} & $\begin{array}{l}\text { ¿Qué se sabe de la población adulta } \\
\text { mayor en el mundo? }\end{array}$ & $\begin{array}{l}\text { El proceso de envejecimiento es variado en el mundo. Hay poblaciones que } \\
\text { han enviado rápidamente. El Perú se encuentra en un proceso moderado de } \\
\text { transición al envejecimiento. En mis } 20 \text { de años de experiencia hemos pasado } \\
\text { de } 1 \text { millón a } 3 \text { millones de peruanos. }\end{array}$ \\
\hline & $\begin{array}{l}\text { ¿Cuál considera usted que es el principal } \\
\text { problema que enfrenta el adulto mayor en } \\
\text { el Perú? }\end{array}$ & $\begin{array}{l}\text { Problemática es basta, compleja y diversa. Desde mi experiencia los adultos } \\
\text { mayores no acceden a una política previsional. Son una carga muy fuerte para } \\
\text { el estado. No se han jubilado y ya no lo harán. Que no se jubilan }\end{array}$ \\
\hline & $\begin{array}{l}\text { ¿Por qué se le podría considerar } \\
\text { población vulnerable? }\end{array}$ & $\begin{array}{l}\text { No gozan de jubilación, ni atención médica adecuada. EI SIS es amplio y no } \\
\text { llega al nivel de atención personalizada y particularizada. Los adultos mayores } \\
\text { trabajan, y cuando no trabajan no comen. }\end{array}$ \\
\hline & $\begin{array}{l}\text { ¿Cuál es el aporte que realiza su } \\
\text { organización a la situación del adulto } \\
\text { mayor? }\end{array}$ & $\begin{array}{l}\text { Somos un ente estrictamente normativo. Contamos con una política nacional, } \\
\text { desde el } 2011 \text {, se tienen los grandes lineamientos y hoja de ruta del tema, se } \\
\text { describe la problemática. Se tienen planes que se deben cumplirse en el nive } \\
\text { central, regional y local. Planes quinquenales que tienen metas concretas que } \\
\text { deben resolverse. }\end{array}$ \\
\hline \multirow{5}{*}{$\begin{array}{l}\text { Consecuencias } \\
\text { económicas y } \\
\text { sociales del } \\
\text { envejecimiento }\end{array}$} & $\begin{array}{l}\text { ¿Qué tendencia se está siguiendo en el } \\
\text { Mundo sobre la educación en los adultos } \\
\text { mayores? }\end{array}$ & \\
\hline & $\begin{array}{l}\text { OEA: " La persona mayor tiene derecho a } \\
\text { la educación en igualdad de condiciones } \\
\text { con otros sectores de la población y sin } \\
\text { discriminación" ¿Conoce si en el país } \\
\text { existe políticas al respecto? }\end{array}$ & $\begin{array}{l}\text { Tenemos casi un } 20 \% \text { de personas adultas mayores analfabetas, nos hacen } \\
\text { falta espacios para alfabetizar. No hay discriminación, pero también existe } \\
\text { también analfabetos funcionales que solo tienen inicial. Es necesario fortalecer } \\
\text { las políticas educativas para que las personas adultas mayores accedan a una } \\
\text { política educativa especializado ahora inexistente. }\end{array}$ \\
\hline & $\begin{array}{l}\text { Le menciono que hay autores que } \\
\text { consideran a la fragilidad e inactividad de } \\
\text { los adultos mayores como un gran mito. } \\
\text { ¿Qué opina al respecto? }\end{array}$ & $\begin{array}{l}\text { Habla de su mamá de } 91 \text { años. La edad trae cambios. No somos una población } \\
\text { vulnerable a per se, pero depende de las condiciones de vida en particular. Los } \\
\text { hábitos crean. Hay personas que somos mayores y podemos trabajar. Pone e } \\
\text { ejemplo de una nadadora olímpica de adulta mayor. Depende del desarrollo } \\
\text { de nuestra vida para tener una vejez saludable. Habla de una nadadora } \\
\text { olímpica, adulta mayor, peruana. Hay pico de vulnerabilidad, los niños de } 0-5 \\
\text { años lo son, las mujeres gestantes lo son. Proponemos el envejecimiento } \\
\text { Digno, activo, productivo y saludable. Debemos tener una vida activa desde el } \\
\text { inicio, y con buena alimentación. }\end{array}$ \\
\hline & $\begin{array}{l}\text { Los adultos mayores realizan diferentes } \\
\text { actividades no remuneradas, ¿qué se } \\
\text { sabe al respecto? ¿Sería posible que nos } \\
\text { brinde algunos ejemplos o cifras? }\end{array}$ & \\
\hline & $\begin{array}{l}\text { Se sabe que los adultos mayores son un } \\
\text { grupo que se encuentra lejos de ser un } \\
\text { grupo homogéneo dado que es diferente } \\
\text { ser mayor de } 60 \text { y ser mujer o hombre, } \\
\text { con pensión o sin pensión, pobre, o de } \\
\text { extrema pobreza. Se trabaja calidad de } \\
\text { vida en base a estas diferencias. Conoce } \\
\text { de políticas públicas basadas en calidad } \\
\text { de vida }\end{array}$ & $\begin{array}{l}\text { Nuestras primeras políticas eran urbanas citadinas, limeñas y las actuales } \\
\text { tienen una connotación rural. Estamos actualizando nuestras políticas en Base } \\
\text { a la política CEPLAN que se ha dictado este año, en diferencias porque } \\
\text { actualmente no aluden a personas que tienen cuidados paliativos, diversidad } \\
\text { sexual, privadas de su libertad, se ha propuesto desarrollar políticas que } \\
\text { atiendan a poblaciones más vulnerables }\end{array}$ \\
\hline
\end{tabular}




\begin{tabular}{|c|c|c|}
\hline & $\begin{array}{l}\text { Siendo el envejecimiento poblacional un } \\
\text { éxito en las mejoras sanitarias. ¿Qué } \\
\text { retos visualiza usted va enfrentar el } \\
\text { Estado Peruano en los próximos años? }\end{array}$ & $\begin{array}{l}\text { Tenemos en mente que el país suscriba, Convención Interamericana de los } \\
\text { derechos de las personas adultas mayores, una convención de alto nivel, un } \\
\text { documento de alto nivel, que será para el Perú la única herramienta de política } \\
\text { internacional con efecto vinculante en el Perú. Va permitir acceder en general } \\
\text { a todos los espacios, ya que es responsabilidad de todos los espacios, no solo } \\
\text { de un área y de las propias personas mayores. }\end{array}$ \\
\hline \multirow{6}{*}{$\begin{array}{l}\text { Políticas del } \\
\text { Estado Peruano }\end{array}$} & $\begin{array}{l}\text { La Ley } 30490 \text {, la ley de los adultos } \\
\text { mayores se promulgó con el objetivo } \\
\text { principal de propiciar la integración del } \\
\text { adulto mayor al desarrollo social, } \\
\text { económico, político y cultural de la } \\
\text { nación. }\end{array}$ & $\begin{array}{l}\text { El reglamento de la Ley se encuentra en la PCM, a un minuto de ser aprobado. } \\
\text { La ley debería estar gravada en la mente de cada persona adulta mayor para } \\
\text { reclamar y lograr conquistas sociales. La ley no es conocida. Ninguna ley logra } \\
\text { el envejeciente adecuada, es un mecanismo de presión a las autoridades. }\end{array}$ \\
\hline & $\begin{array}{l}\text { ¿Cuáles son los programas dirigidos al } \\
\text { adulto mayor que se proponen a través } \\
\text { de la organización a la que usted } \\
\text { representa? }\end{array}$ & $\begin{array}{l}\text { No tenemos programas, somos un ente que dicta la política pública para el } \\
\text { sector que luego se aterrizan en los planes. Lo que nosotros definamos y } \\
\text { discutimos se convierten en programas. }\end{array}$ \\
\hline & $\begin{array}{l}\text { Tiene conocimientos de planes dirigidos } \\
\text { a personas adultas mayores en situación } \\
\text { de pobreza o pobreza extrema }\end{array}$ & El Midis trabaja con ese sector de la población como Pensión 65. \\
\hline & $\begin{array}{l}\text { ¿Considera al programa social pensión } \\
65 \text { como un éxito de políticas públicas? }\end{array}$ & $\begin{array}{l}\text { Pensión } 65 \text { es un programa de transferencia económica. Consideramos que } \\
\text { las personas adultas mayores deben acceder a una política previsional para } \\
\text { las personas adultas mayores y las que no pudieron acceder a esto merecen } \\
\text { una subvención del estado. }\end{array}$ \\
\hline & $\begin{array}{l}\text { Según INEI, solo el } 37.6 \% \text { de adultos } \\
\text { mayores en el Perú, está afiliado a un } \\
\text { sistema de pensiones. ¿Qué se está } \\
\text { haciendo al respecto? }\end{array}$ & $\begin{array}{l}\text { Se le ha presentado a la actual ministra la necesidad de tener una política en } \\
\text { ese entorno. Ya tenemos una propuesta que debió ser aprobada en el } 2009 \text {, y } \\
\text { queremos retomarla. En el } 2021 \text { buscamos tener una política en base. }\end{array}$ \\
\hline & $\begin{array}{l}\text { ¿Considera usted que el sistema de salud } \\
\text { y de acceso a estos, por parte del adulto } \\
\text { mayor es el óptimo? Se atrevería a dar } \\
\begin{array}{l}\text { sugerencias de cambio bajo su } \\
\text { experiencia. }\end{array}\end{array}$ & $\begin{array}{l}\text { EI SIS tiene una gran cobertura para los adultos mayores, no les cubre en la } \\
\text { totalidad ni en la cabalidad de sus necesidades. Al menos tiene una atención } \\
\text { primaria. El problema parte desde mucho atrás de la edad del adulto mayor, } \\
\text { parte de mucho atrás desde un trabajo digno para tener una jubilación digna } \\
\text { sino tenemos políticas de parche. }\end{array}$ \\
\hline \multirow{3}{*}{$\begin{array}{l}\text { Envejecimiento } \\
\text { Productivo }\end{array}$} & $\begin{array}{l}\text { Bajo su experiencia qué podría hacer } \\
\text { mejor el Estado Peruano para fomentar el } \\
\text { desarrollo social, económico de los } \\
\text { adultos mayores }\end{array}$ & $\begin{array}{l}\text { Empezar a trabajar desde que somos niños. Si logramos que los adultos } \\
\text { mayores del futuro hoy día fueran técnicos profesionales de éxito, serían } \\
\text { adultos mayores de éxito. }\end{array}$ \\
\hline & $\begin{array}{l}\text { ¿Cuál es el rol que forma la familia, no } \\
\text { solo para los adultos mayores } \\
\text { vulnerables, dependientes sino para } \\
\text { quienes buscan envejecer de forma } \\
\text { exitosa? }\end{array}$ & $\begin{array}{l}\text { Hablamos de las familias, porque tenemos diferentes tipos de familias. Las } \\
\text { familias están en crisis, y al no ser fuertes, sus miembros son más vulnerables. } \\
\text { Es necesario repensar las familias como un primer espacio de socialización sin } \\
\text { cargarles la total asistencia y cuidado de los adultos mayores o personas } \\
\text { discapacitados, sino podrían pasar de ser pobres a extremadamente pobres. }\end{array}$ \\
\hline & $\begin{array}{l}\text { ¿Cuáles son las últimas mejoras en el } \\
\text { sistema de salud que se hayan enfocado } \\
\text { al adulto mayor? }\end{array}$ & $\begin{array}{l}\text { La ampliación de cobertura al cáncer. La creación del SIS. La salud debe ser } \\
\text { un tema preventiva, cuando estoy sano debo ir a las instancias necesarias para } \\
\text { seguir estando sanos. Debemos tener un control similar a la del niño sano. No } \\
\text { tenemos cultura de prevención y debemos fomentarla. }\end{array}$ \\
\hline $\begin{array}{l}\text { Observaciones } \\
\text { después de la } \\
\text { entrevista }\end{array}$ & & $\begin{array}{l}\text { La directora se muestra contenta, vuelve a sus actividades, nos brinda } \\
\text { consejos y nos da material para seguir profundizando en nuestra investigación. } \\
\text { Nos felicita en reiteradas veces por la tesis y se ofrece ayudar en todo lo } \\
\text { posible. }\end{array}$ \\
\hline $\begin{array}{l}\text { Percepción de la } \\
\text { entrevista }\end{array}$ & & $\begin{array}{l}\text { La directora se muestra segura, se le reconoce que maneja el tema, que } \\
\text { además lo comprende y lo vive en carne propia. Su destreza para tocar en } \\
\text { todos los niveles el tema, nos da claridad en varios temas que debemos volver } \\
\text { a revisar. }\end{array}$ \\
\hline
\end{tabular}




\begin{tabular}{|c|c|c|}
\hline & & $\begin{array}{l}\text { Dra. Rosa Mercedes Rincón Huamán- directora del Centro de } \\
\text { Atención Residencial Gerento Geriátrico Ignacia Rodulfo Viuda } \\
\text { de Canevaro }\end{array}$ \\
\hline Contexto Interno & & $\begin{array}{l}\text { Conseguir una entrevista con la directora fue complicado, sentimos mucha } \\
\text { burocracia y dificultad para llegar a ella, rechazo en un inicio por parte de su } \\
\text { secretaria y luego del coordinador del centro, pero luego al hablar directamente } \\
\text { con ella y explicarle la finalidad de la entrevista, así como de las personas que } \\
\text { están participando, accede a recibirnos }\end{array}$ \\
\hline Contexto externo & & $\begin{array}{l}\text { La entrevista se realiza en la oficina de la directora, en las instalaciones del } \\
\text { Centro Canevaro en el Rímac }\end{array}$ \\
\hline \multirow{4}{*}{$\begin{array}{l}\text { Situación del } \\
\text { adulto mayor }\end{array}$} & $\begin{array}{l}\text { ¿Qué se sabe de la población adulta } \\
\text { mayor en el mundo? }\end{array}$ & $\begin{array}{l}\text { La población se encuentra en incremento, para el } 2030 \text { se estaba hablando de } \\
\text { contar con una base diferente. El incremento va del } 20 \text { al } 30 \% \text { a diferencia de } \\
\text { décadas anteriores en que el aumento era el } 10 \%\end{array}$ \\
\hline & $\begin{array}{l}\text { ¿Cuál considera usted que es el principal } \\
\text { problema que enfrenta el adulto mayor en } \\
\text { el Perú? }\end{array}$ & $\begin{array}{l}\text { No sabe envejecer. Una persona en el Perú nunca planifica su vejez. Planifica } \\
\text { la universidad, casarte, tener hijos, planeamos la vida de los hijos. Cuando } \\
\text { llegas a la etapa de jubilación no lo haz planeado. }\end{array}$ \\
\hline & $\begin{array}{l}\text { ¿Por qué se le podría considerar } \\
\text { población vulnerable? }\end{array}$ & $\begin{array}{l}\text { Es un tema que los políticos utilizan. La vejez si es bien llevada no tiene que } \\
\text { ser vulnerable. Se presenta como médico, y habla de la fragilidad, de la } \\
\text { funcionalidad. Un anciano tiene tendencia a ser frágil. Pone el ejemplo de una } \\
\text { anciana que va al mercado y se resbala por culpa del envejecimiento. }\end{array}$ \\
\hline & $\begin{array}{l}\text { ¿Cuál es el aporte que realiza su } \\
\text { organización a la situación del adulto } \\
\text { mayor? }\end{array}$ & $\begin{array}{l}\text { El aporte es grande, no pertenecemos al estado. Somos una institución que se } \\
\text { autogestioma, pertenecemos a la beneficencia que además cuenta con otras } \\
\text { instituciones, comedores, hogar de la madre. Y en cuanto al adulto mayor, } \\
\text { nosotros tenemos } 500 \text { adultos mayores. que nos solo tienen un lugar para vivir } \\
\text { sino para morir de la mejor manera. Además de la Hotelería, tenemos } \\
\text { profesionales de la salud, enfermeras, cuidadoras, psiquiatras. El aspecto } \\
\text { logístico. Habla de la historia de la beneficencia, que tiene adultos mayores } \\
\text { trabajando. }\end{array}$ \\
\hline \multirow{6}{*}{$\begin{array}{l}\text { Consecuencias } \\
\text { económicas y } \\
\text { sociales del } \\
\text { envejecimiento }\end{array}$} & $\begin{array}{l}\text { ¿Qué tendencia se está siguiendo en el } \\
\text { Mundo sobre la educación en los adultos } \\
\text { mayores? }\end{array}$ & $\begin{array}{l}\text { En Europa se destaca la evaluación del adulto mayor. La tecnología ha } \\
\text { ayudado a integrar a los adultos. Aquí en el Perú menciona que la universidad } \\
\text { católica tiene un programa para adultos mayores }\end{array}$ \\
\hline & $\begin{array}{l}\text { OEA: " La persona mayor tiene derecho a } \\
\text { la educación en igualdad de condiciones } \\
\text { con otros sectores de la población y sin } \\
\text { discriminación" ¿Conoce si en el país } \\
\text { existe políticas al respecto? }\end{array}$ & \\
\hline & $\begin{array}{l}\text { Le menciono que hay autores que } \\
\text { consideran a la fragilidad e inactividad de } \\
\text { los adultos mayores como un gran mito. } \\
\text { ¿Qué opina al respecto? }\end{array}$ & $\begin{array}{l}\text { Que no son geriatras. Confundimos términos, hay que separar actividad de } \\
\text { fragilidad. Hace la comparación con un niño que si puede cuidarse solo durante } \\
\text { cierto tiempo. Medir la capacidad del adulto mayor se mide en la funcionalidad, } \\
\text { desde sus actividades diarias, funcionales. (bañarse, cambiarse, ir al baño) } \\
\text { llustra con un ejemplo. }\end{array}$ \\
\hline & $\begin{array}{l}\text { Los adultos mayores realizan diferentes } \\
\text { actividades no remuneradas, ¿qué se } \\
\text { sabe al respecto? ¿Sería posible que nos } \\
\text { brinde algunos ejemplos o cifras? }\end{array}$ & Existe, y deberían medirse. \\
\hline & $\begin{array}{l}\text { Se sabe que los adultos mayores son un } \\
\text { grupo que se encuentra lejos de ser un } \\
\text { grupo homogéneo dado que es diferente } \\
\text { ser mayor de } 60 \text { y ser mujer o hombre, } \\
\text { con pensión o sin pensión, pobre, o de } \\
\text { extrema pobreza. Se trabaja calidad de } \\
\text { vida en base a estas diferencias. Conoce } \\
\text { de políticas públicas basadas en calidad } \\
\text { de vida }\end{array}$ & $\begin{array}{l}\text { Se hizo se conoce el estudio SABE, determina que las mujeres envejecen más } \\
\text { rápido. Actualmente la mujer se empodera y ahora ellas reciben pensión, que } \\
\text { incluso envejecerán solas, porque el hecho de tener una profesión. En el Perú } \\
\text { no hay. }\end{array}$ \\
\hline & $\begin{array}{l}\text { Siendo el envejecimiento poblacional un } \\
\text { éxito en las mejoras sanitarias. ¿Qué } \\
\text { retos visualiza usted va enfrentar el } \\
\text { Estado Peruano en los próximos años? }\end{array}$ & $\begin{array}{l}\text { En el caso de salud, las enfermedades en el adulto mayor. No hay } \\
\text { presupuestos, con políticas que nos lleven a la prevención. Cuando un adulto } \\
\text { mayor se enferma no tiene una sola patología sino varias. Pone varios } \\
\text { ejemplos de complicaciones que pueden tener los adultos mayores. Conseguir } \\
\text { una cita es una crueldad. Lo que se le avecina al estado, es terrible. }\end{array}$ \\
\hline
\end{tabular}




\begin{tabular}{|c|c|c|}
\hline \multirow{6}{*}{$\begin{array}{l}\text { Políticas del } \\
\text { Estado Peruano }\end{array}$} & $\begin{array}{l}\text { La Ley } 30490 \text {, la ley de los adultos } \\
\text { mayores se promulgó con el objetivo } \\
\text { principal de propiciar la integración del } \\
\text { adulto mayor al desarrollo social, } \\
\text { económico, político y cultural de la } \\
\text { nación. }\end{array}$ & $\begin{array}{l}\text { Tiene muy buena intención, pero le falta mejorar mucho. Como procurar } \\
\text { proteger del adulto mayor cuando intentan. Solo dos instituciones han logrado } \\
\text { calificar a la acreditación. }\end{array}$ \\
\hline & $\begin{array}{l}\text { ¿Cuáles son los programas dirigidos al } \\
\text { adulto mayor que se proponen a través } \\
\text { de la organización a la que usted } \\
\text { representa? }\end{array}$ & $\begin{array}{l}\text { Nosotros estamos teniendo como programa propiciar al envejecimiento activo. } \\
\text { Desde la actividad física, mejoramiento de la parte mental. }\end{array}$ \\
\hline & $\begin{array}{l}\text { Tiene conocimientos de planes dirigidos } \\
\text { a personas adultas mayores en situación } \\
\text { de pobreza o pobreza extrema }\end{array}$ & Plan de la Sociedad de la Beneficencia de Lima \\
\hline & $\begin{array}{l}\text { ¿Considera al programa social pensión } \\
65 \text { como un éxito de políticas públicas? }\end{array}$ & $\begin{array}{l}\text { No, porque una mínima cantidad de dinero no soluciona los problemas de } \\
\text { adulto mayor. En vez de darle } 200 \text { soles a cada adulto mayor es preferible } \\
\text { mejorar el acceso a la salud, el que no le falte medicamento, medicamentos. }\end{array}$ \\
\hline & $\begin{array}{l}\text { Según INEI, solo el } 37.6 \% \text { de adultos } \\
\text { mayores en el Perú, está afiliado a un } \\
\text { sistema de pensiones. ¿Qué se está } \\
\text { haciendo al respecto? }\end{array}$ & $\begin{array}{l}\text { Se sigue en lo mismo, con lo que termina uno recibiendo al jubilarse no va } \\
\text { alcanzar para el futuro. Uno tiene que proyectarse para el futuro. }\end{array}$ \\
\hline & $\begin{array}{l}\text { ¿Considera usted que el sistema de salud } \\
\text { y de acceso a estos, por parte del adulto } \\
\text { mayor es el óptimo? Se atrevería a dar } \\
\text { sugerencias de cambio bajo su } \\
\text { experiencia. }\end{array}$ & \\
\hline \multirow{3}{*}{$\begin{array}{l}\text { Envejecimiento } \\
\text { Productivo }\end{array}$} & $\begin{array}{l}\text { Bajo su experiencia qué podría hacer } \\
\text { mejor el Estado Peruano para fomentar el } \\
\text { desarrollo social, económico de los } \\
\text { adultos mayores }\end{array}$ & $\begin{array}{l}\text { Crear una política donde el adulto mayor sea capaz de desarrollar un trabajo. } \\
\text { Crear espacios donde el adulto mayor pueda verter su experiencia. }\end{array}$ \\
\hline & $\begin{array}{l}\text { ¿Cuál es el rol que forma la familia, no } \\
\text { solo para los adultos mayores } \\
\text { vulnerables, dependientes sino para } \\
\text { quienes buscan envejecer de forma } \\
\text { exitosa? }\end{array}$ & $\begin{array}{l}\text { Es fundamental, los lazos sociales son importantes. La gente que está en un } \\
\text { centro como este tiene un problema social de fondo. }\end{array}$ \\
\hline & $\begin{array}{l}\text { ¿Cuáles son las últimas mejoras en el } \\
\text { sistema de salud que se hayan enfocado } \\
\text { al adulto mayor? }\end{array}$ & $\begin{array}{l}\text { Se está dando mucho impulso a la Demencia. Nadie quiere olvidarse de las } \\
\text { cosas, debe ser fatal olvidarse de las personas que uno quiere. Es caro } \\
\text { inalcanzable para una sociedad como la nuestra aminorar los síntomas de la } \\
\text { demencia. Traumatológicamente ahora es más fácil. Los problemas visuales, } \\
\text { la cirugía de cataratas es ambulatoria. Los adultos mayores son marginados } \\
\text { para la donación de órganos. }\end{array}$ \\
\hline $\begin{array}{l}\text { Observaciones } \\
\text { después de la } \\
\text { entrevista }\end{array}$ & & $\begin{array}{l}\text { La directora y el coordinador de psicología acceden a que podamos entrevistar } \\
\text { adultos mayores vulnerables como parte de nuestra investigación. Muestran el } \\
\text { albergue y sus necesidades. }\end{array}$ \\
\hline $\begin{array}{l}\text { Percepción de la } \\
\text { entrevista }\end{array}$ & & $\begin{array}{l}\text { Una entrevista complicada, al inicio tensa, difícil de manejar, totalmente } \\
\text { diplomática. La directora a la defensiva no quiso quedarse sola con la } \\
\text { entrevistadora, quería estar segura de la finalidad de la entrevista, de quien } \\
\text { era la persona que se lo hacía. Conforme fue apreciando el fin académico de } \\
\text { la investigación fue soltándose, aunque por momentos contestaba irónica. } \\
\text { Terminamos de forma agradable, conversando de temas personales. }\end{array}$ \\
\hline
\end{tabular}




\begin{tabular}{|c|c|c|}
\hline & & $\begin{array}{l}\text { Dra. María Edith Baca Psicóloga Salubrista - Consultora } \\
\text { Nacional de la OPS }\end{array}$ \\
\hline Contexto Interno & & $\begin{array}{l}\text { La Dra. Baca nos recibió en las instalaciones de la OPS, ha sido para ella todo } \\
\text { un día de recibir personas, y estar en varias reuniones, sin embargo, está } \\
\text { animosa, nos felicita por la investigación. }\end{array}$ \\
\hline Contexto externo & & $\begin{array}{l}\text { La entrevista se llevó a cabo en Monterrico, Chacarilla en las instalaciones de } \\
\text { OPS en el Perú, en la oficina de la consultora Dra. Edith Baca }\end{array}$ \\
\hline \multirow{4}{*}{$\begin{array}{l}\text { Situación del } \\
\text { adulto mayor }\end{array}$} & $\begin{array}{l}\text { ¿Qué se sabe de la población adulta } \\
\text { mayor en el mundo? }\end{array}$ & $\begin{array}{l}\text { La esperanza de vida se ha incrementado. Las personas no se han preparado } \\
\text { para enfrentar la longevidad de manera saludable y menos productiva. }\end{array}$ \\
\hline & $\begin{array}{l}\text { ¿Cuál considera usted que es el principal } \\
\text { problema que enfrenta el adulto mayor en } \\
\text { el Perú? }\end{array}$ & $\begin{array}{l}\text { La exclusión social, el abandono familiar, afectivo, económico, violencia. La } \\
\text { vulneración de sus derechos }\end{array}$ \\
\hline & $\begin{array}{l}\text { ¿Por qué se le podría considerar } \\
\text { población vulnerable? }\end{array}$ & $\begin{array}{l}\text { Es una población que no está siendo atendida de acuerdo sus necesidades. } \\
\text { La respuesta del estado no está a la medida de las personas mayores }\end{array}$ \\
\hline & $\begin{array}{l}\text { ¿Cuál es el aporte que realiza su } \\
\text { organización a la situación del adulto } \\
\text { mayor? }\end{array}$ & $\begin{array}{l}\text { El nuevo enfoque es personas mayores. Nuestro enfoque es envejecimiento } \\
\text { saludable, como clave para bienestar para la parte productiva y la calidad de } \\
\text { vida, este enfoque trasciende lo físico, la alimentación, el vestido, factores } \\
\text { asociados, para que la longevidad sea en mejores condiciones. Estamos } \\
\text { envejeciendo en precarias condiciones. }\end{array}$ \\
\hline \multirow{6}{*}{$\begin{array}{l}\text { Consecuencias } \\
\text { económicas y } \\
\text { sociales del } \\
\text { envejecimiento }\end{array}$} & $\begin{array}{l}\text { ¿Qué tendencia se está siguiendo en el } \\
\text { Mundo sobre la educación en los adultos } \\
\text { mayores? }\end{array}$ & $\begin{array}{l}\text { No conozco. En el país ha tenido avances, para incorporar a personas } \\
\text { mayores. Se ha bajado las cifras de analfabetismo. Universidades peruanas } \\
\text { están tratando de incorporar programas para personas mayores }\end{array}$ \\
\hline & $\begin{array}{l}\text { OEA: " La persona mayor tiene derecho a } \\
\text { la educación en igualdad de condiciones } \\
\text { con otros sectores de la población y sin } \\
\text { discriminación" ¿Conoce si en el país } \\
\text { existe políticas al respecto? }\end{array}$ & $\begin{array}{l}\text { El problema del Perú no es falta de políticas, tenemos un buen nivel, el } \\
\text { problema es la implementación. El problema son las barreras técnicas, } \\
\text { financiera, administrativas, fuera y dentro del sector. Barreras de gestión. }\end{array}$ \\
\hline & $\begin{array}{l}\text { Le menciono que hay autores que } \\
\text { consideran a la fragilidad e inactividad de } \\
\text { los adultos mayores como un gran mito. } \\
\text { ¿Qué opina al respecto? }\end{array}$ & $\begin{array}{l}\text { Se puede ser frágil a los } 14 \text { a los } 20 \text {. La fragilidad no tiene que ver con la edad. } \\
\text { Nosotros hacemos frágil a las personas incluyéndolas o excluyéndolas, } \\
\text { dándoles grados de libertad. La fragilidad no es intrínseca es adquirida por lo } \\
\text { que la gente recibe. }\end{array}$ \\
\hline & $\begin{array}{l}\text { Los adultos mayores realizan diferentes } \\
\text { actividades no remuneradas, ¿qué se } \\
\text { sabe al respecto? ¿Sería posible que nos } \\
\text { brinde algunos ejemplos o cifras? }\end{array}$ & $\begin{array}{l}\text { Hay iniciativas de algunas empresas de incorporar adultas mayores, son } \\
\text { iniciativas incipientes, no es una política pública, se está haciendo desde el } \\
\text { lado informal, desde consultorías. }\end{array}$ \\
\hline & $\begin{array}{l}\text { Se sabe que los adultos mayores son un } \\
\text { grupo que se encuentra lejos de ser un } \\
\text { grupo homogéneo dado que es diferente } \\
\text { ser mayor de } 60 \text { y ser mujer o hombre, } \\
\text { con pensión o sin pensión, pobre, o de } \\
\text { extrema pobreza. Se trabaja calidad de } \\
\text { vida en base a estas diferencias. Conoce } \\
\text { de políticas públicas basadas en calidad } \\
\text { de vida }\end{array}$ & $\begin{array}{l}\text { Los programas sociales están diseñados para la sobrevivencia, es decir para } \\
\text { sacar a la gente de la extrema pobreza, no están orientados a la calidad de } \\
\text { vida, para tener calidad de vida hay que haber salido de la pobreza y darles un } \\
\text { escalón más. Es difícil centrarse en la calidad de vida. Sacarlos de la Anemia, } \\
\text { con pensión } 65 \text {. Del maltrato. }\end{array}$ \\
\hline & $\begin{array}{l}\text { Siendo el envejecimiento poblacional un } \\
\text { éxito en las mejoras sanitarias. ¿Qué } \\
\text { retos visualiza usted va enfrentar el } \\
\text { Estado Peruano en los próximos años? }\end{array}$ & $\begin{array}{l}\text { El envejecimiento de la salud de las personas no ha mejorado. Lo que ha } \\
\text { mejorado es la mortandad, que se ha reducido, y es un avance, pero la calidad } \\
\text { de la salud de las personas no ha mejorado. El sector salud está conectado, el } \\
\text { país está conectado. salir y transcender para tener acceso a la salud para las } \\
\text { personas mayores }\end{array}$ \\
\hline
\end{tabular}




\begin{tabular}{|c|c|c|}
\hline \multirow{6}{*}{$\begin{array}{l}\text { Políticas del } \\
\text { Estado Peruano }\end{array}$} & $\begin{array}{l}\text { La Ley } 30490 \text {, la ley de los adultos } \\
\text { mayores se promulgó con el objetivo } \\
\text { principal de propiciar la integración del } \\
\text { adulto mayor al desarrollo social, } \\
\text { económico, político y cultural de la } \\
\text { nación. }\end{array}$ & $\begin{array}{l}\text { La ley no es de ahorita, a la ley le falta actualizar. Porque hay otros contextos, } \\
\text { el indicador de aumento de tasa de esperanza de vida. Lo avanzado a parti } \\
\text { de esta ley es la formación de un grupo multisectorial, para el plan de las } \\
\text { personas mayores. Eso ha hecho que el plan se ejecute con sus dificultados, } \\
\text { con } 16 \text { sectores. Se va sacar una nueva política para evaluar la aplicación de } \\
\text { plan. ya en el } 2018 \text { ya no hay plan sino una política a pedido de CEPLAN, } \\
\text { definiendo hacia dónde vamos. La convención de derechos de las personas } \\
\text { mayores, que nos vamos adherir, pero está en cancha del congreso. }\end{array}$ \\
\hline & $\begin{array}{l}\text { ¿Cuáles son los programas dirigidos al } \\
\text { adulto mayor que se proponen a través } \\
\text { de la organización a la que usted } \\
\text { representa? }\end{array}$ & $\begin{array}{l}\text { Nuestro enfoque es de salud pública, potenciar los servicios de salud para las } \\
\text { personas mayores, y promover factores protectores. Se trabajan programas } \\
\text { que ayuden a proteger una de ellas es la estrategia mundial de ciudades } \\
\text { amigables con adultos mayores, tiene que ver con el rol de los municipios que } \\
\text { hace el lugar una ciudad amigable para personas mayores. El otro programa } \\
\text { tomando iniciativa con su salud, que es un programa de alianza con Stanford, } \\
\text { es una guía para capacitar facilitadores, que puedan enseñar a otros adultos } \\
\text { mayores a cuidarse. }\end{array}$ \\
\hline & $\begin{array}{l}\text { Tiene conocimientos de planes dirigidos } \\
\text { a personas adultas mayores en situación } \\
\text { de pobreza o pobreza extrema }\end{array}$ & Plan 65 \\
\hline & $\begin{array}{l}\text { ¿Considera al programa social pensión } \\
65 \text { como un éxito de políticas públicas? }\end{array}$ & $\begin{array}{l}\text { Es una buena política que no ha sido fortalecida, cuando surgen las políticas } \\
\text { surgen en una primera etapa y suben por una decisión política. Nuestro país } \\
\text { tiene el problema de no tener una política de estado, sino de gobierno. Cambia } \\
\text { el gobierno y cambia la política. Las políticas del gobierno anterior continúan, } \\
\text { pero se les baja el volumen. }\end{array}$ \\
\hline & $\begin{array}{l}\text { Según INEI, solo el } 37.6 \% \text { de adultos } \\
\text { mayores en el Perú, está afiliado a un } \\
\text { sistema de pensiones. ¿Qué se está } \\
\text { haciendo al respecto? }\end{array}$ & $\begin{array}{l}\text { La afiliación para las personas mayores ha mejorado. Pero el problema no es } \\
\text { la cobertura. El problema es por acceso y cobertura universal de la salud. E } \\
\text { mundo informal es muy complicado y ahí se complica el tema de la pensión, e } \\
\text { tema es quien va pagar esas pensiones, pero sus hijos sus nietos lo van sentir. }\end{array}$ \\
\hline & $\begin{array}{l}\text { ¿Considera usted que el sistema de salud } \\
\text { y de acceso a estos, por parte del adulto } \\
\text { mayor es el óptimo? Se atrevería a dar } \\
\text { sugerencias de cambio bajo su } \\
\text { experiencia. }\end{array}$ & $\begin{array}{l}\text { En ninguna parte del mundo es óptimos. las demandas de la persona mayor } \\
\text { son multidimensionales. Uno no sabe con qué limitaciones va terminar. Hay un } \\
\text { estándar mínimo. El Perú tiene mucha experiencia ganada en actividades de } \\
\text { prevención, desde paseos, etc. pero en las emergencias el } 90 \% \text { son personas } \\
\text { mayores, y no hay capacidad de respuesta, y carga el sistema de salud. }\end{array}$ \\
\hline \multirow{3}{*}{$\begin{array}{l}\text { Envejecimiento } \\
\text { Productivo }\end{array}$} & $\begin{array}{l}\text { Bajo su experiencia qué podría hacer } \\
\text { mejor el Estado Peruano para fomentar el } \\
\text { desarrollo social, económico de los } \\
\text { adultos mayores }\end{array}$ & $\begin{array}{l}\text { El estado está teniendo un enfoque de política pública multisectorial, todos los } \\
\text { sectores deben dar una respuesta. Sino tienen trabajo, sino tienen vivienda } \\
\text { impacta la salud. No es posible contribuir desarrollo sin salud, sin salud mental, } \\
\text { todo está concatenado. La tarea es por el } 1 \text {. enfoque de la política, } 2.1 \text { la } \\
\text { inversión en la política, por } 3 . \text { las competencias que los sectores vayan } \\
\text { desarrollando por mejorar la respuesta. Y como esta transciende políticas de } \\
\text { gobierno para ser políticas de estado }\end{array}$ \\
\hline & $\begin{array}{l}\text { ¿Cuál es el rol que forma la familia, no } \\
\text { solo para los adultos mayores } \\
\text { vulnerables, dependientes sino para } \\
\text { quienes buscan envejecer de forma } \\
\text { exitosa? }\end{array}$ & $\begin{array}{l}\text { El afecto, la capacidad que tenga la familia de salud y de salud mental para } \\
\text { incorporar a la persona mayor como sujeto a derechos, por las cosmovisiones } \\
\text { Se asume que la persona mayor es un infante, donde ya no tiene derecho a } \\
\text { tomar decisiones, se empiezan a vulnerar sus derechos y usar a los adultos } \\
\text { mayores en labores domésticas y no cuenta. No hay una valoración de la } \\
\text { persona mayor. Este trabajo con las familias es clave, si la familia tiene que } \\
\text { cambiar el imaginario social que las personas mayores son y de las } \\
\text { necesidades que tienen y las respuestas que merecen. }\end{array}$ \\
\hline & $\begin{array}{l}\text { ¿Cuáles son las últimas mejoras en el } \\
\text { sistema de salud que se hayan enfocado } \\
\text { al adulto mayor? }\end{array}$ & $\begin{array}{l}\text { Programas de cuidadores, los cuidadores son la misma familia. (Habla de su } \\
\text { vida familiar) El desgaste emocional, el familiar se afecta. Los cuidadores que } \\
\text { en su mayoría son mujeres, incluso mueren antes de la persona cuidada. Hay } \\
\text { programas de autocuidado, para que las personas mayores puedan tener un } \\
\text { rol protagónico. Teniendo una línea de autocuidado con una línea de trabajo } \\
\text { con los cuidadores, y otra línea de trabajo con los municipios. E } \\
\text { envejecimiento va estar en mejores condiciones. }\end{array}$ \\
\hline \multicolumn{3}{|l|}{$\begin{array}{l}\text { Observaciones } \\
\text { después de la } \\
\text { entrevista }\end{array}$} \\
\hline $\begin{array}{l}\text { Percepción de la } \\
\text { entrevista }\end{array}$ & & \\
\hline
\end{tabular}




\begin{tabular}{|c|c|c|}
\hline & & Coincidencias \\
\hline \multirow{4}{*}{$\begin{array}{l}\text { Situación del } \\
\text { adulto mayor }\end{array}$} & $\begin{array}{l}\text { ¿Qué se sabe de la población adulta } \\
\text { mayor en el mundo? }\end{array}$ & $\begin{array}{l}\text { Población adulta mayor en crecimiento, en aumento significativo en relación a la } \\
\text { última década. Transición demográfica moderada. Incremento de la esperanza } \\
\text { de vida }\end{array}$ \\
\hline & $\begin{array}{l}\text { ¿Cuál considera usted que es el principal } \\
\text { problema que enfrenta el adulto mayor en } \\
\text { el Perú? }\end{array}$ & $\begin{array}{l}\text { Falta de políticas de estado. Falta de planificación para la vejez. Falta de acceso } \\
\text { a la salud. Vulnerabilidad de derechos de los adultos mayores. }\end{array}$ \\
\hline & $\begin{array}{l}\text { ¿Por qué se le podría considerar } \\
\text { población vulnerable? }\end{array}$ & $\begin{array}{l}\text { Coinciden en aclarar que la vejez no es sinónimo de vulnerabilidad y hacen } \\
\text { diferencia en el concepto de fragilidad, y adultos robustos y productivos. La vejez } \\
\text { bien llevada no debe ser vulnerable. Los adultos mayores no están recibiendo } \\
\text { herramientas que lo ayuden a ser dependientes. Destacan que el nivel de salud } \\
\text { de las personas mayores es complejo y no se está atendiendo de acuerdo con } \\
\text { las necesidades o de manera integral. El SIS es básico, amplio y no es } \\
\text { personalizado ni atiende las necesidades de esta población. }\end{array}$ \\
\hline & $\begin{array}{l}\text { ¿Cuál es el aporte que realiza su } \\
\text { organización a la situación del adulto } \\
\text { mayor? }\end{array}$ & $\begin{array}{l}\text { En su mayoría coinciden en el aporte de lineamientos, normativa, investigación, } \\
\text { acciones academias, y como entidades normativas de gobierno. Casi en su } \\
\text { totalidad no lleva a cabo la acción, no realizan programas o hechos concretos. } \\
\text { Uno se autogestión de donativos. }\end{array}$ \\
\hline \multirow{6}{*}{$\begin{array}{l}\text { Consecuencias } \\
\text { económicas y } \\
\text { sociales del } \\
\text { envejecimiento }\end{array}$} & $\begin{array}{l}\text { ¿Qué tendencia se está siguiendo en el } \\
\text { Mundo sobre la educación en los adultos } \\
\text { mayores? }\end{array}$ & $\begin{array}{l}\text { Hay un estereotipo arraigado que debe revertirse pues los adultos mayores son } \\
\text { capaces de aprender actividades nuevas. Las personas que recibieron mayor } \\
\text { educación son los que cognitivamente son más funcionales. }\end{array}$ \\
\hline & $\begin{array}{l}\text { OEA: " La persona mayor tiene derecho a } \\
\text { la educación en igualdad de condiciones } \\
\text { con otros sectores de la población y sin } \\
\text { discriminación" ¿Conoce si en el país } \\
\text { existe políticas al respecto? }\end{array}$ & $\begin{array}{l}\text { Reconocen que existe un problema educativo con los adultos mayores, no } \\
\text { identifican programas de educación privados, y el estado solo trabaja en } \\
\text { alfabetizar a los analfabetos. Coinciden que existe una política de no } \\
\text { discriminación pero que no se implementa por falta de gestión. }\end{array}$ \\
\hline & $\begin{array}{l}\text { Le menciono que hay autores que } \\
\text { consideran a la fragilidad e inactividad de } \\
\text { los adultos mayores como un gran mito. } \\
\text { ¿Qué opina al respecto? }\end{array}$ & $\begin{array}{l}\text { Coinciden en separar los términos Fragilidad de Activad. La vejez no es sinónimo } \\
\text { de vulnerabilidad depende de las condiciones en las que se ha vivido, del tipo de } \\
\text { alimentación y actividad. Destacan adultos mayores profesionales, reconocidos } \\
\text { que no son necesariamente vulnerables. }\end{array}$ \\
\hline & $\begin{array}{l}\text { Los adultos mayores realizan diferentes } \\
\text { actividades no remuneradas, ¿qué se } \\
\text { sabe al respecto? ¿Sería posible que nos } \\
\text { brinde algunos ejemplos o cifras? }\end{array}$ & $\begin{array}{l}\text { Coinciden que existe actividades que realizan y que deberían medirse porque son } \\
\text { de aporte económico y/o social pero no son actividades remuneradas }\end{array}$ \\
\hline & $\begin{array}{l}\text { Se sabe que los adultos mayores son un } \\
\text { grupo que se encuentra lejos de ser un } \\
\text { grupo homogéneo dado que es diferente } \\
\text { ser mayor de } 60 \text { y ser mujer o hombre, con } \\
\text { pensión o sin pensión, pobre, o de extrema } \\
\text { pobreza. Se trabaja calidad de vida en } \\
\text { base a estas diferencias. Conoce de } \\
\text { políticas públicas basadas en calidad de } \\
\text { vida }\end{array}$ & $\begin{array}{l}\text { Coinciden en mencionar que la calidad de vida es un término mal usado, la calidad } \\
\text { de vida se da en el acompañamiento de la vida del adulto mayor. Mencionan el } \\
\text { estereotipo arraigado que separa generaciones y el no respeto que se le tiene al } \\
\text { adulto mayor. El adulto mayor no tiene la calidad de vida que merecen. Las } \\
\text { actuales políticas no abarcan todas las diferencias poblacionales que existen en } \\
\text { esta población. Los programas sociales no están basados en calidad de vida sino } \\
\text { en sacar a la gente de la pobreza. }\end{array}$ \\
\hline & $\begin{array}{l}\text { Siendo el envejecimiento poblacional un } \\
\text { éxito en las mejoras sanitarias. ¿Qué retos } \\
\text { visualiza usted va enfrentar el Estado } \\
\text { Peruano en los próximos años? }\end{array}$ & $\begin{array}{l}\text { En su mayoría coinciden en el que el acceso a la salud será en definitiva un reto } \\
\text { importante en el futuro de Perú, visionan un caos en el acceso la salud, un } \\
\text { colapso. Una crisis epidemiológica, donde las enfermedades crónicas en los } \\
\text { adultos mayores complican su situación. }\end{array}$ \\
\hline
\end{tabular}




\begin{tabular}{|c|c|c|}
\hline \multirow{6}{*}{$\begin{array}{l}\text { Políticas del } \\
\text { Estado Peruano }\end{array}$} & $\begin{array}{l}\text { La Ley } 30490 \text {, la ley de los adultos } \\
\text { mayores se promulgó con el objetivo } \\
\text { principal de propiciar la integración del } \\
\text { adulto mayor al desarrollo social, } \\
\text { económico, político y cultural de la nación. }\end{array}$ & $\begin{array}{l}\text { Consideran que a I ley le falta difusión que solo se queda en papel, que existe } \\
\text { gran desconocimiento, no solo de las entidades de gobierno, regionales sino } \\
\text { además de los propios adultos mayores. Se necesita un cambio de cultura que } \\
\text { abarque a las nuevas generaciones. Consideran que es necesario una política } \\
\text { transversal y multisectorial que ya se viene aplicando en el estado, a través de } \\
\text { CEPLAN y con el fin de integrar a todos los sectores de gobierno en la solución } \\
\text { de problemas de esta población }\end{array}$ \\
\hline & $\begin{array}{l}\text { ¿Cuáles son los programas dirigidos al } \\
\text { adulto mayor que se proponen a través de } \\
\text { la organización a la que usted representa? }\end{array}$ & $\begin{array}{l}\text { Cada institución realiza actividades desde su enfoque y de acuerdo a su línea de } \\
\text { trabajo. }\end{array}$ \\
\hline & $\begin{array}{l}\text { Tiene conocimientos de planes dirigidos a } \\
\text { personas adultas mayores en situación de } \\
\text { pobreza o pobreza extrema }\end{array}$ & Coinciden la mayoría en Pensión 65 \\
\hline & $\begin{array}{l}\text { ¿Considera al programa social pensión } 65 \\
\text { como un éxito de políticas públicas? }\end{array}$ & $\begin{array}{l}\text { Coinciden en que el programa no es una solución, ha impactado en poca } \\
\text { población y es un programa de transferencia económica que no ataca el problema } \\
\text { de fondo y no soluciona los principales problemas del adulto mayor. Aclaran que } \\
\text { son decisiones políticas y que el Perú se afecta por tener políticas de gobierno, } \\
\text { del gobierno de turno. }\end{array}$ \\
\hline & $\begin{array}{l}\text { Según INEI, solo el } 37.6 \% \text { de adultos } \\
\text { mayores en el Perú, está afiliado a un } \\
\text { sistema de pensiones. ¿Qué se está } \\
\text { haciendo al respecto? }\end{array}$ & $\begin{array}{l}\text { Coinciden en que no se está haciendo nada para mejorar el acceso a una } \\
\text { jubilación digna. Que no se ataca el problema del no acceso a programas de } \\
\text { jubilación. Representante de gobierno indica que no hay una política al respecto. } \\
\text { Y la especialista de la OPS considera que el gran problema es la informalidad. }\end{array}$ \\
\hline & $\begin{array}{l}\text { ¿Considera usted que el sistema de salud } \\
\text { y de acceso a estos, por parte del adulto } \\
\text { mayor es el óptimo? Se atrevería a dar } \\
\text { sugerencias de cambio bajo su } \\
\text { experiencia. }\end{array}$ & $\begin{array}{l}\text { El sistema de salud no es el óptimo en el país y menos para los adultos mayores. } \\
\text { Los consideran discriminados, consideran un abuso y una crueldad el poco } \\
\text { acceso a la salud de los adultos mayores. Consideran optimizar el acceso a través } \\
\text { de los médicos de familia, y la atención en domicilio, considerando que el hospital } \\
\text { es el peor lugar para ellos. }\end{array}$ \\
\hline \multirow{3}{*}{$\begin{array}{l}\text { Envejecimiento } \\
\text { Productivo }\end{array}$} & $\begin{array}{l}\text { Bajo su experiencia qué podría hacer } \\
\text { mejor el Estado Peruano para fomentar el } \\
\text { desarrollo social, económico de los } \\
\text { adultos mayores }\end{array}$ & $\begin{array}{l}\text { Coinciden es que es problema de gobiernos, de no tener una política de estado, } \\
\text { coinciden que el problema no es la política pública, es un problema que necesita } \\
\text { la atención del estado, de funcionalidad y gestión. Se necesita una política } \\
\text { transversal donde todos los organismos del estado participen. }\end{array}$ \\
\hline & $\begin{array}{l}\text { ¿Cuál es el rol que forma la familia, no solo } \\
\text { para los adultos mayores vulnerables, } \\
\text { dependientes sino para quienes buscan } \\
\text { envejecer de forma exitosa? }\end{array}$ & $\begin{array}{l}\text { Coinciden que el rol de la familia es clave, es fundamental, destacan el tema } \\
\text { social, destacando el valor de la persona mayor sin vulnerar sus derechos. } \\
\text { Hacerlos partícipe de la familia dándoles el lugar que merecen }\end{array}$ \\
\hline & $\begin{array}{l}\text { ¿Cuáles son las últimas mejoras en el } \\
\text { sistema de salud que se hayan enfocado } \\
\text { al adulto mayor? }\end{array}$ & $\begin{array}{l}\text { Coinciden en la apertura del SIS, los avance en investigación de las } \\
\text { enfermedades como el la Demencia y el alzhéimer. Resaltan la falta de acceso a } \\
\text { la salud de forma integral. }\end{array}$ \\
\hline
\end{tabular}




\section{Bitácoras - aportantes}

\begin{tabular}{|c|c|c|}
\hline & & \multirow[b]{2}{*}{$\begin{array}{c}\text { Entrevistado } \\
\text { Gerente general-Farmacia Universal }\end{array}$} \\
\hline & & \\
\hline & & $\begin{array}{l}\text { Mg. Dolores G.P. } 62 \text { años } \\
\text { Gerente General Farmacia Universal. }\end{array}$ \\
\hline Categoría & Adultos mayores aportantes & Respuestas \\
\hline \multirow{2}{*}{ 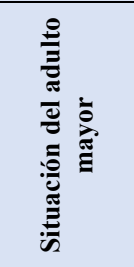 } & $\begin{array}{l}\text { ¿Qué opina de que se considere en el Perú que una persona } \\
\text { que llega a tener más de } 60 \text { años ya es inactiva? }\end{array}$ & $\begin{array}{l}\text { Completamente errado, considera que no son los } 60 \text { de antes, los mayores } \\
\text { de } 50 \text { son un grupo etario no definido, como lo fueron en su momento los } \\
\text { adolescentes, somos muy activos (trabajamos, estudiamos, realizamos } \\
\text { actividades físicas) y tenemos ganas de seguir viviendo. }\end{array}$ \\
\hline & $\begin{array}{l}\text { ¿Cuáles cree usted que son las características físicas, } \\
\text { sociales, económicas que caracterizan la etapa de vida que } \\
\text { está viviendo? }\end{array}$ & $\begin{array}{l}\text { Practicar deporte, para mantenerse saludable, la alimentación, lectura; } \\
\text { además, como los hijos se fueron de casa, se tiene más tiempo para uno } \\
\text { mismo. Actividades sociales. }\end{array}$ \\
\hline \multirow{6}{*}{ 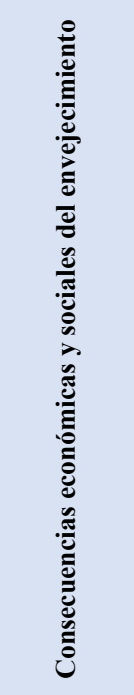 } & ¿Cuál es su grado de instrucción alcanzado? & Maestría y diplomados \\
\hline & $\begin{array}{l}\text { ¿Le gustaría seguir estudiando? Tiene algún proyecto al } \\
\text { respecto }\end{array}$ & $\begin{array}{l}\text { Me gustaría seguir estudiando en lo que pueda, voy a hacer un curso de } \\
\text { directores en el extranjero }\end{array}$ \\
\hline & $\begin{array}{l}\text { Nos podría describir: ¿Cuál es su ocupación, profesión? } \\
\text { ¿Actualmente a qué se dedica? }\end{array}$ & $\begin{array}{l}\text { Administradora de empresa, gerente general de farmacia universal, realiza } \\
\text { deporte en la mañana, luego trabajo hasta las } 6 \mathrm{pm} \text {, reuniones en la cámara } \\
\text { de comercio. }\end{array}$ \\
\hline & $\begin{array}{l}\text { ¿Qué actividades realiza que podría considerar como un } \\
\text { trabajo no remunerado? ¿Esta actividad a quién beneficia? } \\
\text { ¿Por qué lo hace? (iniciativa, obligación) }\end{array}$ & $\begin{array}{l}\text { Reuniones en la cámara de comercio y los comités a los que pertenezco, } \\
\text { brindando opiniones sobre mejoras en las políticas de estado. Iniciativa. }\end{array}$ \\
\hline & $\begin{array}{l}\text { ¿Cuál es la percepción personal de su situación de vida? } \\
\text { En relación con sus objetivos, expectativas, valores. ¿Está } \\
\text { a gusto, se siente bien al respecto? }\end{array}$ & $\begin{array}{l}\text { Manifiesta estar siempre agradecida, tiene responsabilidades. Enseña cómo } \\
\text { dar un mejor servicio al público. Dar lo mejor de uno mismo. }\end{array}$ \\
\hline & $\begin{array}{l}\text { ¿Cómo se imagina que será su vida en los próximos años? } \\
\text { ¿Tendrá algún reto que enfrentar: (social, económico, de } \\
\text { salud)? }\end{array}$ & $\begin{array}{l}\text { Mantenerse activa lo más que se pueda. Realizar actividades o viajando, no } \\
\text { se visualiza estando quieta. }\end{array}$ \\
\hline \multirow{4}{*}{ 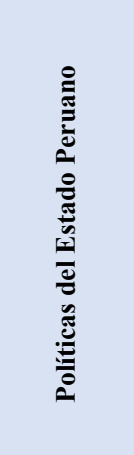 } & $\begin{array}{l}\text { Conoce de algunas de las políticas de Estado Peruano para } \\
\text { contribuir con el desarrollo de las personas adultas } \\
\text { mayores }\end{array}$ & En las municipalidades hay algunos programas. \\
\hline & $\begin{array}{l}\text { Considera usted que el Estado Peruano le ha brindado } \\
\text { herramientas de desarrollo económico, social para la } \\
\text { salud. }\end{array}$ & No lo considera, pienso que uno debe dar su aporte al país. \\
\hline & $\begin{array}{l}\text { ¿Contribuye usted a un sistema de pensiones? ¿Qué } \\
\text { opinión le merece que el estado mediante ley determina el } \\
\text { tiempo en que las todas las personas deben jubilarse? }\end{array}$ & $\begin{array}{l}\text { Si tengo sistema de pensiones, me parece mal que el estado plantee la } \\
\text { jubilación a esa edad }\end{array}$ \\
\hline & ¿Cuenta usted con algún tipo de seguro de salud? & EsSalud y privado. \\
\hline \multirow{3}{*}{ 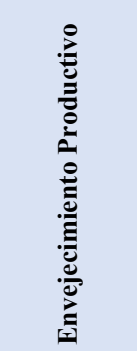 } & ¿Cómo se visualiza usted? ¿Tiene algún proyecto? & En los siguientes años estar en actividad, viajar y estudiar. \\
\hline & $\begin{array}{l}\text { ¿Cuál es el rol que cumple la familia en su desempeño y } \\
\text { actividad del día a día? }\end{array}$ & $\begin{array}{l}\text { La familia es súper importante, es el apoyo. Es importante pasar momento } \\
\text { con la familia, la unión, amor hacia ellos. }\end{array}$ \\
\hline & $\begin{array}{l}\text { ¿Qué considera usted que necesita para mejorar su estado } \\
\text { de salud, o considera que su estado de salud actual es el } \\
\text { óptimo? }\end{array}$ & $\begin{array}{l}\text { Se encuentra bien. Chequeos médicos que se realiza una vez al año. Tuvo } \\
\text { problemas de salud, pero han sido superadas }\end{array}$ \\
\hline
\end{tabular}




\begin{tabular}{|c|c|c|}
\hline & & $\begin{array}{c}\text { Entrevistado } \\
\text { Tesorero CAFAE-SE }\end{array}$ \\
\hline & & $\begin{array}{c}\text { Sr. Luis M.O.H } 69 \text { años } \\
\text { Tesorero empresa CAFAE-SE. }\end{array}$ \\
\hline Categoría & Adultos mayores aportantes & Respuestas \\
\hline \multirow{2}{*}{ 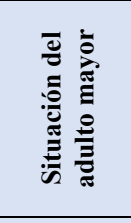 } & $\begin{array}{l}\text { ¿Qué opina de que se considere en el Perú que una persona } \\
\text { que llega a tener más de } 60 \text { años ya es inactiva? }\end{array}$ & $\begin{array}{l}\text { Piensa que es relativo, de acuerdo con las facultades físicas o mentales de } \\
\text { las personas y pueden seguir trabajando, sobre todo en labore que no } \\
\text { requieren mayor esfuerzo físico }\end{array}$ \\
\hline & $\begin{array}{l}\text { ¿Cuáles cree usted que son las características físicas, } \\
\text { sociales, económicas que caracterizan la etapa de vida que } \\
\text { está viviendo? }\end{array}$ & $\begin{array}{l}\text { Su labor es en oficina y no amerita esfuerzo físico por lo que puede seguir } \\
\text { realizando sus actividades. }\end{array}$ \\
\hline \multirow{6}{*}{ 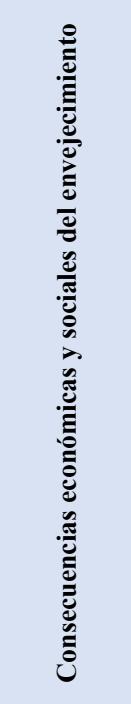 } & ¿Cuál es su grado de instrucción alcanzado? & $\begin{array}{l}\text { Estudios técnicos en administración pública. La empresa actualmente nos } \\
\text { envía a capacitaciones. }\end{array}$ \\
\hline & $\begin{array}{l}\text { ¿Le gustaría seguir estudiando? Tiene algún proyecto al } \\
\text { respecto }\end{array}$ & $\begin{array}{l}\text { No cree que pueda estudiar, pero sí que puede aprender otras actividades o } \\
\text { actualizaciones principalmente en el ámbito informático. Con respecto a } \\
\text { proyecto da a entender que no requiere puesto que tiene una pensión y sus } \\
\text { ingresos actuales. Solo quiere dedicarse a su esposa. }\end{array}$ \\
\hline & $\begin{array}{l}\text { Nos podría describir: ¿Cuál es su ocupación, profesión? } \\
\text { ¿Actualmente a qué se dedica? }\end{array}$ & Trabaja de 8 am a 7:30 pm por las labores que realiza. \\
\hline & $\begin{array}{l}\text { ¿Qué actividades realiza que podría considerar como un } \\
\text { trabajo no remunerado? ¿Esta actividad a quién beneficia? } \\
\text { ¿Por qué lo hace? (iniciativa, obligación) }\end{array}$ & No realiza trabajos no remunerados. \\
\hline & $\begin{array}{l}\text { ¿Cuál es la percepción personal de su situación de vida? } \\
\text { En relación con sus objetivos, expectativas, valores. ¿Está } \\
\text { a gusto, se siente bien al respecto? }\end{array}$ & $\begin{array}{l}\text { Indica que se siente a gusto en parte espiritual y laboral, trata de llevarse } \\
\text { bien con todos en el trabajo. }\end{array}$ \\
\hline & $\begin{array}{l}\text { ¿Cómo se imagina que será su vida en los próximos años? } \\
\text { ¿Tendrá algún reto que enfrentar: (social, económico, de } \\
\text { salud)? }\end{array}$ & $\begin{array}{l}\text { No reto, en parte económica no tendría problemas, en el ámbito personal o } \\
\text { espiritual tampoco. }\end{array}$ \\
\hline \multirow{4}{*}{ 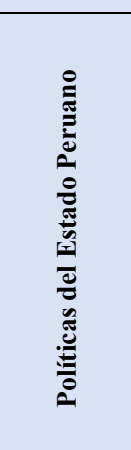 } & $\begin{array}{l}\text { Conoce de algunas de las políticas de Estado Peruano para } \\
\text { contribuir con el desarrollo de las personas adultas } \\
\text { mayores }\end{array}$ & $\begin{array}{l}\text { Atención preferencial, pensiones bajas en la administración pública y } \\
\text { privada, son muy bajas, debería mejorar. }\end{array}$ \\
\hline & $\begin{array}{l}\text { Considera usted que el Estado Peruano le ha brindado } \\
\text { herramientas de desarrollo económico, social para la } \\
\text { salud. }\end{array}$ & $\begin{array}{l}\text { No. Cuando ha trabajado para el estado me han remunerado sin ningún } \\
\text { beneficio adicional. }\end{array}$ \\
\hline & $\begin{array}{l}\text { ¿Contribuye usted a un sistema de pensiones? ¿Qué } \\
\text { opinión le merece que el estado mediante ley determina el } \\
\text { tiempo en que las todas las personas deben jubilarse? }\end{array}$ & $\begin{array}{l}\text { AFP, la jubilación debe ser relativo, porque hay personas de } 70 \text { años que } \\
\text { pueden seguir laborando. }\end{array}$ \\
\hline & ¿Cuenta usted con algún tipo de seguro de salud? & EPS, por su trabajo actual. Si deja de trabajar se quedará sólo Es salud. \\
\hline \multirow{3}{*}{ 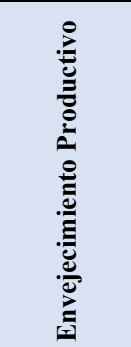 } & ¿Cómo se visualiza usted? ¿Tiene algún proyecto? & No proyectos. \\
\hline & $\begin{array}{l}\text { ¿Cuál es el rol que cumple la familia en su desempeño y } \\
\text { actividad del día a día? }\end{array}$ & $\begin{array}{l}\text { Sólo esta su esposa en su familia es la persona que ha estado siempre a su } \\
\text { lado, es su apoyo. Tiene una buena relación }\end{array}$ \\
\hline & $\begin{array}{l}\text { ¿Qué considera usted que necesita para mejorar su estado } \\
\text { de salud, o considera que su estado de salud actual es el } \\
\text { óptimo? }\end{array}$ & $\begin{array}{l}\text { Hay que realizar controles para mantener una buena salud. La prevención es } \\
\text { importante }\end{array}$ \\
\hline
\end{tabular}




\begin{tabular}{|c|c|c|}
\hline & & $\begin{array}{c}\text { Entrevistado } \\
\text { Recepción CAFAE-SE }\end{array}$ \\
\hline & & $\begin{array}{c}\text { Sra. Luz A.R.H. } 60 \text { años } \\
\text { Auxiliar administrativo CAFAE-SE. } \\
\text { Secretariado ejecutivo - estudios técnicos }\end{array}$ \\
\hline Categoría & Adultos mayores aportantes & Respuestas \\
\hline \multirow{2}{*}{ 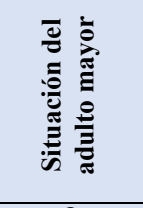 } & $\begin{array}{l}\text { ¿Qué opina de que se considere en el Perú que una persona } \\
\text { que llega a tener más de } 60 \text { años ya es inactiva? }\end{array}$ & $\begin{array}{l}\text { Indica que esa idea no va, desde su punto de vista, puesto que ella se } \\
\text { considera activa. }\end{array}$ \\
\hline & $\begin{array}{l}\text { ¿Cuáles cree usted que son las características físicas, } \\
\text { sociales, económicas que caracterizan la etapa de vida que } \\
\text { está viviendo? }\end{array}$ & $\begin{array}{l}\text { Se siente bien, indicando que, si está bien de salud, todo lo demás está bien, } \\
\text { refiere lleva una vida social como la de una chica de } 35 \text { años, indica que su } \\
\text { edad no es obstáculo. }\end{array}$ \\
\hline \multirow{6}{*}{ 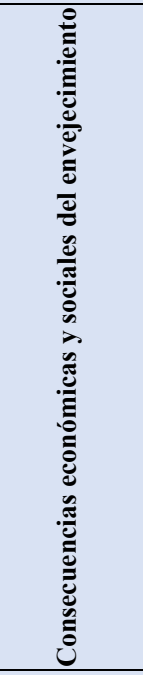 } & ¿Cuál es su grado de instrucción alcanzado? & Técnico - Secretariado Ejecutivo. \\
\hline & $\begin{array}{l}\text { ¿Le gustaría seguir estudiando? Tiene algún proyecto al } \\
\text { respecto }\end{array}$ & $\begin{array}{l}\text { Le gustaría estudia idioma - francés. Indica que un obstáculo es el horario } \\
\text { de trabajo. }\end{array}$ \\
\hline & $\begin{array}{l}\text { Nos podría describir: ¿Cuál es su ocupación, profesión? } \\
\text { ¿Actualmente a qué se dedica? }\end{array}$ & Recepción de documentos, llamadas, atención al cliente en toda la empresa. \\
\hline & $\begin{array}{l}\text { ¿Qué actividades realiza que podría considerar como un } \\
\text { trabajo no remunerado? ¿Esta actividad a quién beneficia? } \\
\text { ¿Por qué lo hace? (iniciativa, obligación) }\end{array}$ & $\begin{array}{l}\text { Tiene a su nieto bajo su cuidado e indica que eso le da más fuerza, es } \\
\text { responsable y colabora económicamente debido a que su hijo no tiene } \\
\text { trabajo estable. }\end{array}$ \\
\hline & $\begin{array}{l}\text { ¿Cuál es la percepción personal de su situación de vida? } \\
\text { En relación con sus objetivos, expectativas, valores. ¿Está } \\
\text { a gusto, se siente bien al respecto? }\end{array}$ & $\begin{array}{l}\text { No se siente a gusto porque piensa que puede dar más de sí. Realiza otras } \\
\text { actividades que genera ingreso extra para su familia. }\end{array}$ \\
\hline & $\begin{array}{l}\text { ¿Cómo se imagina que será su vida en los próximos años? } \\
\text { ¿Tendrá algún reto que enfrentar: (social, económico, de } \\
\text { salud)? }\end{array}$ & $\begin{array}{l}\text { Igual a la de ahora, a menos que se presente una enfermedad, lo cual sería } \\
\text { el único obstáculo. Su reto es mejorar económicamente. }\end{array}$ \\
\hline \multirow{4}{*}{ 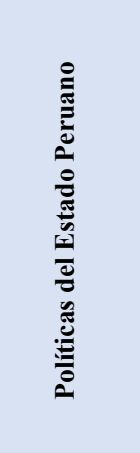 } & $\begin{array}{l}\text { Conoce de algunas de las políticas de Estado Peruano para } \\
\text { contribuir con el desarrollo de las personas adultas } \\
\text { mayores }\end{array}$ & $\begin{array}{l}\text { Conoce de PADOMI y las actividades de las municipalidades dirigidas a los } \\
\text { adultos mayores }\end{array}$ \\
\hline & $\begin{array}{l}\text { Considera usted que el Estado Peruano le ha brindado } \\
\text { herramientas de desarrollo económico, social para la } \\
\text { salud. }\end{array}$ & No. \\
\hline & $\begin{array}{l}\text { ¿Contribuye usted a un sistema de pensiones? ¿Qué } \\
\text { opinión le merece que el estado mediante ley determina el } \\
\text { tiempo en que las todas las personas deben jubilarse? }\end{array}$ & $\begin{array}{l}\text { AFP, refiere que la jubilación debería ser antes de la que se indica ahora, } \\
\text { para que pueda realizar sus proyectos personales. }\end{array}$ \\
\hline & ¿Cuenta usted con algún tipo de seguro de salud? & EPS, Es salud \\
\hline \multirow{3}{*}{ 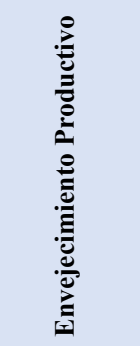 } & ¿Cómo se visualiza usted? ¿Tiene algún proyecto? & Quisiera poner un negocio propio según sus habilidades \\
\hline & $\begin{array}{l}\text { ¿Cuál es el rol que cumple la familia en su desempeño y } \\
\text { actividad del día a día? }\end{array}$ & $\begin{array}{l}\text { La familia es importante porque siente que le dan más fuerza. Es bueno no } \\
\text { sentirse sola. }\end{array}$ \\
\hline & $\begin{array}{l}\text { ¿Qué considera usted que necesita para mejorar su estado } \\
\text { de salud, o considera que su estado de salud actual es el } \\
\text { óptimo? }\end{array}$ & $\begin{array}{l}\text { No es óptimo. Es incomodo pedir permiso en el trabajo para realizar terapias } \\
\text { y mejorar su salud. }\end{array}$ \\
\hline
\end{tabular}




\begin{tabular}{|c|c|c|}
\hline & & \multirow[b]{2}{*}{$\begin{array}{c}\text { Entrevistado } \\
\text { Jefe de Sistemas- Atlantic City }\end{array}$} \\
\hline & & \\
\hline & & \begin{tabular}{|c|} 
Sr. Andrés R.E.Q 64 años \\
jefe del departamento Online, ingeniería electrónica - Casino Atlantic City \\
- Miraflores. \\
Ingeniero electrónico
\end{tabular} \\
\hline \multirow{3}{*}{ 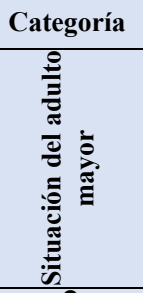 } & Adultos mayores aportantes & Respuestas \\
\hline & $\begin{array}{l}\text { ¿Qué opina de que se considere en el Perú que una persona } \\
\text { que llega a tener más de } 60 \text { años ya es inactiva? }\end{array}$ & $\begin{array}{l}\text { Considera que es falso, los tiempos han cambiado, los temas de salud han } \\
\text { mejorado, la gente igual que yo, sigue estudiando y actualizando. }\end{array}$ \\
\hline & $\begin{array}{l}\text { ¿Cuáles cree usted que son las características físicas, } \\
\text { sociales, económicas que caracterizan la etapa de vida que } \\
\text { está viviendo? }\end{array}$ & $\begin{array}{l}\text { A cada persona le afecta de forma diferente, hay algunos que tienen vida } \\
\text { social otros no. }\end{array}$ \\
\hline \multirow{6}{*}{ 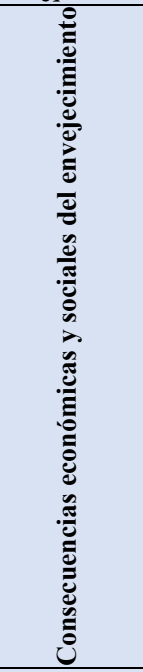 } & ¿Cuál es su grado de instrucción alcanzado? & Ingeniero electrónico, especialización en sistemas. \\
\hline & $\begin{array}{l}\text { ¿Le gustaría seguir estudiando? Tiene algún proyecto al } \\
\text { respecto }\end{array}$ & $\begin{array}{l}\text { Actualmente está estudiando curso de proyectos. Quiere hacer Diplomado } \\
\text { en ESAN de Proyectos internacionales. }\end{array}$ \\
\hline & $\begin{array}{l}\text { Nos podría describir: ¿Cuál es su ocupación, profesión? } \\
\text { ¿Actualmente a qué se dedica? }\end{array}$ & Jefe del área on line del casino, ingeniero electrónico. \\
\hline & $\begin{array}{l}\text { ¿Qué actividades realiza que podría considerar como un } \\
\text { trabajo no remunerado? ¿Esta actividad a quién beneficia? } \\
\text { ¿Por qué lo hace? (iniciativa, obligación) }\end{array}$ & Actividades del hogar, visita familiar, los fines de semana. \\
\hline & $\begin{array}{l}\text { ¿Cuál es la percepción personal de su situación de vida? } \\
\text { En relación con sus objetivos, expectativas, valores. ¿Está } \\
\text { a gusto, se siente bien al respecto? }\end{array}$ & Se siente a gusto con su vida. \\
\hline & $\begin{array}{l}\text { ¿Cómo se imagina que será su vida en los próximos años? } \\
\text { ¿Tendrá algún reto que enfrentar: (social, económico, de } \\
\text { salud)? }\end{array}$ & $\begin{array}{l}\text { Piensa trabajar } 3 \text { o } 4 \text { años más, porque ya va ser hora de compartir más } \\
\text { tiempo con su esposa. }\end{array}$ \\
\hline \multirow{4}{*}{ 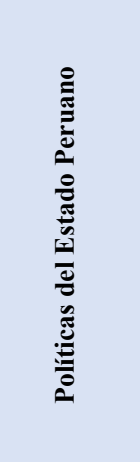 } & $\begin{array}{l}\text { Conoce de algunas de las políticas de Estado Peruano para } \\
\text { contribuir con el desarrollo de las personas adultas } \\
\text { mayores }\end{array}$ & No conoce \\
\hline & $\begin{array}{l}\text { Considera usted que el Estado Peruano le ha brindado } \\
\text { herramientas de desarrollo económico, social para la } \\
\text { salud. }\end{array}$ & No nunca \\
\hline & $\begin{array}{l}\text { ¿Contribuye usted a un sistema de pensiones? ¿Qué } \\
\text { opinión le merece que el estado mediante ley determina el } \\
\text { tiempo en que las todas las personas deben jubilarse? }\end{array}$ & $\begin{array}{l}\text { AFP, piensa que el tiempo está bien, luego indica que es facultad de la } \\
\text { empresa y no por la ley }\end{array}$ \\
\hline & ¿Cuenta usted con algún tipo de seguro de salud? & EPS, Es salud. \\
\hline \multirow{3}{*}{ 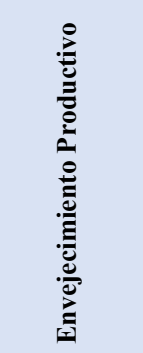 } & ¿Cómo se visualiza usted? ¿Tiene algún proyecto? & Estudiando y realizando proyectos. \\
\hline & $\begin{array}{l}\text { ¿Cuál es el rol que cumple la familia en su desempeño y } \\
\text { actividad del día a día? }\end{array}$ & Su familia es un ente motivador \\
\hline & $\begin{array}{l}\text { ¿Qué considera usted que necesita para mejorar su estado } \\
\text { de salud, o considera que su estado de salud actual es el } \\
\text { óptimo? }\end{array}$ & En general se siente bien, realizar ejercicios. \\
\hline
\end{tabular}




\begin{tabular}{|c|c|c|}
\hline \multirow[b]{3}{*}{ Categoría } & \multirow[b]{3}{*}{ Adultos mayores aportantes } & $\begin{array}{l}\text { Ex Futbolista Profesional } \\
\text { Entrenador }\end{array}$ \\
\hline & & $\begin{array}{l}\text { Sr. Guillermo L.R } 65 \text { años } \\
\text { director técnico, profesor, academia de futbol. }\end{array}$ \\
\hline & & Respuestas \\
\hline \multirow{2}{*}{ 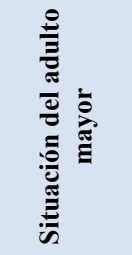 } & $\begin{array}{l}\text { ¿Qué opina de que se considere en el Perú que una persona } \\
\text { que llega a tener más de } 60 \text { años ya es inactiva? }\end{array}$ & $\begin{array}{l}\text { Todo depende del cuidado, los alimentos, la vida agitada puede afectar y } \\
\text { conlleva al envejecimiento, lo espiritual es importante. Yo puedo seguir } \\
\text { activo por la forma en que viví. }\end{array}$ \\
\hline & $\begin{array}{l}\text { ¿Cuáles cree usted que son las características físicas, } \\
\text { sociales, económicas que caracterizan la etapa de vida que } \\
\text { está viviendo? }\end{array}$ & Mantenerme activo y tener una vida espiritual tranquila. \\
\hline \multirow{6}{*}{ 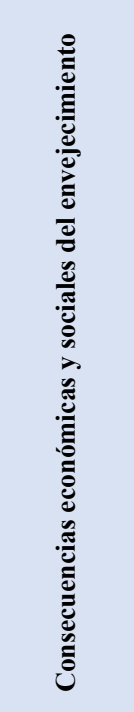 } & ¿Cuál es su grado de instrucción alcanzado? & $\begin{array}{l}\text { Superior trunco, luego se dedicó al deporte y llegó a ser un futbolista } \\
\text { profesional }\end{array}$ \\
\hline & $\begin{array}{l}\text { ¿Le gustaría seguir estudiando? Tiene algún proyecto al } \\
\text { respecto }\end{array}$ & Actualización en deporte, catequista en parroquia, charla para los padres. \\
\hline & $\begin{array}{l}\text { Nos podría describir: ¿Cuál es su ocupación, profesión? } \\
\text { ¿Actualmente a qué se dedica? }\end{array}$ & $\begin{array}{l}\text { Me levanto a las } 5 \text { am y rezo, luego voy a la parroquia a las } 7: 30 \text { como } \\
\text { acólito, luego a mi casa y en la tarde estoy en el colegio enseñando taller. } \\
\text { Siempre me encuentro en actividad. }\end{array}$ \\
\hline & $\begin{array}{l}\text { ¿Qué actividades realiza que podría considerar como un } \\
\text { trabajo no remunerado? ¿Esta actividad a quién beneficia? } \\
\text { ¿Por qué lo hace? (iniciativa, obligación) }\end{array}$ & Catequesis y charla para los padres, en una comunidad de 300 personas. \\
\hline & $\begin{array}{l}\text { ¿Cuál es la percepción personal de su situación de vida? } \\
\text { En relación con sus objetivos, expectativas, valores. ¿Está } \\
\text { a gusto, se siente bien al respecto? }\end{array}$ & Me siento feliz como persona, con mi esposa y con Dios. \\
\hline & $\begin{array}{l}\text { ¿Cómo se imagina que será su vida en los próximos años? } \\
\text { ¿Tendrá algún reto que enfrentar: (social, económico, de } \\
\text { salud)? }\end{array}$ & $\begin{array}{l}\text { Estar al lado de mi familia. Mi proyecto es tener un campo propio, videoteca, } \\
\text { etc. en favor de los chicos y ayudar a la familia. }\end{array}$ \\
\hline \multirow{4}{*}{ 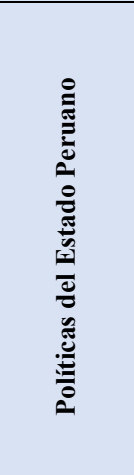 } & $\begin{array}{l}\text { Conoce de algunas de las políticas de Estado Peruano para } \\
\text { contribuir con el desarrollo de las personas adultas } \\
\text { mayores }\end{array}$ & $\begin{array}{l}\text { Muy poco ayuda el gobierno, ha visto a las municipalidades (San Borja) que } \\
\text { realiza actividades. }\end{array}$ \\
\hline & $\begin{array}{l}\text { Considera usted que el Estado Peruano le ha brindado } \\
\text { herramientas de desarrollo económico, social para la } \\
\text { salud. }\end{array}$ & No \\
\hline & $\begin{array}{l}\text { ¿Contribuye usted a un sistema de pensiones? ¿Qué } \\
\text { opinión le merece que el estado mediante ley determina el } \\
\text { tiempo en que las todas las personas deben jubilarse? }\end{array}$ & $\begin{array}{l}\text { AFP, es de doble filo, porque cuando te sacan de un trabajo piensan que ya } \\
\text { no sirves. Porque cuando te retiras sientes un vacío por eso tienes que estar } \\
\text { preparado. Habla de su retiro para el futbol a los } 36 \text { años y lo difícil que fue }\end{array}$ \\
\hline & ¿Cuenta usted con algún tipo de seguro de salud? & EsSalud. \\
\hline \multirow{3}{*}{ 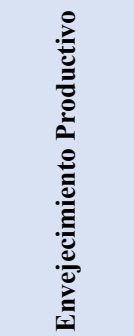 } & ¿Cómo se visualiza usted? ¿Tiene algún proyecto? & Ampliar la academia \\
\hline & $\begin{array}{l}\text { ¿Cuál es el rol que cumple la familia en su desempeño y } \\
\text { actividad del día a día? }\end{array}$ & $\begin{array}{l}\text { La familia es fundamental, la mayoría de familias está destruida porque no } \\
\text { hay amor. La soledad te envejece. }\end{array}$ \\
\hline & $\begin{array}{l}\text { ¿Qué considera usted que necesita para mejorar su estado } \\
\text { de salud, o considera que su estado de salud actual es el } \\
\text { óptimo? }\end{array}$ & $\begin{array}{l}\text { Realizo deporte, trato de llevar una vida sana, como fruta, verdura, etc. } \\
\text { Tengo mucha paz en mi vida. Así voy envejeciendo feliz. }\end{array}$ \\
\hline
\end{tabular}




\begin{tabular}{|c|c|c|}
\hline \multirow[b]{3}{*}{ Categoría } & \multirow[b]{3}{*}{ Adultos mayores aportantes } & $\begin{array}{l}\text { Técnica Enfermera } \\
\text { Encargada de Tópico Club Lima Cricket }\end{array}$ \\
\hline & & $\begin{array}{l}\text { Sra. María Esther S.O. } 62 \text { años } \\
\text { Técnica Enfermera en el Club Lima Cricket. }\end{array}$ \\
\hline & & Respuestas \\
\hline \multirow{2}{*}{ 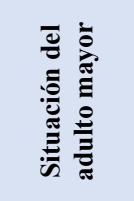 } & $\begin{array}{l}\text { ¿Qué opina de que se considere en el Perú que una persona } \\
\text { que llega a tener más de } 60 \text { años ya es inactiva? }\end{array}$ & No está de acuerdo, considera que mientras pueda, debe seguir trabajando \\
\hline & $\begin{array}{l}\text { ¿Cuáles cree usted que son las características físicas, } \\
\text { sociales, económicas que caracterizan la etapa de vida que } \\
\text { está viviendo? }\end{array}$ & Las personas mayores tenemos mucho que dar. \\
\hline \multirow{6}{*}{ 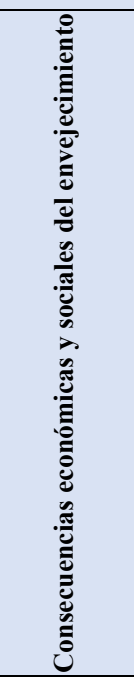 } & ¿Cuál es su grado de instrucción alcanzado? & Técnica en enfermería \\
\hline & $\begin{array}{l}\text { ¿Le gustaría seguir estudiando? Tiene algún proyecto al } \\
\text { respecto }\end{array}$ & Le gustaría llegar a la universidad, si estuviera a su alcance si lo haría \\
\hline & $\begin{array}{l}\text { Nos podría describir: ¿Cuál es su ocupación, profesión? } \\
\text { ¿Actualmente a qué se dedica? }\end{array}$ & Trabaja atendiendo un tópico de enfermería. Le gusta su trabajo. \\
\hline & $\begin{array}{l}\text { ¿Qué actividades realiza que podría considerar como un } \\
\text { trabajo no remunerado? ¿Esta actividad a quién beneficia? } \\
\text { ¿Por qué lo hace? (iniciativa, obligación) }\end{array}$ & $\begin{array}{l}\text { Colabora con cuidar a una persona mayor, sin cobrar. Cuida de su hermano } \\
\text { que está mal de salud. }\end{array}$ \\
\hline & $\begin{array}{l}\text { ¿Cuál es la percepción personal de su situación de vida? } \\
\text { En relación con sus objetivos, expectativas, valores. ¿Está } \\
\text { a gusto, se siente bien al respecto? }\end{array}$ & Le gustaría haber hecho otras cosas. Y quiere llegar a ser voluntaria. \\
\hline & $\begin{array}{l}\text { ¿Cómo se imagina que será su vida en los próximos años? } \\
\text { ¿Tendrá algún reto que enfrentar: (social, económico, de } \\
\text { salud)? }\end{array}$ & Le gustaría estar con personas de su edad. Y le gusta ayudar. \\
\hline \multirow{4}{*}{ 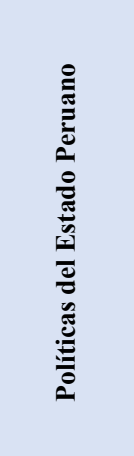 } & $\begin{array}{l}\text { Conoce de algunas de las políticas de Estado Peruano para } \\
\text { contribuir con el desarrollo de las personas adultas } \\
\text { mayores }\end{array}$ & $\begin{array}{l}\text { No ve ni conoce alguna política del estado peruano. Siente que el estado no } \\
\text { se preocupa. }\end{array}$ \\
\hline & $\begin{array}{l}\text { Considera usted que el Estado Peruano le ha brindado } \\
\text { herramientas de desarrollo económico, social para la } \\
\text { salud. }\end{array}$ & No, no lo ha requerido, pero observa que quien lo necesita no lo recibe \\
\hline & $\begin{array}{l}\text { ¿Contribuye usted a un sistema de pensiones? ¿Qué } \\
\text { opinión le merece que el estado mediante ley determina el } \\
\text { tiempo en que las todas las personas deben jubilarse? }\end{array}$ & $\begin{array}{l}\text { Si a la ONP, dice que no le va bastar. Las personas deben jubilarse cuando } \\
\text { lo crea pertinente. Como también hay personas que no pueden jubilarse por } \\
\text { el tiempo de aportación que solicitan }\end{array}$ \\
\hline & ¿Cuenta usted con algún tipo de seguro de salud? & Es salud \\
\hline \multirow{3}{*}{ 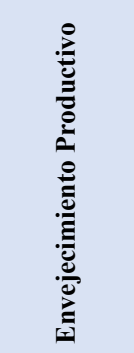 } & ¿Cómo se visualiza usted? ¿Tiene algún proyecto? & Le gustaría ayudar, viajar, estudiar. Pero sobre todo ayudar \\
\hline & $\begin{array}{l}\text { ¿Cuál es el rol que cumple la familia en su desempeño y } \\
\text { actividad del día a día? }\end{array}$ & Si, su trabajo es básico para mantenerse activa \\
\hline & $\begin{array}{l}\text { ¿Qué considera usted que necesita para mejorar su estado } \\
\text { de salud, o considera que su estado de salud actual es el } \\
\text { óptimo? }\end{array}$ & $\begin{array}{l}\text { No se siente mal, le gustaría hacerse un chequeo general. Quisiera hacer } \\
\text { prevención }\end{array}$ \\
\hline
\end{tabular}




\begin{tabular}{|c|c|c|}
\hline \multirow[b]{3}{*}{ Categoría } & \multirow[b]{3}{*}{ Adultos mayores aportantes } & \multirow{2}{*}{$\begin{array}{c}\text { Contadora Pública } \\
\text { Gerente de Estudio Contable }\end{array}$} \\
\hline & & \\
\hline & & Respuestas \\
\hline \multirow{2}{*}{ 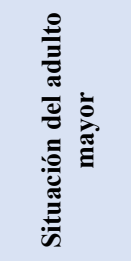 } & $\begin{array}{l}\text { ¿Qué opina de que se considere en el Perú que una persona } \\
\text { que llega a tener más de } 60 \text { años ya es inactiva? }\end{array}$ & $\begin{array}{l}\text { No está de acuerdo. Todavía existe la capacidad de poder emprender. A los } \\
60 \text { años menciona tener proyectos y siente que puede dar más }\end{array}$ \\
\hline & $\begin{array}{l}\text { ¿Cuáles cree usted que son las características físicas, } \\
\text { sociales, económicas que caracterizan la etapa de vida que } \\
\text { está viviendo? }\end{array}$ & $\begin{array}{l}\text { Socialmente bien, siente que se desenvuelve mejor. Económicamente, es } \\
\text { gracias a estudios. Físicamente tiene algunos dolores. Se da ánimos para } \\
\text { superarse }\end{array}$ \\
\hline \multirow{6}{*}{ 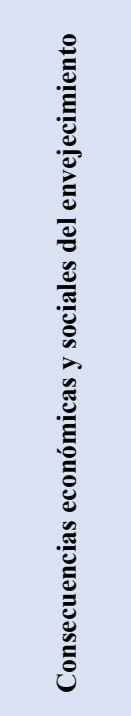 } & ¿Cuál es su grado de instrucción alcanzado? & Contadora Pública. Maestría en Sistema y Política Tributaria \\
\hline & $\begin{array}{l}\text { ¿Le gustaría seguir estudiando? Tiene algún proyecto al } \\
\text { respecto }\end{array}$ & Quiere estudiar Derecho en el aspecto y familia. \\
\hline & $\begin{array}{l}\text { Nos podría describir: ¿Cuál es su ocupación, profesión? } \\
\text { ¿Actualmente a qué se dedica? }\end{array}$ & 6am de la mañana ya está levantada. Trabaja en su estudio contable \\
\hline & $\begin{array}{l}\text { ¿Qué actividades realiza que podría considerar como un } \\
\text { trabajo no remunerado? ¿Esta actividad a quién beneficia? } \\
\text { ¿Por qué lo hace? (iniciativa, obligación) }\end{array}$ & Realiza visita a niños en grupos jóvenes. Enseña. \\
\hline & $\begin{array}{l}\text { ¿Cuál es la percepción personal de su situación de vida? } \\
\text { En relación con sus objetivos, expectativas, valores. ¿Está } \\
\text { a gusto, se siente bien al respecto? }\end{array}$ & Se siente satisfecha con lo que ha logrado. \\
\hline & $\begin{array}{l}\text { ¿Cómo se imagina que será su vida en los próximos años? } \\
\text { ¿Tendrá algún reto que enfrentar: (social, económico, de } \\
\text { salud)? }\end{array}$ & $\begin{array}{l}\text { No tiene hijos. Y se preocupa porque quien va hacer su soporte. Y espera } \\
\text { que sus sobrinos }\end{array}$ \\
\hline \multirow{4}{*}{ 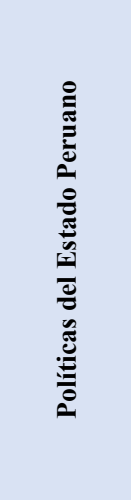 } & $\begin{array}{l}\text { Conoce de algunas de las políticas de Estado Peruano para } \\
\text { contribuir con el desarrollo de las personas adultas } \\
\text { mayores }\end{array}$ & $\begin{array}{l}\text { Considera que siempre son proyectos y son buenos, pero siempre son mal } \\
\text { manejados }\end{array}$ \\
\hline & $\begin{array}{l}\text { Considera usted que el Estado Peruano le ha brindado } \\
\text { herramientas de desarrollo económico, social para la } \\
\text { salud. }\end{array}$ & $\begin{array}{l}\text { Considera que sus méritos son propios. Incluso identifica barreras, por } \\
\text { ejemplo, para acceder a la salud. Y por eso se acude a clínicas privadas. Los } \\
\text { servicios del estado no son ayuda inmediata }\end{array}$ \\
\hline & $\begin{array}{l}\text { ¿Contribuye usted a un sistema de pensiones? ¿Qué } \\
\text { opinión le merece que el estado mediante ley determina el } \\
\text { tiempo en que las todas las personas deben jubilarse? }\end{array}$ & $\begin{array}{l}\text { ONP. Cree que deberían jubilarse a menos tiempo para poder disfrutarlo. } \\
\text { Yo quisiera jubilarme, pero las tasas no son óptimas. }\end{array}$ \\
\hline & ¿Cuenta usted con algún tipo de seguro de salud? & Es salud \\
\hline \multirow{3}{*}{ 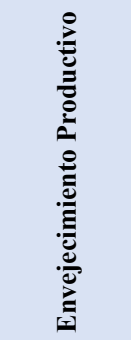 } & ¿Cómo se visualiza usted? ¿Tiene algún proyecto? & Quiere estudiar Derecho. \\
\hline & $\begin{array}{l}\text { ¿Cuál es el rol que cumple la familia en su desempeño y } \\
\text { actividad del día a día? }\end{array}$ & Es muy importante. Somos 10 hermanos. Somos muy unidos. \\
\hline & $\begin{array}{l}\text { ¿Qué considera usted que necesita para mejorar su estado } \\
\text { de salud, o considera que su estado de salud actual es el } \\
\text { óptimo? }\end{array}$ & $\begin{array}{l}\text { Los medicamentos, es una persona diabética, ella puede comprase los } \\
\text { medicamentos, pero sabe que hay personas que no pueden, y no tienen } \\
\text { acceso a buenos medicamentos. }\end{array}$ \\
\hline
\end{tabular}




\begin{tabular}{|c|c|c|}
\hline & & $\begin{array}{l}\text { Docente Universitaria } \\
\text { de la UNMSM }\end{array}$ \\
\hline & & $\begin{array}{l}\text { Sra. Imelda T. P. } 67 \text { años } \\
\text { Docente Universitaria UNMSM }\end{array}$ \\
\hline Categoría & Adultos mayores aportantes & Respuestas \\
\hline \multirow{2}{*}{ 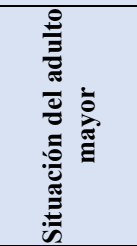 } & $\begin{array}{l}\text { ¿Qué opina de que se considere en el Perú que una persona } \\
\text { que llega a tener más de } 60 \text { años ya es inactiva? }\end{array}$ & $\begin{array}{l}\text { Es una idea equivoca, la experiencia hace a las personas más competitivos } \\
\text { y productivos. }\end{array}$ \\
\hline & $\begin{array}{l}\text { ¿Cuáles cree usted que son las características físicas, } \\
\text { sociales, económicas que caracterizan la etapa de vida que } \\
\text { está viviendo? }\end{array}$ & $\begin{array}{l}\text { Físicas es un estado mental. El envejecimiento es normal. La actitud } \\
\text { depende de cómo el individuo se enfrenta }\end{array}$ \\
\hline \multirow{6}{*}{ 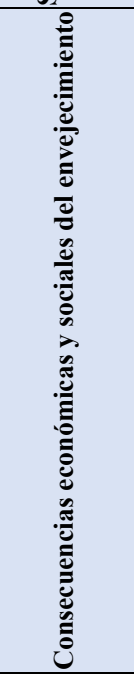 } & ¿Cuál es su grado de instrucción alcanzado? & Doctorado en Economía \\
\hline & $\begin{array}{l}\text { ¿Le gustaría seguir estudiando? Tiene algún proyecto al } \\
\text { respecto }\end{array}$ & Sigue estudiando Arte \\
\hline & $\begin{array}{l}\text { Nos podría describir: ¿Cuál es su ocupación, profesión? } \\
\text { ¿Actualmente a qué se dedica? }\end{array}$ & Docente Universitaria en pre grado y post grado \\
\hline & $\begin{array}{l}\text { ¿Qué actividades realiza que podría considerar como un } \\
\text { trabajo no remunerado? ¿Esta actividad a quién beneficia? } \\
\text { ¿Por qué lo hace? (iniciativa, obligación) }\end{array}$ & $\begin{array}{l}\text { Se reúne con sus promocionales y hacer labores de investigación para } \\
\text { promocionar la investigación académica }\end{array}$ \\
\hline & $\begin{array}{l}\text { ¿Cuál es la percepción personal de su situación de vida? } \\
\text { En relación con sus objetivos, expectativas, valores. ¿Está } \\
\text { a gusto, se siente bien al respecto? }\end{array}$ & $\begin{array}{l}\text { Se siente muy bien en su zona de confort. Por falta de tiempo no hace } \\
\text { muchas otras cosas. }\end{array}$ \\
\hline & $\begin{array}{l}\text { ¿Cómo se imagina que será su vida en los próximos años? } \\
\text { ¿Tendrá algún reto que enfrentar: (social, económico, de } \\
\text { salud)? }\end{array}$ & $\begin{array}{l}\text { Escuchando música, cultivando su espíritu. Leyendo Libros. Con alguna } \\
\text { actividad en beneficio de sus discípulos. }\end{array}$ \\
\hline \multirow{4}{*}{ 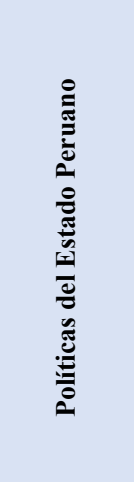 } & $\begin{array}{l}\text { Conoce de algunas de las políticas de Estado Peruano para } \\
\text { contribuir con el desarrollo de las personas adultas } \\
\text { mayores }\end{array}$ & $\begin{array}{l}\text { No creo que exista una política de ayuda a sobrellevar el envejecimiento en } \\
\text { las personas adultas }\end{array}$ \\
\hline & $\begin{array}{l}\text { Considera usted que el Estado Peruano le ha brindado } \\
\text { herramientas de desarrollo económico, social para la } \\
\text { salud. }\end{array}$ & $\begin{array}{l}\text { Reconoce que estudió en una universidad y colegio público y trabaja en una } \\
\text { universidad pública }\end{array}$ \\
\hline & $\begin{array}{l}\text { ¿Contribuye usted a un sistema de pensiones? ¿Qué } \\
\text { opinión le merece que el estado mediante ley determina el } \\
\text { tiempo en que las todas las personas deben jubilarse? }\end{array}$ & $\begin{array}{l}\text { A la seguridad social y también privada. Es muy complejo, cuando cultivas } \\
\text { tu estado mental puede ser muy activo. Pero en el aspecto físico no siempre } \\
\text { se puede. }\end{array}$ \\
\hline & ¿Cuenta usted con algún tipo de seguro de salud? & Si. \\
\hline \multirow{3}{*}{ 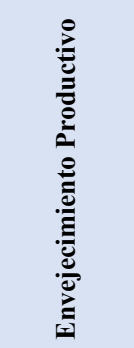 } & ¿Cómo se visualiza usted? ¿Tiene algún proyecto? & Si quiere seguir estudiando. \\
\hline & $\begin{array}{l}\text { ¿Cuál es el rol que cumple la familia en su desempeño y } \\
\text { actividad del día a día? }\end{array}$ & La familia debe contribuir a que el adulto mayor no debe sentirse inútil. \\
\hline & $\begin{array}{l}\text { ¿Qué considera usted que necesita para mejorar su estado } \\
\text { de salud, o considera que su estado de salud actual es el } \\
\text { óptimo? }\end{array}$ & Está satisfecha con lo que tiene. Y pide siempre salud, para poder continuar. \\
\hline
\end{tabular}




\begin{tabular}{|c|c|c|}
\hline Categoría & Adultos mayores aportantes & Similitudes / Diferencias \\
\hline \multirow{2}{*}{ 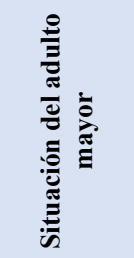 } & $\begin{array}{l}\text { ¿Qué opina de que se considere en el Perú que una persona } \\
\text { que llega a tener más de } 60 \text { años ya es inactiva? }\end{array}$ & $\begin{array}{l}\text { No están de acuerdo. Considera que una persona mayor de } 60 \text { sigue siendo } \\
\text { activa, tiene experiencia y pueden seguir trabajando }\end{array}$ \\
\hline & $\begin{array}{l}\text { ¿Cuáles cree usted que son las características físicas, } \\
\text { sociales, económicas que caracterizan la etapa de vida que } \\
\text { está viviendo? }\end{array}$ & $\begin{array}{l}\text { En esta etapa (según los entrevistados) desarrollan más actividades físicas y } \\
\text { están preocupados por mantenerse saludables y activos. }\end{array}$ \\
\hline \multirow{6}{*}{ 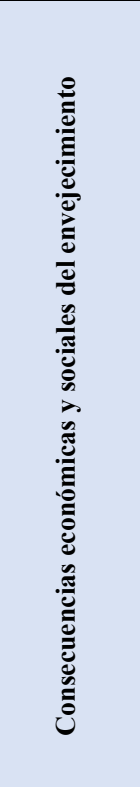 } & ¿Cuál es su grado de instrucción alcanzado? & $\begin{array}{l}\text { Todos los entrevistados tuvieron la oportunidad de estudiar una carrera } \\
\text { superior, sea técnico o universitario; } 01 \text { practicó deporte de forma } \\
\text { profesional. }\end{array}$ \\
\hline & $\begin{array}{l}\text { ¿Le gustaría seguir estudiando? Tiene algún proyecto al } \\
\text { respecto }\end{array}$ & $\begin{array}{l}\text { Todos refieren tener interés en seguir estudiando o aprendiendo actividades } \\
\text { nuevas. }\end{array}$ \\
\hline & $\begin{array}{l}\text { Nos podría describir: ¿Cuál es su ocupación, profesión? } \\
\text { ¿Actualmente a qué se dedica? }\end{array}$ & Todos están trabajando activamente un mínimo de 7 horas al día \\
\hline & $\begin{array}{l}\text { ¿Qué actividades realiza que podría considerar como un } \\
\text { trabajo no remunerado? ¿Esta actividad a quién beneficia? } \\
\text { ¿Por qué lo hace? (iniciativa, obligación) }\end{array}$ & $\begin{array}{l}\text { El } 88 \% \text { por ciento por lo menos realiza una actividad no remunerada. El } \\
25 \% \text { se encarga del cuidado de un familiar directo. }\end{array}$ \\
\hline & $\begin{array}{l}\text { ¿Cuál es la percepción personal de su situación de vida? } \\
\text { En relación con sus objetivos, expectativas, valores. ¿Está } \\
\text { a gusto, se siente bien al respecto? }\end{array}$ & $\begin{array}{l}\text { Todos refieren sentirse a gusto con la vida que tiene, pero uno de los } \\
\text { entrevistados indica que en el ámbito laboral no se siente a gusto, pues } \\
\text { refiere que puede dar más de sí. }\end{array}$ \\
\hline & $\begin{array}{l}\text { ¿Cómo se imagina que será su vida en los próximos años? } \\
\text { ¿Tendrá algún reto que enfrentar: (social, económico, de } \\
\text { salud)? }\end{array}$ & $\begin{array}{l}\text { El } 80 \% \text { refiere tener un proyecto personal, sea enfocado a la familia o su } \\
\text { situación económica; sin embargo, el } 20 \% \text { de entrevistados indica no tener } \\
\text { retos ni problemas económicos o personales. }\end{array}$ \\
\hline \multirow{4}{*}{ 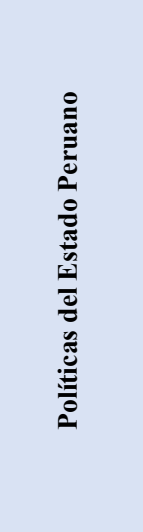 } & $\begin{array}{l}\text { Conoce de algunas de las políticas de Estado Peruano para } \\
\text { contribuir con el desarrollo de las personas adultas } \\
\text { mayores }\end{array}$ & $\begin{array}{l}\text { El } 50 \% \text { de los entrevistado no conocer de alguna política de estado. El } \\
37,5 \% \text { conoce de los programas municipales. Y el } 12,5 \text { por ciento refiere } \\
\text { menciona conocer la atención preferencial }\end{array}$ \\
\hline & $\begin{array}{l}\text { Considera usted que el Estado Peruano le ha brindado } \\
\text { herramientas de desarrollo económico, social para la } \\
\text { salud. }\end{array}$ & $\begin{array}{l}\text { EL } 87,5 \text { por ciento de los entrevistados destaca no haber recibido apoyo } \\
\text { alguno del estado. Y el } 12,5 \% \text { indica haber estudiado y actualmente trabajar } \\
\text { para el estado. }\end{array}$ \\
\hline & $\begin{array}{l}\text { ¿Contribuye usted a un sistema de pensiones? ¿Qué } \\
\text { opinión le merece que el estado mediante ley determina el } \\
\text { tiempo en que las todas las personas deben jubilarse? }\end{array}$ & $\begin{array}{l}\text { Todos los entrevistados refieren tener un sistema de pensiones(privado) } \\
\text { Con respecto a la edad de jubilación, hay } 03 \text { puntos de vista diferentes: } \\
\text { A) Está mal que sea por la edad, es un aspecto relativo. } \\
\text { B) Debe ser facultad de } \text { la } \\
\text { C) Debería ser antes para realizar otras actividades. }\end{array}$ \\
\hline & ¿Cuenta usted con algún tipo de seguro de salud? & $\begin{array}{l}\text { Todos los entrevistados tiene ES Salud y el } 50 \% \text { refiere tener } \\
\text { adicionalmente un seguro de salud privado. }\end{array}$ \\
\hline \multirow{3}{*}{ 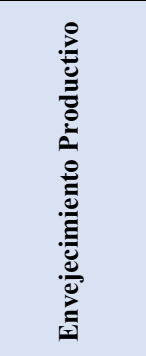 } & ¿Cómo se visualiza usted? ¿Tiene algún proyecto? & $\begin{array}{l}\text { El } 87,5 \% \text { de ellos menciona tener un proyecto (viajes y negocio) sin } \\
\text { embargo, el } 12,5 \% \text { de ellos indica que no tiene proyectos a futuro. }\end{array}$ \\
\hline & $\begin{array}{l}\text { ¿Cuál es el rol que cumple la familia en su desempeño y } \\
\text { actividad del día a día? }\end{array}$ & $\begin{array}{l}\text { Todos refieren que la familia es un pilar importante para el desarrollo y para } \\
\text { que logren sus objetivos. }\end{array}$ \\
\hline & $\begin{array}{l}\text { ¿Qué considera usted que necesita para mejorar su estado } \\
\text { de salud, o considera que su estado de salud actual es el } \\
\text { óptimo? }\end{array}$ & $\begin{array}{l}\text { El } 87,5 \% \text { de los entrevistados refiere estar bien de salud; de ellos, el } 50 \% \\
\text { indica que se realiza un chequeo médico anual y el otro } 50 \% \text { indica que } \\
\text { realiza } \\
\text { El } 12,5 \% \text { de loste. } \\
\text { ploventrevistados refiere que lograr estar bien de salud le } \\
\text { provomodidad en su trabajo por los permisos que tiene que pedir. }\end{array}$ \\
\hline
\end{tabular}


Bitácoras No aportantes

\begin{tabular}{|c|c|c|c|}
\hline & & & Entrevistado 1 \\
\hline $\begin{array}{l}\text { Observaciones } \\
\text { antes de la } \\
\text { entrevista }\end{array}$ & Contexto Interno & & $\begin{array}{l}\text { Sr. Manuel de la Rosa Olivo, } 65 \text { años } \\
\text { área } 9 \text { del Hogar Canevaro. }\end{array}$ \\
\hline & Categorías & Segmento 3 - No aportantes, vulnerables & $\begin{array}{l}\text { Hogar Canevaro. } \\
\text { La entrevista se realizó en compañía del personal de } \\
\text { psicología, quien nos acompañó en todo momento y } \\
\text { fue quien nos brindó información relevante que los } \\
\text { residentes no recordaban o no brindaban. }\end{array}$ \\
\hline \multirow{3}{*}{$\begin{array}{l}\text { Observaciones } \\
\text { durante la } \\
\text { entrevista }\end{array}$} & $\begin{array}{l}\text { Consecuencias } \\
\text { económicas y } \\
\text { sociales del } \\
\text { envejecimiento }\end{array}$ & $\begin{array}{l}\text { Nos podría indicar si el Sr. (a) tenía algún } \\
\text { oficio u ocupación. ¿Cuál era? } \\
\text { Si su grado de dependencia lo permite, el } \\
\text { señor (a) realiza algún tipo de actividad } \\
\text { ¿Cuál es la situación del señor (a), } \\
\text { satisface sus principales necesidades: } \\
\text { salud, económicas, sociales (cultiva } \\
\text { amistades, mantiene una vida social) }\end{array}$ & $\begin{array}{l}\text { Refiere que hacía de todo en su juventud, trabajaba de } \\
\text { reciclador, vendiendo periódico, etc. } \\
\text { El Sr. Se encuentra acostado (postrado) por ulcera en } \\
\text { pie, es dependiente. } \\
\text { No satisface sus propias necesidades, cuenta con SIS } \\
\text { y por las enfermedades que tiene se trata en el } \\
\text { hospital Noguchi. }\end{array}$ \\
\hline & $\begin{array}{l}\text { Políticas del } \\
\text { Estado Peruano }\end{array}$ & $\begin{array}{l}\text { ¿Tiene conocimiento que existen } \\
\text { programas sociales en el Estado Peruano? } \\
\text { ¿Pertenece el Sr. (a) a alguno?, podría } \\
\text { contarnos su experiencia. } \\
\text { ¿El señor (ar) se encuentra ya jubilado? } \\
\text { ¿Nos podría indicar en cuanto consiste su } \\
\text { monto de pensión? } \\
\text { ¿Cuál es la situación de salud en la que se } \\
\text { encuentra el señor (a)? ¿Cuenta con algún } \\
\text { sistema de salud? De ser así, ¿Podría } \\
\text { describir exactamente en qué situaciones } \\
\text { lo usa? }\end{array}$ & $\begin{array}{l}\text { No. } \\
\text { No se jubiló por lo que no recibe pensión. } \\
\text { El Sr. Es dependiente y tiene problemas de salud } \\
\text { (ulcera y trastorno psicótico). }\end{array}$ \\
\hline & $\begin{array}{l}\text { Envejecimiento } \\
\text { Productivo }\end{array}$ & $\begin{array}{l}\text { ¿Cómo considera usted que el señor (a) } \\
\text { puede mejorar su situación? } \\
\text { ¿Quién es la persona responsable del } \\
\text { cuidado del cuidado del Señor (a)? ¿Si no } \\
\text { estuviera esa persona a cargo que } \\
\text { actividad desarrollaría? ¿Recibe apoyo de } \\
\text { algún otro familiar? }\end{array}$ & $\begin{array}{l}\text { Es } \\
\text { Los trabajadores del Hogar Canevaro, no recibe apoyo } \\
\text { de familia. Cuenta con SIS. Lo utiliza cuando lo } \\
\text { requiere. }\end{array}$ \\
\hline
\end{tabular}




\begin{tabular}{|c|c|c|c|}
\hline & & & Entrevistado 2 \\
\hline $\begin{array}{l}\text { Observaciones antes } \\
\text { de la entrevista }\end{array}$ & Contexto Interno & & 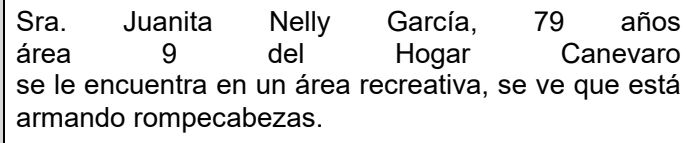 \\
\hline & Categorías & Segmento 3 - No aportantes, vulnerables & $\begin{array}{l}\text { Hogar Canevaro. } \\
\text { La entrevista se realizó en compañía del personal de } \\
\text { psicología, quien nos acompañó en todo momento y } \\
\text { fue quien nos brindó información relevante que los } \\
\text { residentes no recordaban o no brindaban. }\end{array}$ \\
\hline \multirow{3}{*}{$\begin{array}{l}\text { Observaciones } \\
\text { durante la entrevista }\end{array}$} & $\begin{array}{l}\text { Consecuencias } \\
\text { económicas y } \\
\text { sociales del } \\
\text { envejecimiento }\end{array}$ & $\begin{array}{l}\text { Nos podría indicar si el Sr. (a) tenía algún } \\
\text { oficio u ocupación. ¿Cuál era? } \\
\text { Si su grado de dependencia lo permite, el } \\
\text { señor (a) realiza algún tipo de actividad } \\
\text { ¿Cuál es la situación del señor (a), } \\
\text { satisface sus principales necesidades: } \\
\text { salud, económicas, sociales (cultiva } \\
\text { amistades, mantiene una vida social) }\end{array}$ & $\begin{array}{l}\text { La señora refiere que de joven trabajo en casas } \\
\text { familiares. } \\
\text { La Sra. No tiene grado de dependencia para sus } \\
\text { actividades diarias y personales (camina y se baña } \\
\text { sola). } \\
\text { No satisface sus propias necesidades (económicas, } \\
\text { salud, etc.). Presenta sordera. }\end{array}$ \\
\hline & $\begin{array}{l}\text { Políticas del Estado } \\
\text { Peruano }\end{array}$ & $\begin{array}{l}\text { ¿Tiene conocimiento que existen } \\
\text { programas sociales en el Estado } \\
\text { Peruano? ¿Pertenece el Sr. (a) a alguno?, } \\
\text { podría contarnos su experiencia. } \\
\text { ¿El señor (ar) se encuentra ya jubilado? } \\
\text { ¿Nos podría indicar en cuanto consiste su } \\
\text { monto de pensión? } \\
\text { ¿Cuál es la situación de salud en la que se } \\
\text { encuentra el señor (a)? ¿Cuenta con } \\
\text { algún sistema de salud? De ser así, } \\
\text { ¿Podría describir exactamente en qué } \\
\text { situaciones lo usa? }\end{array}$ & $\begin{array}{l}\text { No. } \\
\text { No recibe pensión, no tuvo trabajo formal. }\end{array}$ \\
\hline & $\begin{array}{l}\text { Envejecimiento } \\
\text { Productivo }\end{array}$ & $\begin{array}{l}\text { ¿Cómo considera usted que el señor (a) } \\
\text { puede mejorar su situación? } \\
\text { ¿Quién es la persona responsable del } \\
\text { cuidado del cuidado del Señor (a)? ¿Si no } \\
\text { estuviera esa persona a cargo que } \\
\text { actividad desarrollaría? ¿Recibe apoyo de } \\
\text { algún otro familiar? }\end{array}$ & $\begin{array}{l}\text { No tiene familia, al finalizar la entrevista llora al } \\
\text { recordar un episodio de robo. Tiene SIS. }\end{array}$ \\
\hline
\end{tabular}




\begin{tabular}{|c|c|c|c|}
\hline & & & Entrevistado 3 \\
\hline \multirow[t]{2}{*}{$\begin{array}{l}\text { Observaciones antes } \\
\text { de la entrevista }\end{array}$} & Contexto Interno & & 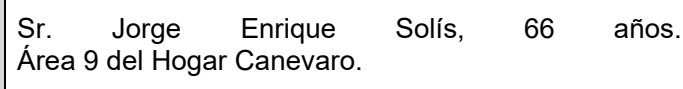 \\
\hline & Categorías & Segmento 3 - No aportantes, vulnerables & \begin{tabular}{|c|} 
Hogar Canevaro. \\
La entrevista se realizó en compañía del personal de \\
psicología, quien nos acompañó en todo momento y \\
fue quien nos brindó información relevante que los \\
residentes no recordaban o no brindaban.
\end{tabular} \\
\hline \multirow{3}{*}{$\begin{array}{c}\text { Observaciones } \\
\text { durante la entrevista }\end{array}$} & $\begin{array}{l}\text { Consecuencias } \\
\text { económicas y } \\
\text { sociales del } \\
\text { envejecimiento }\end{array}$ & $\begin{array}{l}\text { Nos podría indicar si el Sr. (a) tenía algún } \\
\text { oficio u ocupación. ¿Cuál era? } \\
\text { Si su grado de dependencia lo permite, el } \\
\text { señor (a) realiza algún tipo de actividad } \\
\text { ¿Cuál es la situación del señor (a), } \\
\text { satisface sus principales necesidades: } \\
\text { salud, económicas, sociales (cultiva } \\
\text { amistades, mantiene una vida social) }\end{array}$ & $\begin{array}{l}\text { El señor refiere que tuvo varios trabajos } \\
\text { independientes (repartidor de leche y escenografías } \\
\text { de teatros) y posteriormente en la cámara de } \\
\text { comercio; sin embargo, reconoce que no cumplió el } \\
\text { tiempo para poder gozar de beneficios (pensión). } \\
\text { Indica que es bombero retirado. } \\
\text { No presenta mayor grado de dependencia, es } \\
\text { independiente para sus actividades personales y de } \\
\text { aseo. }\end{array}$ \\
\hline & $\begin{array}{l}\text { Políiticas del Estado } \\
\text { Peruano }\end{array}$ & $\begin{array}{l}\text { ¿Tiene conocimiento que existen } \\
\text { programas sociales en el Estado } \\
\text { Peruano? ¿Pertenece el Sr. (a) a alguno?, } \\
\text { podría contarnos su experiencia. } \\
\text { ¿El señor (ar) se encuentra ya jubilado? } \\
\text { ¿Nos podría indicar en cuanto consiste su } \\
\text { monto } \\
\text { ¿Cuál es la situación de salud pensión? } \\
\text { encuentra el señor (a)? ¿Cuenta con } \\
\text { algún sistema de salud? De ser así, } \\
\text { ¿Podria describir exactamente en qué } \\
\text { situaciones lo usa? }\end{array}$ & 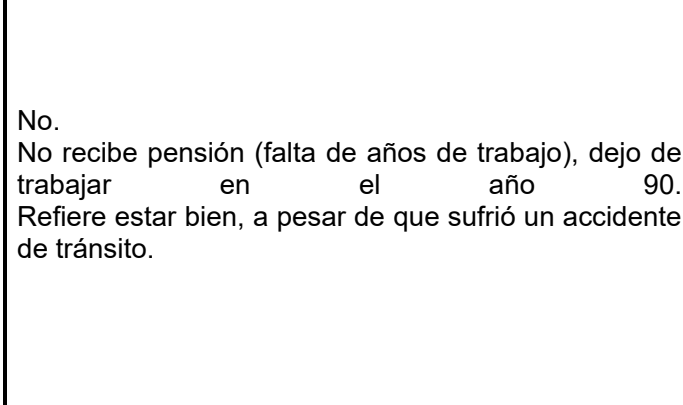 \\
\hline & $\begin{array}{l}\text { Envejecimiento } \\
\text { Productivo }\end{array}$ & $\begin{array}{l}\text { ¿Cómo considera usted que el señor (a) } \\
\text { puede mejorar su situación? } \\
\text { ¿Quién es la persona responsable del } \\
\text { cuidado del cuidado del Señor (a)? ¿Si no } \\
\text { estuviera esa persona a cargo que } \\
\text { actividad desarrollaría? ¿Recibe apoyo de } \\
\text { algún otro familiar? }\end{array}$ & $\begin{array}{l}\text { Refiere que tiene un hijo y un nieto. } \\
\text { El señor indica que antes estuvo en otro asilo. } \\
\text { Además resalta que él tomó la decisión de internarse } \\
\text { indicando "Si no le sumo a mi hijo, tampoco voy a } \\
\text { restarle". Tiene SIS. }\end{array}$ \\
\hline
\end{tabular}




\begin{tabular}{|c|c|c|c|}
\hline & & & Entrevistado 4 \\
\hline $\begin{array}{l}\text { Observaciones antes } \\
\text { de la entrevista }\end{array}$ & Contexto Interno & & 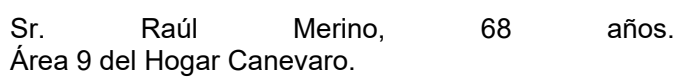 \\
\hline & Categorías & Segmento 3 - No aportantes, vulnerables & $\begin{array}{l}\text { Hogar Canevaro. } \\
\text { La entrevista se realizó en compañía del personal de } \\
\text { psicología, quien nos acompañó en todo momento y } \\
\text { fue quien nos brindó información relevante que los } \\
\text { residentes no recordaban o no brindaban. }\end{array}$ \\
\hline \multirow{3}{*}{$\begin{array}{l}\text { Observaciones } \\
\text { durante la entrevista }\end{array}$} & $\begin{array}{l}\text { Consecuencias } \\
\text { económicas y } \\
\text { sociales del } \\
\text { envejecimiento }\end{array}$ & $\begin{array}{l}\text { Nos podría indicar si el Sr. (a) tenía algún } \\
\text { oficio u ocupación. ¿Cuál era? } \\
\text { Si su grado de dependencia lo permite, el } \\
\text { señor (a) realiza algún tipo de actividad } \\
\text { ¿Cuál es la situación del señor (a), } \\
\text { satisface sus principales necesidades: } \\
\text { salud, económicas, sociales (cultiva } \\
\text { amistades, mantiene una vida social) }\end{array}$ & $\begin{array}{l}\text { El señor refiere que tuvo trabajos independientes y } \\
\text { después en el banco de mi vivienda, sin embargo, no } \\
\text { logró jubilarse por lo que no puede gozar de beneficios } \\
\text { (pensión). } \\
\text { Satisface sus necesidades de aseo, por lo que no tiene } \\
\text { mayor grado de dependencia. }\end{array}$ \\
\hline & $\begin{array}{l}\text { Políticas del } \\
\text { Estado Peruano }\end{array}$ & 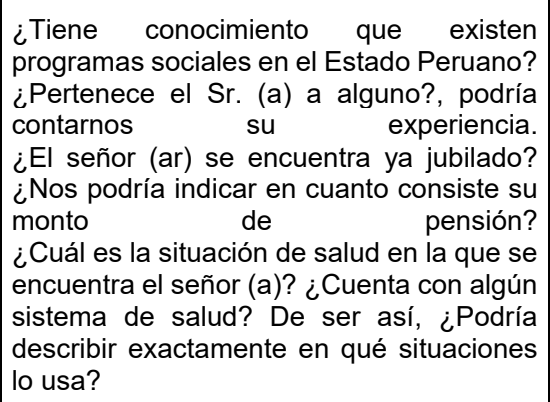 & $\begin{array}{l}\text { No. } \\
\text { No recibe pensión. }\end{array}$ \\
\hline & $\begin{array}{l}\text { Envejecimiento } \\
\text { Productivo }\end{array}$ & $\begin{array}{l}\text { ¿Cómo considera usted que el señor (a) } \\
\text { puede mejorar su situación? } \\
\text { ¿Quién es la persona responsable del } \\
\text { cuidado del cuidado del Señor (a)? ¿Si no } \\
\text { estuviera esa persona a cargo que } \\
\text { actividad desarrollaría? ¿Recibe apoyo de } \\
\text { algún otro familiar? }\end{array}$ & $\begin{array}{l}\text { No recibe apoyo de familiar a pesar de contar con una } \\
\text { hermana lo visita. No refiere problemas de salud, } \\
\text { cuenta con SIS. }\end{array}$ \\
\hline
\end{tabular}




\begin{tabular}{|c|c|c|c|}
\hline & & & Entrevistado 5 \\
\hline \multirow[t]{2}{*}{$\begin{array}{l}\text { Observaciones antes } \\
\text { de la entrevista }\end{array}$} & Contexto Interno & & $\begin{array}{l}\text { Sra. Nelly Polo Castro, } 91 \text { años } \\
\text { área } 9 \text { del Hogar Canevaro - habitaciones. }\end{array}$ \\
\hline & Categorías & Segmento 3 - No aportantes, vulnerables & $\begin{array}{c}\text { Hogar Canevaro. } \\
\text { La entrevista se realizó en compañía del personal } \\
\text { de psicología, quien nos acompañó en todo } \\
\text { momento y fue quien nos brindó información } \\
\text { relevante que los residentes no recordaban o no } \\
\text { brindaban. }\end{array}$ \\
\hline \multirow{3}{*}{$\begin{array}{l}\text { Observaciones } \\
\text { durante la entrevista }\end{array}$} & $\begin{array}{l}\text { Consecuencias } \\
\text { económicas y } \\
\text { sociales del } \\
\text { envejecimiento }\end{array}$ & $\begin{array}{l}\text { Nos podría indicar si el Sr. (a) tenía algún } \\
\text { oficio u ocupación. ¿Cuál era? } \\
\text { Si su grado de dependencia lo permite, el } \\
\text { señor (a) realiza algún tipo de actividad } \\
\text { ¿Cuál es la situación del señor (a), } \\
\text { satisface sus principales necesidades: } \\
\text { salud, económicas, sociales (cultiva } \\
\text { amistades, mantiene una vida social) }\end{array}$ & $\begin{array}{l}\text { La señora refiere que solo se dedicaba a su casa, } \\
\text { nunca se casó, tuvo una fractura de cadera lo cual } \\
\text { la mantiene en silla de ruedas y necesita del apoyo } \\
\text { del personal (dependencia). }\end{array}$ \\
\hline & $\begin{array}{l}\text { Políticas del Estado } \\
\text { Peruano }\end{array}$ & $\begin{array}{l}\text { ¿Tiene conocimiento que existen } \\
\text { programas sociales en el Estado } \\
\text { Peruano? ¿Pertenece el Sr. (a) a alguno?, } \\
\text { podría contarnos su experiencia. } \\
\text { ¿El señor (ar) se encuentra ya jubilado? } \\
\text { ¿Nos podría indicar en cuanto consiste su } \\
\text { monto de pensión? } \\
\text { ¿Cuál es la situación de salud en la que se } \\
\text { encuentra el señor (a)? ¿Cuenta con } \\
\text { algún sistema de salud? De ser así, } \\
\text { ¿Podría describir exactamente en qué } \\
\text { situaciones lo usa? }\end{array}$ & $\begin{array}{l}\text { No. } \\
\text { Refiere que recibe pensión, sin embargo, se niega a } \\
\text { brindar más información. }\end{array}$ \\
\hline & $\begin{array}{l}\text { Envejecimiento } \\
\text { Productivo }\end{array}$ & $\begin{array}{l}\text { ¿Cómo considera usted que el señor (a) } \\
\text { puede mejorar su situación? } \\
\text { ¿Quién es la persona responsable del } \\
\text { cuidado del cuidado del Señor (a)? ¿Si no } \\
\text { estuviera esa persona a cargo que } \\
\text { actividad desarrollaría? ¿Recibe apoyo de } \\
\text { algún otro familiar? }\end{array}$ & Se rompió la cadera, la operaron. \\
\hline
\end{tabular}




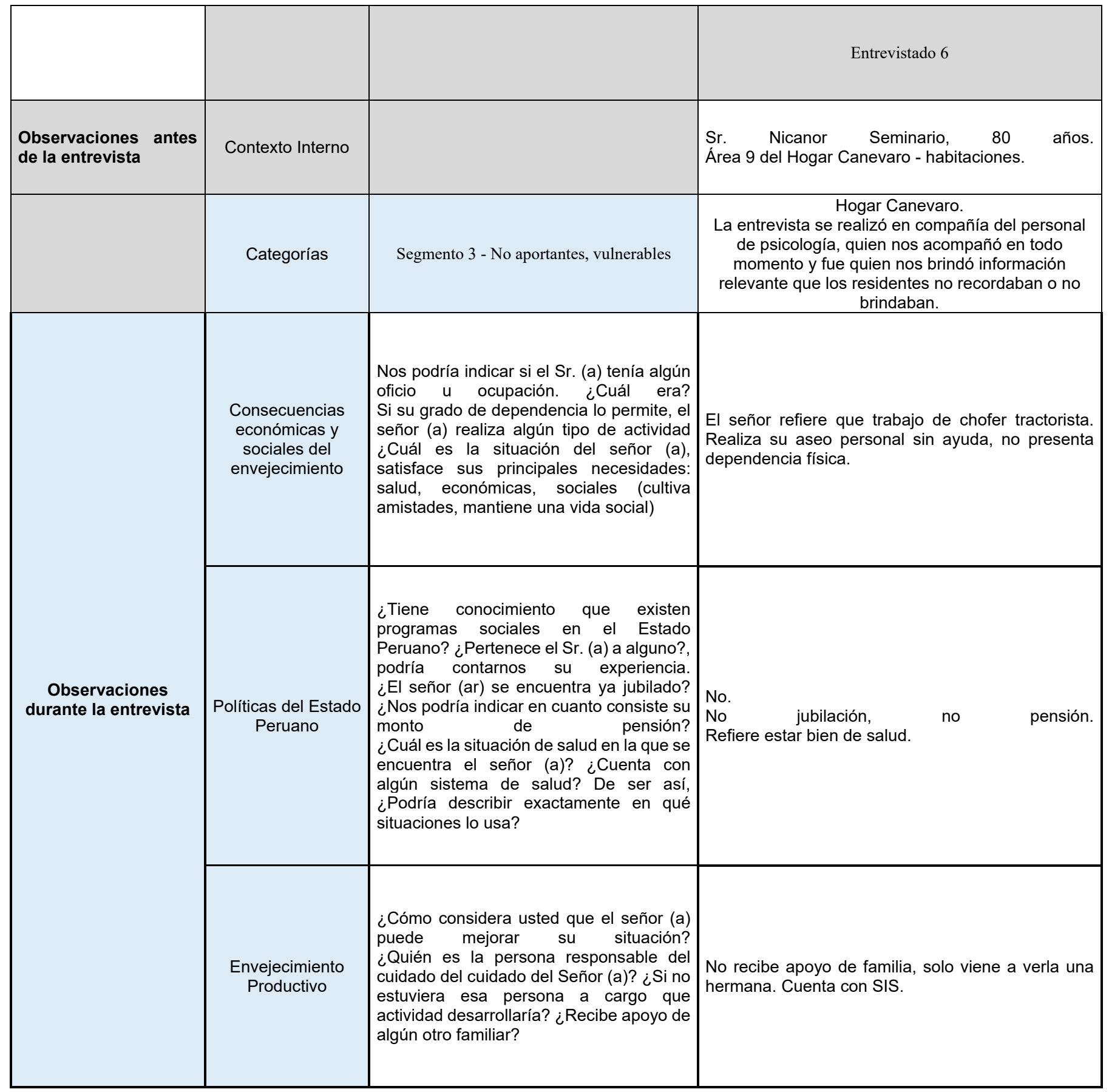




\begin{tabular}{|c|c|c|c|}
\hline & & & Entrevistado 7 \\
\hline \multirow[t]{2}{*}{$\begin{array}{l}\text { Observaciones antes } \\
\text { de la entrevista }\end{array}$} & Contexto Interno & & $\begin{array}{l}\text { Sra. Lidia Ituachiquen Montes, } 69 \text { años } \\
\text { área } 9 \text { del Hogar Canevaro - habitaciones. }\end{array}$ \\
\hline & Categorías & Segmento 3 - No aportantes, vulnerables & $\begin{array}{c}\text { Hogar Canevaro. } \\
\text { La entrevista se realizó en compañía del personal } \\
\text { de psicología, quien nos acompañó en todo } \\
\text { momento y fue quien nos brindó información } \\
\text { relevante que los residentes no recordaban o no } \\
\text { brindaban. }\end{array}$ \\
\hline \multirow{3}{*}{$\begin{array}{l}\text { Observaciones } \\
\text { durante la entrevista }\end{array}$} & $\begin{array}{l}\text { Consecuencias } \\
\text { económicas y } \\
\text { sociales del } \\
\text { envejecimiento }\end{array}$ & $\begin{array}{l}\text { Nos podría indicar si el Sr. (a) tenía algún } \\
\text { oficio u ocupación. ¿Cuál era? } \\
\text { Si su grado de dependencia lo permite, el } \\
\text { señor (a) realiza algún tipo de actividad } \\
\text { ¿Cuál es la situación del señor (a), } \\
\text { satisface sus principales necesidades: } \\
\text { salud, económicas, sociales (cultiva } \\
\text { amistades, mantiene una vida social) }\end{array}$ & 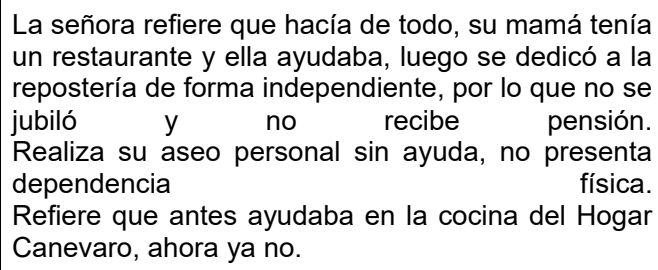 \\
\hline & $\begin{array}{l}\text { Políticas del Estado } \\
\text { Peruano }\end{array}$ & $\begin{array}{l}\text { ¿Tiene conocimiento que existen } \\
\text { programas sociales en el Estado } \\
\text { Peruano? ¿Pertenece el Sr. (a) a alguno?, } \\
\text { podría contarnos su experiencia. } \\
\text { ¿El señor (ar) se encuentra ya jubilado? } \\
\text { ¿Nos podría indicar en cuanto consiste su } \\
\text { monto de pensión? } \\
\text { ¿Cuál es la situación de salud en la que se } \\
\text { encuentra el señor (a)? ¿Cuenta con } \\
\text { algún sistema de salud? De ser así, } \\
\text { ¿Podría describir exactamente en qué } \\
\text { situaciones lo usa? }\end{array}$ & $\begin{array}{l}\text { No. } \\
\text { No jubilación, no pensión. }\end{array}$ \\
\hline & $\begin{array}{l}\text { Envejecimiento } \\
\text { Productivo }\end{array}$ & $\begin{array}{l}\text { ¿Cómo considera usted que el señor (a) } \\
\text { puede mejorar su situación? } \\
\text { ¿Quién es la persona responsable del } \\
\text { cuidado del cuidado del Señor (a)? ¿Si no } \\
\text { estuviera esa persona a cargo que } \\
\text { actividad desarrollaría? ¿Recibe apoyo de } \\
\text { algún otro familiar? }\end{array}$ & $\begin{array}{l}\text { No recibe apoyo de familiar, refiere estar sola, pues } \\
\text { indica que estuvo en Venezuela por } 20 \text { años y al } \\
\text { regresar no encontró su familia. Refiere estar más o } \\
\text { menos de salud, refiere tener un soplo en corazón y } \\
\text { que tomo sus } \\
\text { Cuenta con SIS. }\end{array}$ \\
\hline
\end{tabular}




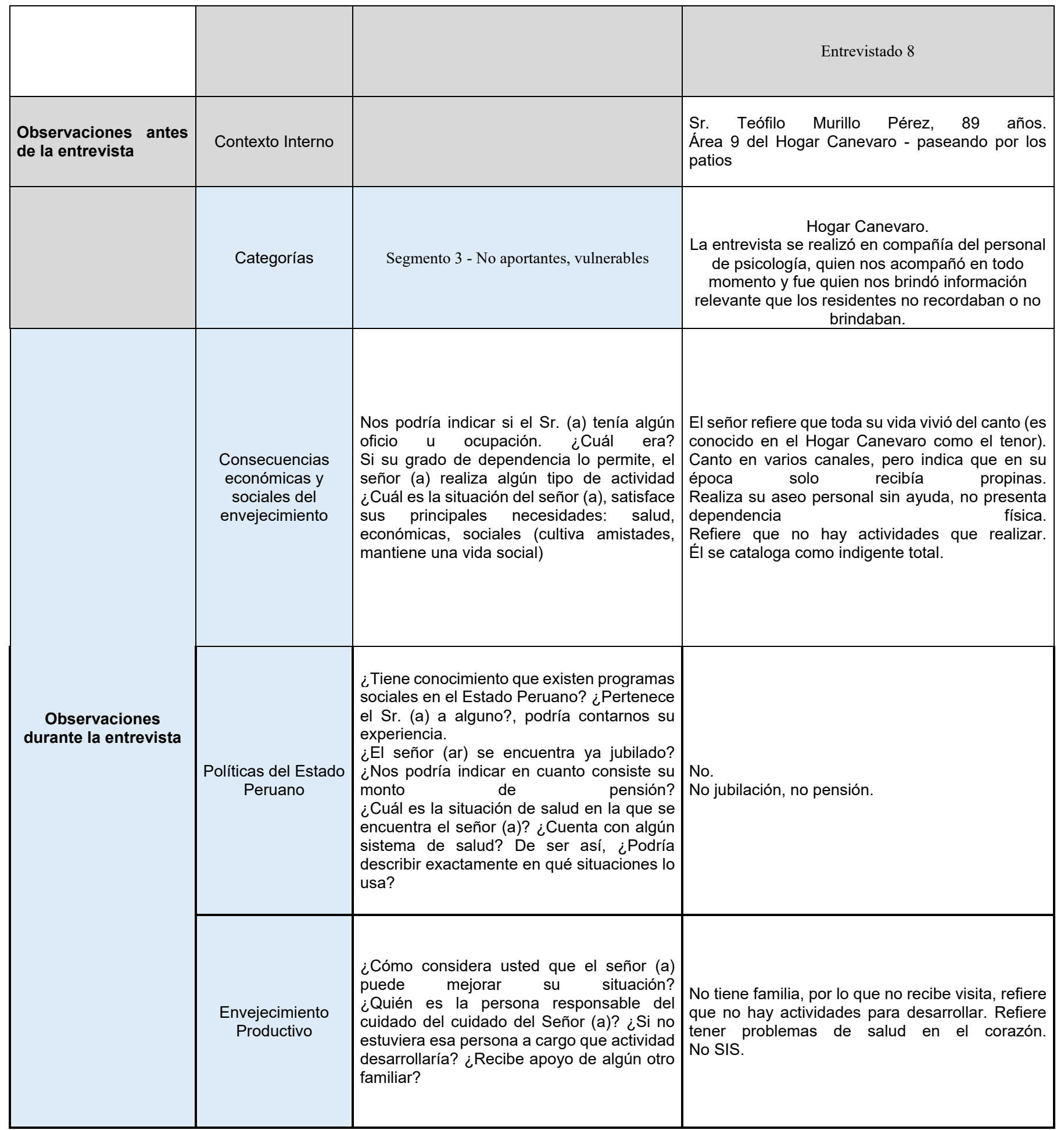




\begin{tabular}{|c|c|c|c|}
\hline & & & Entrevistado 9 \\
\hline $\begin{array}{l}\text { Observaciones } \\
\text { antes de la } \\
\text { entrevista }\end{array}$ & Contexto Interno & & $\begin{array}{l}\text { Sr. Juan Idelio Rubio Mejía, } 78 \text { años } \\
\text { Área } 9 \text { del Hogar Canevaro - paseando por los } \\
\text { patios. }\end{array}$ \\
\hline & Categorías & Segmento 3 - No aportantes, vulnerables & $\begin{array}{c}\text { Hogar Canevaro. } \\
\text { La entrevista se realizó en compañía del personal } \\
\text { de psicología, quien nos acompañó en todo } \\
\text { momento y fue quien nos brindó información } \\
\text { relevante que los residentes no recordaban o no } \\
\text { brindaban. }\end{array}$ \\
\hline \multirow{3}{*}{$\begin{array}{l}\text { Observaciones } \\
\text { durante la } \\
\text { entrevista }\end{array}$} & $\begin{array}{l}\text { Consecuencias } \\
\text { económicas y } \\
\text { sociales del } \\
\text { envejecimiento }\end{array}$ & $\begin{array}{l}\text { Nos podría indicar si el Sr. (a) tenía algún } \\
\text { oficio u ocupación. ¿Cuál era? } \\
\text { Si su grado de dependencia lo permite, el } \\
\text { señor (a) realiza algún tipo de actividad } \\
\text { ¿Cuál es la situación del señor (a), } \\
\text { satisface sus principales necesidades: } \\
\text { salud, económicas, sociales (cultiva } \\
\text { amistades, mantiene una vida social) }\end{array}$ & $\begin{array}{l}\text { El señor refiere que tuvo varios trabajos, trabajo } \\
10 \text { años en cine visión, } 14 \text { años en restaurante } \\
\text { Chinei Queirolo } \\
\text { Realiza su aseo personal sin ayuda, no presenta } \\
\text { dependencia física } \\
\text { Con respecto a la parte económica, refiere que } \\
\text { cobro lo que le correspondía de FONAVI, sin } \\
\text { entrar en más detalles. }\end{array}$ \\
\hline & $\begin{array}{c}\text { Políticas del Estado } \\
\text { Peruano }\end{array}$ & $\begin{array}{l}\text { ¿Tiene conocimiento que existen } \\
\text { programas sociales en el Estado } \\
\text { Peruano? ¿Pertenece el Sr. (a) a alguno?, } \\
\text { podría contarnos su experiencia. } \\
\text { ¿El señor (ar) se encuentra ya jubilado? } \\
\text { ¿Nos podría indicar en cuanto consiste su } \\
\text { monto de pensión? } \\
\text { ¿Cuál es la situación de salud en la que se } \\
\text { encuentra el señor (a)? ¿Cuenta con } \\
\text { algún sistema de salud? De ser así, } \\
\text { ¿Podría describir exactamente en qué } \\
\text { situaciones lo usa? }\end{array}$ & $\begin{array}{l}\text { No. } \\
\text { No jubilación, no pensión. }\end{array}$ \\
\hline & $\begin{array}{l}\text { Envejecimiento } \\
\text { Productivo }\end{array}$ & $\begin{array}{l}\text { ¿Cómo considera usted que el señor (a) } \\
\text { puede mejorar su situación? } \\
\text { ¿Quién es la persona responsable del } \\
\text { cuidado del cuidado del Señor (a)? ¿Si no } \\
\text { estuviera esa persona a cargo que } \\
\text { actividad desarrollaría? ¿Recibe apoyo de } \\
\text { algún otro familiar? }\end{array}$ & $\begin{array}{l}\text { Tiene su hija, quien viene a verlo los días lunes } \\
\text { refiere que actualmente trabaja en la repostería y } \\
\text { jardinería del Hogar Canevaro, antes realizaba } \\
\text { actividades deportivas, ahora se aburre porque no } \\
\text { ve bien. Refiere tener problemas de salud como } \\
\text { diabetes, hipertensión arterial, desprendimiento } \\
\text { de retina y párkinson. }\end{array}$ \\
\hline
\end{tabular}




\begin{tabular}{|c|c|c|c|}
\hline & & & Entrevistado 10 \\
\hline $\begin{array}{l}\text { Observaciones } \\
\text { antes de la } \\
\text { entrevista }\end{array}$ & Contexto Interno & & $\begin{array}{l}\text { E10, } \\
\text { Área } 9 \text { del Hogar Canevaro - paseando por los } \\
\text { patios. }\end{array}$ \\
\hline & Categorías & Segmento 3 - No aportantes, vulnerables & $\begin{array}{c}\text { Hogar Canevaro. } \\
\text { La entrevista se realizó en compañía del personal } \\
\text { de psicología, quien nos acompañó en todo } \\
\text { momento y fue quien nos brindó información } \\
\text { relevante que los residentes no recordaban o no } \\
\text { brindaban. } \\
\end{array}$ \\
\hline & $\begin{array}{l}\text { Consecuencias } \\
\text { económicas y } \\
\text { sociales del } \\
\text { envejecimiento }\end{array}$ & $\begin{array}{l}\text { Nos podría indicar si el Sr. (a) tenía algún } \\
\text { oficio u ocupación. ¿Cuál era? } \\
\text { Si su grado de dependencia lo permite, el } \\
\text { señor (a) realiza algún tipo de actividad } \\
\text { ¿Cuál es la situación del señor (a), } \\
\text { satisface sus principales necesidades: } \\
\text { salud, económicas, sociales (cultiva } \\
\text { amistades, mantiene una vida social) }\end{array}$ & $\begin{array}{l}\text { El señor refiere que trabajo haciendo de todo, es } \\
\text { técnico electrónico. Trabajó formalmente por } 18 \\
\text { años, sin embargo, refiere que no recibe pensión } \\
\text { por que le exigen } 20 \text { años de trabajo. } \\
\text { Realiza su aseo personal sin ayuda, no presenta } \\
\text { dependencia física. }\end{array}$ \\
\hline \multirow[t]{2}{*}{$\begin{array}{l}\text { Observaciones } \\
\text { durante la } \\
\text { entrevista }\end{array}$} & $\begin{array}{c}\text { Políticas del Estado } \\
\text { Peruano }\end{array}$ & $\begin{array}{l}\text { ¿Tiene conocimiento que existen } \\
\text { programas sociales en el Estado } \\
\text { Peruano? ¿Pertenece el Sr. (a) a alguno?, } \\
\text { podría contarnos su experiencia. } \\
\text { ¿El señor (ar) se encuentra ya jubilado? } \\
\text { ¿Nos podría indicar en cuanto consiste su } \\
\text { monto de pensión? } \\
\text { ¿Cuál es la situación de salud en la que se } \\
\text { encuentra el señor (a)? ¿Cuenta con } \\
\text { algún sistema de salud? De ser así, } \\
\text { ¿Podría describir exactamente en qué } \\
\text { situaciones lo usa? }\end{array}$ & $\begin{array}{l}\text { No. } \\
\text { No jubilación, no } \text { pensión. } \\
\text { Refiere que no tiene enfermedades. }\end{array}$ \\
\hline & $\begin{array}{l}\text { Envejecimiento } \\
\text { Productivo }\end{array}$ & $\begin{array}{l}\text { ¿Cómo considera usted que el señor (a) } \\
\text { puede mejorar su situación? } \\
\text { ¿Quién es la persona responsable del } \\
\text { cuidado del cuidado del Señor (a)? ¿Si no } \\
\text { estuviera esa persona a cargo que } \\
\text { actividad desarrollaría? ¿Recibe apoyo de } \\
\text { algún otro familiar? }\end{array}$ & $\begin{array}{l}\text { Refiere que su familia se desapareció, realiza } \\
\text { algunas actividades dentro del Hogar Canevaro. } \\
\text { Cuenta con SIS. }\end{array}$ \\
\hline
\end{tabular}




\begin{tabular}{|c|c|c|c|}
\hline & & & Entrevistado 11 \\
\hline $\begin{array}{l}\text { Observaciones } \\
\text { antes de la } \\
\text { entrevista }\end{array}$ & Contexto Interno & & $\begin{array}{lcr}\text { Eliseo, } & 77 & \text { años } \\
\text { Área } 9 \text { del Hogar Canevaro } & \text { - paseando por los } \\
\text { patios. } & \end{array}$ \\
\hline & Categorías & Segmento 3 - No aportantes, vulnerables & $\begin{array}{l}\text { Hogar Canevaro. } \\
\text { La entrevista se realizó en compañía del personal } \\
\text { de psicología, quien nos acompañó en todo } \\
\text { momento y fue quien nos brindó información } \\
\text { relevante que los residentes no recordaban o no } \\
\text { brindaban. }\end{array}$ \\
\hline & $\begin{array}{l}\text { Consecuencias } \\
\text { económicas y } \\
\text { sociales del } \\
\text { envejecimiento }\end{array}$ & $\begin{array}{l}\text { Nos podría indicar si el Sr. (a) tenía algún } \\
\text { oficio u ocupación. ¿Cuál era? } \\
\text { Si su grado de dependencia lo permite, el } \\
\text { señor (a) realiza algún tipo de actividad } \\
\text { ¿Cuál es la situación del señor (a), } \\
\text { satisface sus principales necesidades: } \\
\text { salud, económicas, sociales (cultiva } \\
\text { amistades, mantiene una vida social) }\end{array}$ & $\begin{array}{l}\text { El señor refiere que trabajaba en varios lugares de } \\
\text { manera eventual y que renunciaba, es técnico } \\
\text { textil y trabajo en fábricas y en topy top } \\
\text { Solo aportó } 13 \text { años, por lo que no recibe } \\
\text { beneficios } \\
\text { Realiza su aseo personal sin ayuda, no presenta) } \\
\text { dependencia física. Ayuda en el comedor en e } \\
\text { Canevaro cada vez que falta personal. }\end{array}$ \\
\hline \multirow[t]{2}{*}{$\begin{array}{l}\text { Observaciones } \\
\text { durante la } \\
\text { entrevista }\end{array}$} & $\begin{array}{c}\text { Políticas del Estado } \\
\text { Peruano }\end{array}$ & $\begin{array}{l}\text { ¿Tiene conocimiento que existen } \\
\text { programas sociales en el Estado } \\
\text { Peruano? ¿Pertenece el Sr. (a) a alguno?, } \\
\text { podría contarnos su experiencia. } \\
\text { ¿El señor (ar) se encuentra ya jubilado? } \\
\text { ¿Nos podría indicar en cuanto consiste su } \\
\text { monto de pensión? } \\
\text { ¿Cuál es la situación de salud en la que se } \\
\text { encuentra el señor (a)? ¿Cuenta con } \\
\text { algún sistema de salud? De ser así, } \\
\text { ¿Podría describir exactamente en qué } \\
\text { situaciones lo usa? }\end{array}$ & $\begin{array}{l}\text { No. } \\
\text { No jubilación, no pensión. }\end{array}$ \\
\hline & $\begin{array}{l}\text { Envejecimiento } \\
\text { Productivo }\end{array}$ & $\begin{array}{l}\text { ¿Cómo considera usted que el señor (a) } \\
\text { puede mejorar su situación? } \\
\text { ¿Quién es la persona responsable del } \\
\text { cuidado del cuidado del Señor (a)? ¿Si no } \\
\text { estuviera esa persona a cargo que } \\
\text { actividad desarrollaría? ¿Recibe apoyo de } \\
\text { algún otro familiar? }\end{array}$ & $\begin{array}{l}\text { Refiere que solo tiene un sobrino } \\
\text { Refiere que en los conventos lo conocen porque } \\
\text { ayudaba. } \\
\text { Realiza actividades, apoya en la cocina. Cuenta } \\
\text { con SIS. En el aspecto de salud, refiere que solo } \\
\text { tiene el colesterol y triglicéridos elevado. }\end{array}$ \\
\hline
\end{tabular}




\begin{tabular}{|c|c|c|c|}
\hline & & & Entrevistado 12 \\
\hline $\begin{array}{l}\text { Observaciones } \\
\text { antes de la } \\
\text { entrevista }\end{array}$ & Contexto Interno & & 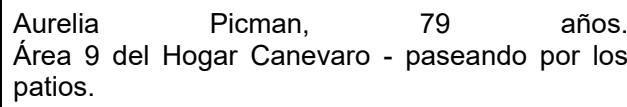 \\
\hline & Categorías & Segmento 3 - No aportantes, vulnerables & $\begin{array}{c}\text { Hogar Canevaro. } \\
\text { La entrevista se realizó en compañía del personal } \\
\text { de psicología, quien nos acompañó en todo } \\
\text { momento y fue quien nos brindó información } \\
\text { relevante que los residentes no recordaban o no } \\
\text { brindaban. }\end{array}$ \\
\hline \multirow{3}{*}{$\begin{array}{l}\text { Observaciones } \\
\text { durante la } \\
\text { entrevista }\end{array}$} & $\begin{array}{l}\text { Consecuencias } \\
\text { económicas y } \\
\text { sociales del } \\
\text { envejecimiento }\end{array}$ & $\begin{array}{l}\text { Nos podría indicar si el Sr. (a) tenía algún } \\
\text { oficio u ocupación. ¿Cuál era? } \\
\text { Si su grado de dependencia lo permite, el } \\
\text { señor (a) realiza algún tipo de actividad } \\
\text { ¿Cuál es la situación del señor (a), } \\
\text { satisface sus principales necesidades: } \\
\text { salud, económicas, sociales (cultiva } \\
\text { amistades, mantiene una vida social) }\end{array}$ & $\begin{array}{l}\text { La señora refiere que trabajo en todo lo que se } \\
\text { podía fábricas de conserva (en chacras pañando } \\
\text { algodón) luego vendiendo golosinas de forma } \\
\text { independiente, por lo que no se jubiló. } \\
\text { Realiza su aseo personal sin ayuda, no presenta } \\
\text { dependencia física. }\end{array}$ \\
\hline & $\begin{array}{c}\text { Políticas del Estado } \\
\text { Peruano }\end{array}$ & $\begin{array}{l}\text { ¿Tiene conocimiento que existen } \\
\text { programas sociales en el Estado } \\
\text { Peruano? ¿Pertenece el Sr. (a) a alguno?, } \\
\text { podría contarnos su experiencia. } \\
\text { ¿El señor (ar) se encuentra ya jubilado? } \\
\text { ¿Nos podría indicar en cuanto consiste su } \\
\text { monto de pensión? } \\
\text { ¿Cuál es la situación de salud en la que se } \\
\text { encuentra el señor (a)? ¿Cuenta con } \\
\text { algún sistema de salud? De ser así, } \\
\text { ¿Podría describir exactamente en qué } \\
\text { situaciones lo usa? }\end{array}$ & $\begin{array}{l}\text { No. } \\
\text { No jubilación, no pensión. }\end{array}$ \\
\hline & $\begin{array}{l}\text { Envejecimiento } \\
\text { Productivo }\end{array}$ & $\begin{array}{l}\text { ¿Cómo considera usted que el señor (a) } \\
\text { puede mejorar su situación? } \\
\text { ¿Quién es la persona responsable del } \\
\text { cuidado del cuidado del Señor (a)? ¿Si no } \\
\text { estuviera esa persona a cargo que } \\
\text { actividad desarrollaría? ¿Recibe apoyo de } \\
\text { algún otro familiar? }\end{array}$ & $\begin{array}{l}\text { Refiere que tiene sobrinas, que la trajeron al hogar } \\
\text { sin consentimiento, lo que cataloga como } \\
\text { secuestro. } \\
\text { No realiza actividades productivas en el hogar. } \\
\text { Cuenta con SIS. }\end{array}$ \\
\hline
\end{tabular}




\begin{tabular}{|c|c|c|c|}
\hline & & & Entrevistado 13 \\
\hline $\begin{array}{l}\text { Observaciones } \\
\text { antes de la } \\
\text { entrevista }\end{array}$ & Contexto Interno & & $\begin{array}{l}\text { María Rosa García Niño, } 65 \text { años. } \\
\text { Área } 9 \text { del Hogar Canevaro - paseando por los } \\
\text { patios. }\end{array}$ \\
\hline & Categorías & Segmento 3 - No aportantes, vulnerables & $\begin{array}{c}\text { Hogar Canevaro. } \\
\text { La entrevista se realizó en compañía del personal } \\
\text { de psicología, quien nos acompañó en todo } \\
\text { momento y fue quien nos brindó información } \\
\text { relevante que los residentes no recordaban o no } \\
\text { brindaban. }\end{array}$ \\
\hline & $\begin{array}{l}\text { Consecuencias } \\
\text { económicas y } \\
\text { sociales del } \\
\text { envejecimiento }\end{array}$ & $\begin{array}{l}\text { Nos podría indicar si el Sr. (a) tenía algún } \\
\text { oficio u ocupación. ¿Cuál era? } \\
\text { Si su grado de dependencia lo permite, el } \\
\text { señor (a) realiza algún tipo de actividad } \\
\text { ¿Cuál es la situación del señor (a), } \\
\text { satisface sus principales necesidades: } \\
\text { salud, económicas, sociales (cultiva } \\
\text { amistades, mantiene una vida social) }\end{array}$ & $\begin{array}{l}\text { La señora refiere que trabajó vendiendo asas y y } \\
\text { arreglando ollas. No se jubiló. } \\
\text { Realiza su aseo personal sin ayuda, no presenta } \\
\text { dependencia física. }\end{array}$ \\
\hline \multirow[t]{2}{*}{$\begin{array}{l}\text { Observaciones } \\
\text { durante la } \\
\text { entrevista }\end{array}$} & $\begin{array}{c}\text { Políticas del Estado } \\
\text { Peruano }\end{array}$ & $\begin{array}{l}\text { ¿Tiene conocimiento que existen } \\
\text { programas sociales en el Estado } \\
\text { Peruano? ¿Pertenece el Sr. (a) a alguno?, } \\
\text { podría contarnos su experiencia. } \\
\text { ¿El señor (ar) se encuentra ya jubilado? } \\
\text { ¿Nos podría indicar en cuanto consiste su } \\
\text { monto de pensión? } \\
\text { ¿Cuál es la situación de salud en la que se } \\
\text { encuentra el señor (a)? ¿Cuenta con } \\
\text { algún sistema de salud? De ser así, } \\
\text { ¿Podría describir exactamente en qué } \\
\text { situaciones lo usa? }\end{array}$ & $\begin{array}{l}\text { No. } \\
\text { No jubilación, no pensión. }\end{array}$ \\
\hline & $\begin{array}{l}\text { Envejecimiento } \\
\text { Productivo }\end{array}$ & $\begin{array}{l}\text { ¿Cómo considera usted que el señor (a) } \\
\text { puede mejorar su situación? } \\
\text { ¿Quién es la persona responsable del } \\
\text { cuidado del cuidado del Señor (a)? ¿Si no } \\
\text { estuviera esa persona a cargo que } \\
\text { actividad desarrollaría? ¿Recibe apoyo de } \\
\text { algún otro familiar? }\end{array}$ & $\begin{array}{l}\text { Refiere que tiene familia, pero no es específica. } \\
\text { Realiza actividades productivas en el taller de } \\
\text { manualidades. Refiere que no tiene problemas de } \\
\text { salud, aunque antes tenía hipertensión arterial. }\end{array}$ \\
\hline
\end{tabular}




\begin{tabular}{|c|c|c|c|}
\hline & & & Entrevistado 14 \\
\hline $\begin{array}{l}\text { Observaciones } \\
\text { antes de la } \\
\text { entrevista }\end{array}$ & Contexto Interno & & $\begin{array}{lccc}\text { Socorro } & \text { Flores, } & 82 & \text { años. } \\
\text { Área } 9 \text { del Hogar Canevaro } & - \text { en el cafetín. }\end{array}$ \\
\hline & Categorías & Segmento 3 - No aportantes, vulnerables & $\begin{array}{c}\text { Hogar Canevaro. } \\
\text { La entrevista se realizó en compañía del personal } \\
\text { de psicología, quien nos acompañó en todo } \\
\text { momento y fue quien nos brindó información } \\
\text { relevante que los residentes no recordaban o no } \\
\text { brindaban. }\end{array}$ \\
\hline & $\begin{array}{l}\text { Consecuencias } \\
\text { económicas y } \\
\text { sociales del } \\
\text { envejecimiento }\end{array}$ & $\begin{array}{l}\text { Nos podría indicar si el Sr. (a) tenía algún } \\
\text { oficio u ocupación. ¿Cuál era? } \\
\text { Si su grado de dependencia lo permite, el } \\
\text { señor (a) realiza algún tipo de actividad } \\
\text { ¿Cuál es la situación del señor (a), } \\
\text { satisface sus principales necesidades: } \\
\text { salud, económicas, sociales (cultiva } \\
\text { amistades, mantiene una vida social) }\end{array}$ & $\begin{array}{l}\text { La señora refiere que es del norte del Perú, trabajó } \\
\text { en casas y lavandería donde le pagaban por día } \\
\text { de } \\
\text { No se } \\
\text { trabajo. } \\
\text { Realiza sus actividades con apoyo, adicional } \\
\text { utiliza andador para deambular. }\end{array}$ \\
\hline \multirow[t]{2}{*}{$\begin{array}{l}\text { Observaciones } \\
\text { durante la } \\
\text { entrevista }\end{array}$} & $\begin{array}{l}\text { Políticas del Estado } \\
\text { Peruano }\end{array}$ & $\begin{array}{l}\text { ¿Tiene conocimiento que existen } \\
\text { programas sociales en el Estado } \\
\text { Peruano? ¿Pertenece el Sr. (a) a alguno?, } \\
\text { podría contarnos su experiencia. } \\
\text { ¿El señor (ar) se encuentra ya jubilado? } \\
\text { ¿Nos podría indicar en cuanto consiste su } \\
\text { monto de ¿ ¿ } \\
\text { ¿Cuál es la situación de salud en la que se } \\
\text { encuentra el señor (a)? ¿Cuenta con } \\
\text { algún sistema de salud? De ser así, } \\
\text { ¿Podría describir exactamente en qué } \\
\text { situaciones lo usa? }\end{array}$ & $\begin{array}{l}\text { No. } \\
\text { No jubilación, no pensión. }\end{array}$ \\
\hline & $\begin{array}{l}\text { Envejecimiento } \\
\text { Productivo }\end{array}$ & $\begin{array}{l}\text { ¿Cómo considera usted que el señor (a) } \\
\text { puede mejorar su situación? } \\
\text { ¿Quién es la persona responsable del } \\
\text { cuidado del cuidado del Señor (a)? ¿Si no } \\
\text { estuviera esa persona a cargo que } \\
\text { actividad desarrollaría? ¿Recibe apoyo de } \\
\text { algún otro familiar? }\end{array}$ & $\begin{array}{l}\text { Refiere que su familia está en el norte. } \\
\text { No realiza actividad en el Hogar. No problemas de } \\
\text { salud. }\end{array}$ \\
\hline
\end{tabular}




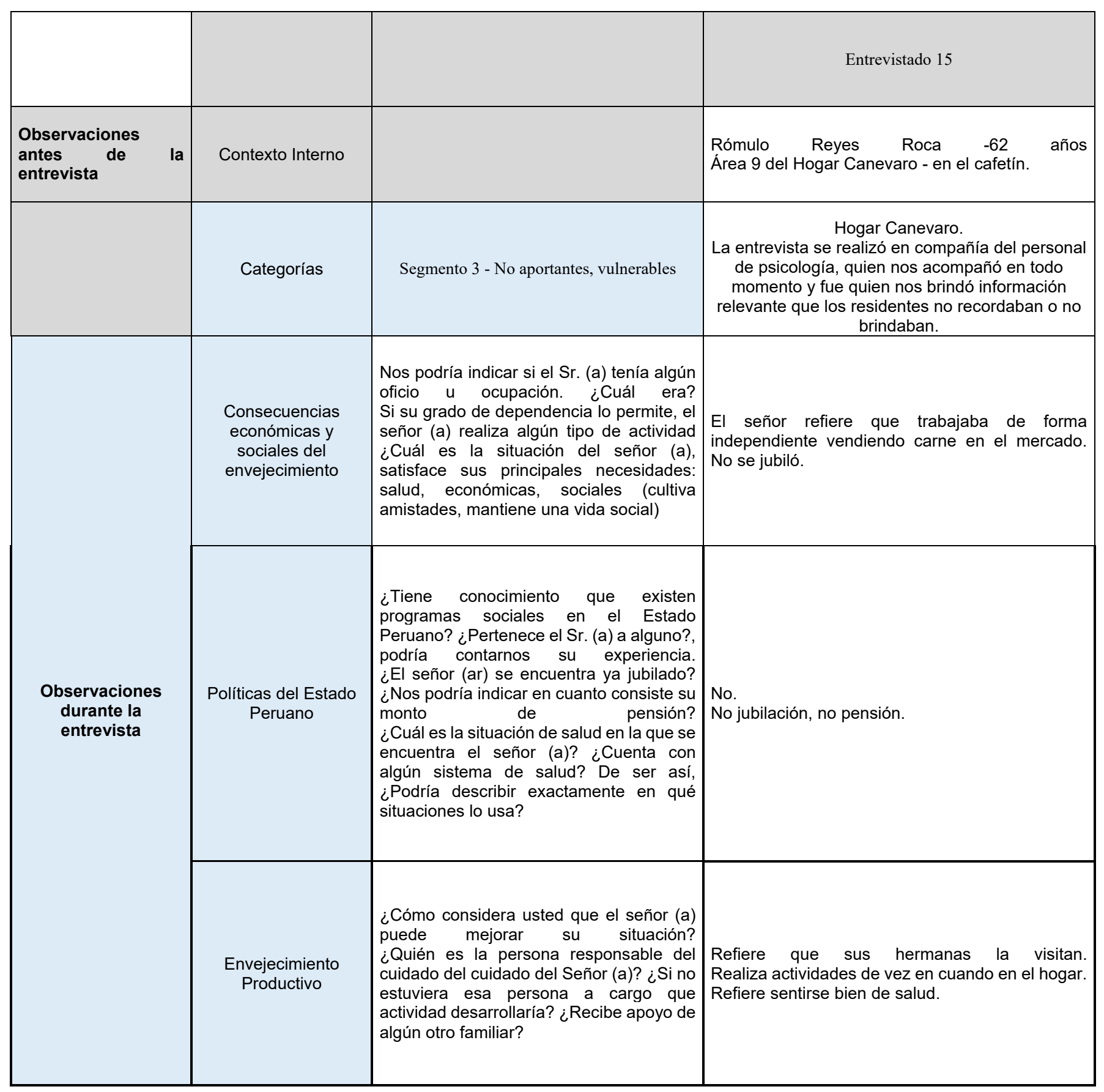




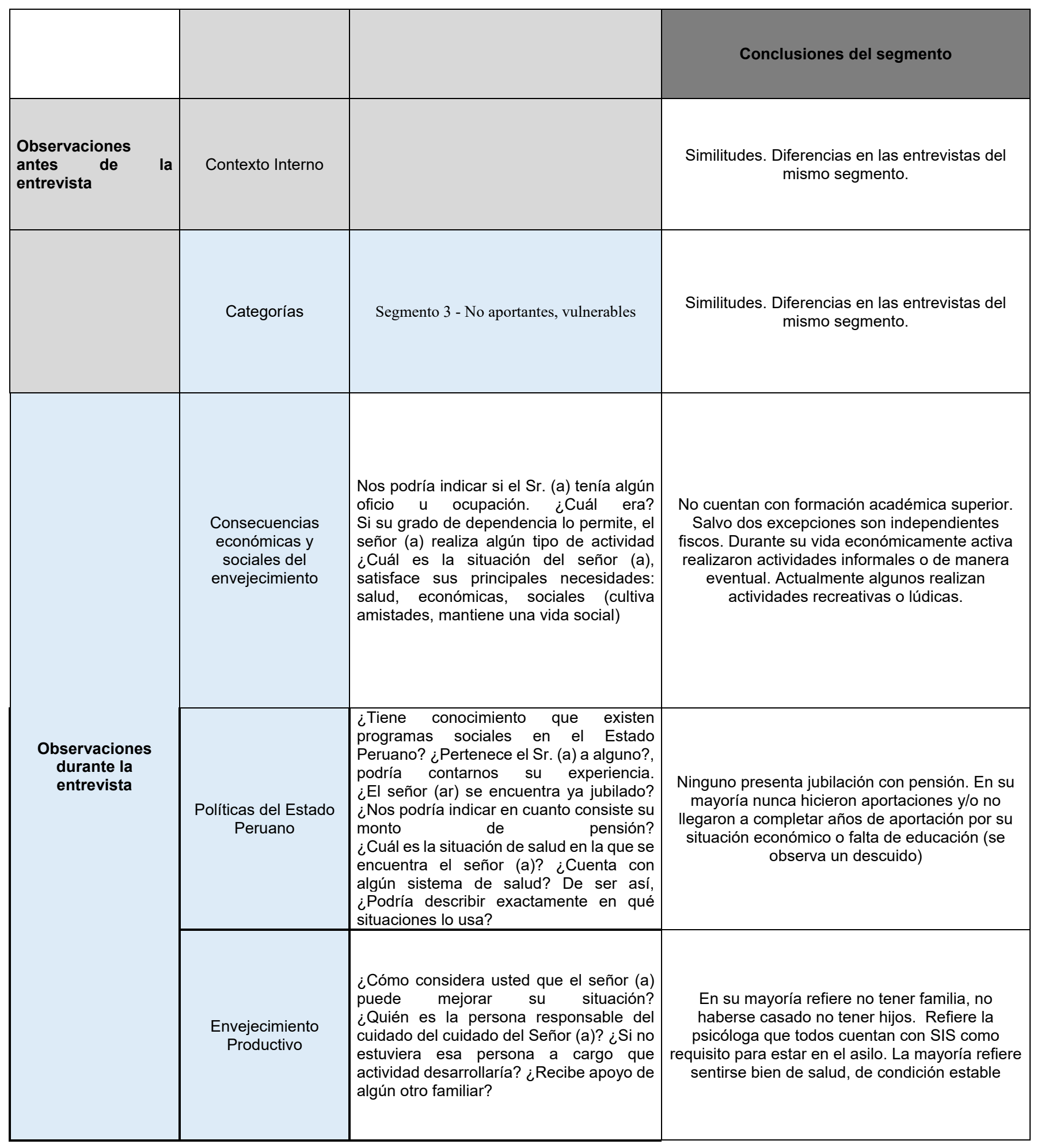

